\title{
LEILA BUTTLER
}

\section{A disfunção da barreira hematoencefálica em SHR é normalizada pelo treinamento aeróbio de baixa a moderada intensidade}

Tese apresentada ao Programa de PósGraduação em Fisiologia Humana do Instituto de Ciências Biomédicas da Universidade de São Paulo, para obtenção do Título de Doutor em Ciências. 


\section{LEILA BUTTLER}

\section{A disfunção da barreira hematoencefálica em SHR é normalizada pelo treinamento aeróbio de baixa a moderada intensidade}

Tese apresentada ao Programa de PósGraduação em Fisiologia Humana do Instituto de Ciências Biomédicas da Universidade de São Paulo, para obtenção do Título de Doutor em Ciências.

Área de concentração: Fisiologia Humana

Orientadora: Profa. Dra. Lisete Compagno Michelini

Versão Original 
DADOS DE CATALOGAÇÃO NA PUBLICAÇÃO (CIP) Serviço de Biblioteca e Informaação Biomédica do Instituto de Ciências Biomédicas da Universidade de São Paulo

reprodução não autorizada pelo autor

Buttler, Leila.

A disfunção da barreira hematoencefálica em SHR é normalizada pelo treinamento aeróbio de baixa a moderada intensidade / Leila Buttler. -- São Paulo, 2016.

Orientador: Prof. Dr. Lisete Compagno Michelini.

Tese (Doutorado) - Universidade de São Paulo. Instituto de Ciências Biomédicas. Departamento de Fisiologia e Biofísica. Área de concentração: Fisiologia Humana. Linha de pesquisa: Fisiologia cardiovascular.

Versão do título para o inglês: Blood brain barrier dysfunction in SHR is normalized by low to moderate intensity exercise training.

1. Hipertensão 2. Treinamento aeróbio 3. Modulação autonômica 4 . Barreira hemato-encefálica 5. Angiotensina II I. Michelini, Prof. Dr. Lisete Compagno II. Universidade de São Paulo. Instituto de Ciências Biomédicas. Programa de Pós-Graduação em Fisilogia e Biofísica III. Título. 


\title{
UNIVERSIDADE DE SÃO PAULO \\ INSTITUTO DE CIÊNCIAS BIOMÉDICAS
}

\begin{abstract}
Candidato(a): $\quad$ Leila Buttler.
Título da Tese:

A disfunção da barreira hematoencefálica em SHR é normalizada pelo treinamento aeróbio de baixa a moderada intensidade.
\end{abstract}

Orientador(a):

Prof. Dr. Lisete Compagno Michelini.

A Comissão Julgadora dos trabalhos de Defesa da Tese de Doutorado, em sessão pública realizada a considerou
( ) Aprovado(a)
( ) Reprovado(a)
Examinador(a): Assinatura:
Nome:
Instituição:
Examinador(a): Assinatura:
Nome:
Instituição:
Examinador(a): Assinatura:
Nome:
Instituição:
Examinador(a): Assinatura:
Nome:
Instituição:
Presidente: $\quad$ Assinatura:
Nome:
Instituição:




\section{Certificado}

Certificamos que o protocolo registrado sob $n^{\circ} 197$ nas fls. 116 do livro 02 para uso de animais em experimentação, sob a responsabilidade do Prof(a) $\operatorname{Dr}(a)$ ) Lisete Campagno Michelini, Coordenador (a) da Linha de pesquisa "Alteraçỏes vasculares da barreira hematoencefálica em animais hipertensos: Efeitos do treinamento aeróbio" do qual participam o(s) aluno(s) Leila Buttler, está de acordo com os Princípios Éticos de Experimentação Animal adotado pela Sociedade Brasileira de Ciência de Animais de Laboratório (SBCAL) e foi aprovado pela COMISSÃO DE ÉTICA NO USO DE ANIMAIS (CEUA) em 16.12.2011, com validade de 4 anos.

São Paulo, 20 de dezembro de 2011.

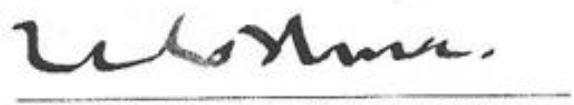

Prof.Dr.Wothan Tavares de Lima Coordenador CEUA - ICB/USP

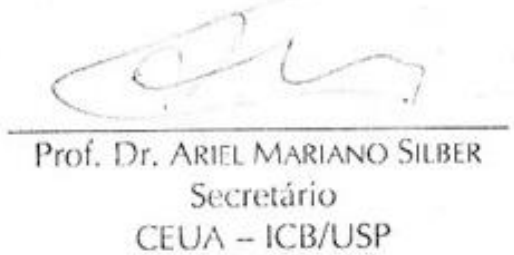




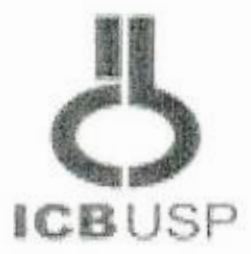

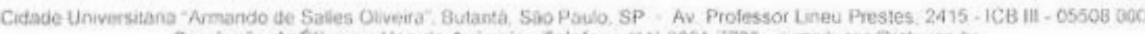
Comissáo de Etica no Uso de Animais - Teletone (11) 3091.7733 - email cepgicb usp br

Of.CEUA. 049.15

São Paulo, 14 de dezembro de 2015.

Prezado(a) Professor(a),

Informo que o projeto intitulado "Alterações vasculares da barreira hematoencefálica em animais hipertensos: Efeitos do treinamento aeróbio", registrado sob o protocolo $\mathrm{n}^{\circ} 197 / 2011$ e aprovado em 20/12/2011 que envolve a produção, manutençâo e/ou utilização de animais pertencentes ao filo Chordata, subfilo Vertebrata (exceto o homem), para fins de pesquisa científica, foi prorrogado até 20/12/2019.

Conforme declarado na solicitação para renovação do certificado, não há necessidade de incluir novos animais no projeto citado acima.

Reitero que, havendo alteração de metodologia e inserção de novos alunos ao projeto de pesquisa vinculado à referida licença a CEUA-ICB deverá ser informada.

Cordialmente,

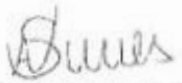

Prof. Dr. Anderson de Sá Nunes

Coordenador - CEUA-ICB/USP

Prof.(a) Dr.(a) Lisete Compagno Michelini

Departamento de Fisiologia e Biofisica

Instituto de Ciências Biomédicas - USP 
Dedico esse trabalho à minha família meus pais João e Maria, meu namorado Danilo, à minha irmã Lilian e aos meus sobrinhos Thiago e Fernando. 


\section{AGRADECIMENTOS}

Agradeço a todas as pessoas que estiveram ao meu lado, acompanhando minhas batalhas e conquistas durante doutorado. Em primeiro lugar agradeço a meus pais, João e Maria, por todo suporte que me deram e sem o qual eu não conseguiria chegar aonde cheguei. Agradeço também a minha irmã Lilian por todo apoio, aos meus sobrinhos Thiago e Fernando que sempre alegram meus dias e ao meu namorado Danilo pelos bons momentos, por todo apoio e compreensão. Agradeço também a professora Lisete por ter acreditado em mim e por todo ensinamento concedido desde o mestrado e durante todo o doutorado, contribuindo para meu amadurecimento como pesquisadora. A todas pessoas que passaram pelo Laboratório de Fisiologia Cardiovascular neste período, em especial a Maria Tereza Jordão, amiga e coautora deste trabalho. À técnica do Laboratório de Neuroanatomia Funcional, Aninha, por toda paciência e empenho em me ensinar a técnica de imunoistoquímica. Aos funcionários do biotério de experimentação e às secretarias de pós-graduação e do departamento. Por fim, agradeço as agências de fomento CNPq e FAPESP, sem as quais o trabalho não seria possível. 
"Só se pode alcançar um grande êxito quando nos mantemos fiéis a nós mesmos" (Friedrich Nietzsche) 


\section{RESUMO}

BUTTLER, L. A disfunção da barreira hematoencefálica em SHR é normalizada pelo treinamento aeróbio de baixa a moderada intensidade. 2016. $108 \mathrm{f}$. Tese (Doutorado em Fisiologia Humana) - Instituto de Ciências Biomédicas, Universidade de São Paulo, São Paulo, 2016.

A hipertensão arterial (HA) cursa com disfunção autonômica e alterações no sistema nervoso central, as quais podem levar ao rompimento da barreira hematoencefálica (BHE) e contribuir para o acidente vascular cerebral. Os mecanismos através dos quais a HA afeta o funcionamento da BHE são pouco conhecidos. Sabe-se que a angiotensina II (ANGII), via receptores $\mathrm{AT}_{1}$, tem importante papel no rompimento da BHE. Experimentos de nosso laboratório têm demonstrado que o treinamento aeróbio corrige a disfunção autonômica, sendo uma eficiente conduta terapêutica para reduzir a expressão/atividade do sistema renina angiotensina cerebral. Nenhuma informação há sobre possíveis efeitos benéficos do treinamento sobre a lesão da BHE em hipertensos. No presente trabalho investigamos em áreas autonômicas de controle cardiovascular de ratos espontaneamente hipertensos (SHR) e controles normotensos (WKY): 1) a evolução temporal da lesão da BHE desde a fase pré-hipertensiva (1 mês) até o estabelecimento da hipertensão crônica (3-5 meses); 2) os efeitos sequenciais (semanas 0, 1, 2, 4 e 8) do treinamento sobre parâmetros funcionais e seus componentes espectrais e sobre a integridade da BHE, avaliada pela quantificação da porcentagem de extravasamento de FITC-dextran de baixo peso molecular para o espaço extravascular encefálico (microscopia de fluorescência). A expressão do antígeno de barreira endotelial (EBA, marcador da integridade da BHE), de podócitos dos astrócitos e da microglia (componentes da BHE), além da expressão de receptores AT1 em neurônios foram avaliadas no núcleo paraventricular do hipotálamo (PVN), núcleo do trato solitário (NTS) e bulbo rostro-ventrolateral (RVLM). SHR e WKY foram submetidos ao treinamento aeróbio ( $\mathrm{T}=50-60 \%$ da capacidade máxima, 1 hora/dia, 5 dias/semana) ou mantidos sedentários (S) por 8 semanas. SHR com 1 mês de idade apresentavam BHE íntegra, mas lesada nas 3 áreas autonômicas a partir dos 3 meses de idade. 0 treinamento impediu o aumento progressivo da variabilidade da pressão arterial (PA) observada nos SHR-S; SHR-T mostraram pronta redução do simpático vasomotor $\left(\mathrm{T}_{1}{ }^{-}\right.$ $\mathrm{T}_{2}$ ), com elevação mais tardia da variabilidade da frequência cardíaca (FC) e do tônus vagal ao coração da instalação da bradicardia de repouso e da queda parcial da PA (todos os efeitos significativos a partir de $\mathrm{T}_{4}$ ). 0 treinamento também determinou intensa redução do extravasamento do FITC-dextran no PVN, NTS e RVLM dos SHR já a partir de $\mathrm{T}_{1}-\mathrm{T}_{2}$, normalizando o funcionamento da BHE, como comprovado pela expressão aumentada do EBA nessas áreas. A infusão simultânea de ANGII (ou salina) intracerebroventricular em SHR treinados por 2-3 semanas indicou ser a redução na disponibilidade de ANGII fundamental para a redução da densidade da microglia com manutenção de seu estado inativado e aumento da expressão de podócitos de astrócitos, importantes constituintes de barreira, cuja preservação contribui sobremaneira para a manutenção da integridade da BHE. Nossos dados sugerem que a manutenção da integridade da BHE nos SHR-T, melhorando a perfusão tecidual no PVN, NTS e RVLM, corrige a disfunção autonômica e contribui para manifestação dos efeitos benéficos do treinamento, mesmo na persistência de níveis pressóricos elevados. 
Palavras-chave: Hipertensão. Treinamento Aeróbio. Modulação autonômica. Barreira Hematoencefálica. Angiotensina II. 


\begin{abstract}
BUTTLER, L. Blood brain barrier dysfunction in SHR is normalized by low to moderate intensity exercise training. 2016. 108 p. Ph. D. thesis (Human Physiology) Instituto de Ciências Biomédicas, Universidade de São Paulo, São Paulo, 2016.
\end{abstract}

The arterial hypertension (AH) is characterized by autonomic dysfunction and central nervous system alterations leading to the disruption of the blood brain barrier (BBB) and to the development of stroke. The mechanisms by which AH affects BBB function are not completely understood. It is known that angiotensin II (ANGII), via AT1 receptors, has an important role in BBB disruption. Studies from our laboratory showed that aerobic training corrects autonomic dysfunction, being an efficient tool to reduce the expression/activity of the brain renin-angiotensin system. There is no information on possible beneficial effects of training on BBB lesion in hypertensive individuals. In this study we investigated in autonomic areas of spontaneously hypertensive rats (SHR) and normotensive controls (WKY): 1) the time-course changes of BBB lesion since the pre-hypertensive (1 month) up to the establishment of chronic hypertension (3-5 months); 2) the sequential effects (weeks 0, 1, 2,4 and 8) of training on functional parameters and their spectral components and on BBB integrity, analyzed by the percent leakage of FITC-dextran, a low molecular weight dye, to the extravascular space (fluorescence microscopy). The expression of endothelial barrier antigen (EBA, a marker of BBB integrity), astrocyte endfeet and microglia (BBB components) and the expression of $\mathrm{AT}_{1}$ receptors in neurons were quantified in the paraventricular nucleus of the hypothalamus (PVN), nucleus of the solitary tract (NTS) and rostroventrolateral medulla (RVLM). SHR and WKY were submitted to aerobic training (T=50 - 60\% of maximum capacity, 1 hour/day, 5 days/week) or kept sedentary (S) for 8 weeks. SHR aged 1 month showed intact BBB, but disrupted BBB in the 3 autonomic areas since the $3^{\text {rd }}$ month of age. Training blocked the progressive increase in arterial pressure (AP) variability observed in the SHR-S; SHR-T showed prompt reduction of sympathetic vasomotor activity $\left(\mathrm{T}_{1}-\mathrm{T}_{2}\right)$ with late increases in heart rate (HR) variability and parasympathetic outflow to the heart, establishment of resting bradycardia and partial AP fall (all these effects significant from $\mathrm{T}_{4}$ on). Training also caused early $\left(\mathrm{T}_{1}-\mathrm{T}_{2}\right.$ ) and marked reduction of FITC-dextran leakage within the PVN, NTS and RVLM of SHR, normalizing BBB function, as demonstrated by increased EBA expression in these areas. The simultaneous intracerebroventricular infusion of ANGII (or saline) for 2-3 weeks in trained SHR confirmed that the reduction in ANGII availability was crucial to decrease microglia density (and for the maintenance of its inactive state) and to increase the expression of astrocyte endfeet, important BBB constituents whose preservation contribute to the maintenance of BBB integrity. Together our data suggest that the maintenance of BBB integrity in the SHR-T improves tissue perfusion within the PVN, NTS and RVLM, corrects autonomic dysfunction and contributes to the beneficial effect of training even in the persistence of hypertension.

Keywords: Hypertension. Aerobic training. Autonomic modulation. Blood Brain Barrier. Angiotensin II. 


\section{LISTA DE AREVIATURAS E SIGLAS}

3V - terceiro ventrículo

ANGII - angiotensina II

Aogen - angiotensinogênio

AP - área postrema

$\mathbf{A T}_{\mathbf{1}}$ - receptor de angiotensina II do tipo 1

AVC - acidente vascular cerebral

BHE - barreira hematoencefálica

CC - canal central

EBA - antígeno de barreira endotelial

EPM - erro padrão da média

FC - frequência cardíaca

FITC - isotiocianato de fluoresceína dextran

GFAP - proteína glial fibrilar ácida

HA - hipertensão arterial

HF - componente de alta frequência da análise espectral

LF - componente de baixa frequência da análise espectral

NTS - núcleo do trato solitário

NTSc - região comissural do núcleo do trato solitário

PA - pressão arterial

PAM - pressão arterial média

PBS - tampão fosfato de sódio

PFA - parafolmaldeído

PVN - núcleo paraventricular do hipotálamo

ROD - rodamina dextran

RVLM - bulbo rostro-ventrolateral

SHR - ratos espontaneamente hipertensos

SHR-S - ratos espontaneamente hipertensos sedentários

SHR-T - ratos espontaneamente hipertensos treinados

SNC - sistema nervoso central

SNS - sistema nervoso simpático

SRA - sistema renina angiotensina

TEM - teste de esforço máximo

TF - treinamento físico

VLF - componente de frequência muito baixa da análise espectral

WKY - Wistar Kyoto

WKY-S - Wistar Kyoto sedentário

WKY-T - Wistar Kyoto treinado 


\section{LISTA DE FIGURAS}

Figura 1 - Esquema representativo da barreira hematoencefálica (BHE) com seus principais constituintes. Modificado de https://cias.rit.edu/faculty-staff/101/faculty/340

Figura 2 - Exemplo de fotomicrografias obtidas em microscópio de fluorescência com os filtros para o corante Rodamina-Dextran de $70 \mathrm{kDa}$ (ROD, vermelho) e FITC-Dextran de $10 \mathrm{kDa}$ (FITC, verde) 38

Figura 3 - Diferentes passos do processo de quantificação do extravasamento de FITC. a- PVN com filtro para ROD; b- PVN com filtro para o FITC; c- imagem binária para a ROD; d- imagem binária para o FITC; e- co-localização da ROD e FITC (imagem em 32 bits), o vermelho corresponde a ROD, o verde o FITC e o branco é a co-localização dos dois corantes; f- colocalização de ROD e FITC (imagem em 8 bits); g- resultado da subtração das imagens colocalizada e FITC 8 bits; h- resultado da porcentagem de área extravasada pelo FITC. 40

Figura 4 - Evolução temporal do desempenho em esteira $(\mathrm{Km} / \mathrm{h})$ dos grupos treinados (SHR-T e WKY-T) e sedentários (SHR-S e WKY-S) ao longo dos protocolos experimentais nas semanas 0, 4 e 8. Significâncias $(\mathrm{P}<0,05) * v s$. WKY † vs. sedentário \# vs. semana 0 .

Figura 5 - Evolução do peso corporal dos SHR e WKY durante os protocolos de treinamento (T) ou sedentarismo (S) nas semanas 0, 4 e 8 dos protocolos experimentais. Significâncias $(\mathrm{P}<0,05)$ * vs. WKY † vs. sedentário \# vs. semana 0 .

Figura 6 - Evolução dos valores basais de pressão arterial média (PAM) ao longo dos protocolos de treinamento $(T)$ ou sedentarismo $(\mathrm{S})$ nos grupos SHR e WKY. Significâncias $(\mathrm{P}<0,05){ }^{*} v s$. WKY † vs. sedentário \# vs. semana 0 .

Figura 7 - Evolução dos valores basais de frequência cardíaca (FC) ao longo dos protocolos de treinamento (T) ou sedentarismo ( $\mathrm{S})$ nos grupos SHR e WKY. Significâncias $(\mathrm{P}<0,05):{ }^{*} v$ s. WKY † vs. sedentário \# vs. semana 0 .

Figura 8 - Comparação dos valores basais de pressão arterial média (PAM) e frequência cardíaca (FC) ao final dos protocolos de treinamento (T) ou sedentarismo (S) nos grupos SHR e WKY. Significâncias $(\mathrm{P}<0,05)$ : *vs. WKY †vs. sedentário.

Figura 9 - Evolução da variabilidade da pressão arterial sistólica (PAS) ao longo dos protocolos de treinamento $(\mathrm{T})$ ou sedentarismo $(\mathrm{S})$ nos grupos SHR e WKY. Significâncias $(\mathrm{P}<0,05):{ }^{*} v s$. WKY † vs. sedentário \# vs. semana 0 . 
Figura 10 - Evolução do componente low frequency (LF) da pressão arterial sistólica (PAS) ao longo dos protocolos de treinamento (T) ou sedentarismo (S) nos grupos SHR e WKY. Significâncias $(\mathrm{P}<0,05)$ : * vs. WKY e \# vs. semana 0 .

Figura 11 - Evolução do componente high frequency (HF) da pressão arterial sistólica (PAS) ao longo dos protocolos de treinamento (T) ou sedentarismo (S) nos grupos SHR e WKY. Significâncias $(\mathrm{P}<0,05):{ }^{*} v s$. WKY e \# vs. semana 0.

Figura 12 - Evolução do componente very low frequency (VLF) da pressão arterial sistólica (PAS) ao longo dos protocolos de treinamento (T) ou sedentarismo (S) nos grupos SHR e WKY. Significâncias $(\mathrm{P}<0,05)$ : * vs. WKY e \# vs. semana 0 .

Figura 13 - Comparação dos valores de A- variabilidade da pressão arterial sistólica (PAS); B componente low frequency (LF) da PAS; C - componente high frequency (HF) da PAS e D componente very low frequency (VLF) da PAS ao final dos protocolos de treinamento (T) ou sedentarismo (S) nos grupos SHR e WKY. Significâncias $(\mathrm{P}<0,05):{ }^{*} v s$. WKY † vs. sedentário....50

Figura 14 - Evolução da variabilidade do intervalo de pulso (IP) ao longo dos protocolos de treinamento $(\mathrm{T})$ ou sedentarismo $(\mathrm{S})$ nos grupos SHR e WKY. Significâncias $(\mathrm{P}<0,05)$ : $v$ s. WKY e \# $v$ s. semana 0 .

Figura 15 - Evolução do componente low frequency (LF) da frequência cardíaca (FC) ao longo dos protocolos de treinamento (T) ou sedentarismo (S) nos grupos SHR e WKY. Significâncias $(\mathrm{P}<0,05): * v s$. WKY e \# vs. semana 0 .

Figura 16 - Evolução do componente high frequency (HF) da frequência cardíaca (FC) ao longo dos protocolos de treinamento (T) ou sedentarismo (S) nos grupos SHR e WKY. Significâncias $(\mathrm{P}<0,05): * v s$. WKY e \# vs. semana 0 .

Figura 17 - Comparação dos valores de A- variabilidade do intervalo de pulso (IP); B componente low frequency (LF) do IP; C - componente high frequency (HF) do IP ao final dos protocolos de treinamento (T) ou sedentarismo (S) nos grupos SHR e WKY. Significâncias $(\mathrm{P}<0,05): * v s$. WKY † vs. sedentário.

Figura 18 - Evolução do índice alfa do componente low frequency (LF) ao longo dos protocolos de treinamento (T) ou sedentarismo (S) nos grupos SHR e WKY. Significância $(\mathrm{P}<0,05)$ : * vs. WKY.

Figura 19 - Evolução do índice alfa do componente high frequency (HF) ao longo dos protocolos de treinamento $(\mathrm{T})$ ou sedentarismo $(\mathrm{S})$ nos grupos SHR e WKY. Significância $(\mathrm{P}<0,05):{ }^{*} v$ s. WKY. 
Figura 20 - Comparação do alfa dos componentes alpha LF e alpha HF ao final dos protocolos de treinamento (T) ou sedentarismo (S) nos grupos SHR e WKY. Significâncias $(\mathrm{P}<0,05):{ }^{*} v s$. WKY † vs. sedentário.

Figura 21 - A. Comparação da porcentagem de extravasamento do corante FITC-Dextran no núcleo paraventricular do hipotálamo (PVN) dos grupos SHR e WKY aos 1, 3 e 5 meses de idade. Significâncias $(\mathrm{P}<0,05):{ }^{*}$ vs. WKY, \# vs. 1 mês, $\dagger$ vs. 3 meses, $\mathrm{n}=4$ WKY e $\mathrm{n}=4$ SHR. B. Figuras ilustrativas do extravasamento do FITC (verde) nos SHR no1ํ. (acima) e 5ํ. mês de idade (abaixo).

Figura 22 - Comparação da porcentagem de extravasamento do corante FITC-Dextran no núcleo do trato solitário (NTS) dos grupos SHR e WKY de 1, 3 e 5 meses de vida. Significâncias $(P<0,05)$ : * vs. WKY, \# vs. 1 mês; $\mathrm{n}=4$ WKY e $\mathrm{n}=4$ SHR. B. Figuras ilustrativas do extravasamento do FITC (verde) nos SHR no1‥ (acima) e 5‥ mês de idade (abaixo). 56

Figura 23 - Comparação da porcentagem de extravasamento do corante FITC-Dextran no bulbo rostro-ventrolateral (RVLM) dos grupos SHR e WKY de 1, 3 e 5 meses de vida. Significâncias $(\mathrm{P}<0,05):{ }^{*} v s$. WKY, \# vs. 1 mês; $\mathrm{n}=4 \mathrm{WKY}$ e $\mathrm{n}=4$ SHR. B. Figuras ilustrativas do extravasamento do FITC (verde) nos SHR no1ํ. (acima) e 5‥ mês de idade (abaixo).

Figura 24 - Comparação de imagens obtidas por microscopia de fluorescência do núcleo paraventricular do hipotálamo (PVN), núcleo do trato solitário (NTS) e bulbo rostroventrolateral (RVLM) de SHR e WKY sedentários no início dos protocolos - semana 0 (S0). Vermelho $=$ ROD $70 \mathrm{kDa}$, verde $=$ FITC $10 \mathrm{kDa}$, branco $=$ co-localização da ROD 70kDa e FITC $10 \mathrm{kDa}, 3 \mathrm{~V}=$ terceiro ventrículo e $\mathrm{cc}=$ canal central.

Figura 25 - Comparação de imagens obtidas por microscopia de fluorescência do núcleo paraventricular do hipotálamo (PVN) de SHR sedentários (S) nas semanas 0 (A) e 8 (D) e SHR treinados $(\mathrm{T})$ nas semanas $2(\mathrm{~B})$ e $8(\mathrm{C})$. Vermelho $=\mathrm{ROD} 70 \mathrm{kDa}$, verde $=$ FITC $10 \mathrm{kDa}$, branco $=$ co-localização da ROD $70 \mathrm{kDa}$ e FITC 10kDa. Em E apresentamos a evolução temporal da extravasamento do FITC (valores percentuais) no PVN dos grupos SHR e WKY, S e T, ao longo das 8 semanas experimentais e em $\mathrm{F}$ comparamos ambos os grupos considerando o valor inicial na semana zero de WKY e SHR como 100\%. Significâncias $(\mathrm{P}<0,05):{ }^{*} v s$. WKY † vs. sedentário \# vs. semana 0 .

Figura 26 - Comparação de imagens obtidas por microscopia de fluorescência do núcleo do trato solitário (NTS) de SHR sedentários (S) nas semanas 0 (A) e 8 (D) e SHR treinados (T) nas semanas 2 (B) e 8 (C). Vermelho $=$ ROD $70 \mathrm{kDa}$, verde $=$ FITC 10kDa, branco = co-localização da ROD 70kDa e FITC 10kDa. Em E apresentamos a evolução temporal do extravasamento do FITC (valores percentuais) no PVN dos grupos SHR e WKY, S e T, ao longo das 8 semanas experimentais e em $\mathrm{F}$ comparamos ambos os grupos considerando o valor inicial na semana zero de WKY e SHR como 100\%. Significâncias $(\mathrm{P}<0,05):{ }^{*} v s$. WKY † vs. sedentário \# vs. semana $0 . . .60$ 
Figura 27 - Comparação de imagens obtidas por microscopia de fluorescência (140x) do bulbo rostro-ventrolateral (RVLM) de SHR sedentários (S) nas semanas 0 (A) e 8 (D) e SHR treinados (T) nas semanas 2 (B) e 8 (C). Vermelho $=$ ROD 70kDa, verde $=$ FITC $10 \mathrm{kDa}$, branco $=$ co localização da ROD 70kDa e FITC 10kDa. Em E apresentamos a evolução temporal do extravasamento do FITC (valores percentuais) no PVN dos grupos SHR e WKY, S e T, ao longo das 8 semanas experimentais e em $\mathrm{F}$ comparamos ambos os grupos considerando o valor inicial na semana zero de WKY e SHR como 100\%. Significâncias $(\mathrm{P}<0,05):{ }^{*} v s$. WKY † vs. sedentário \# vs. semana 0 .

Figura 28 - Comparação da porcentagem de extravasamento do corante FITC-Dextran no núcleo paraventricular do hipotálamo (PVN), núcleo do trato solitário (NTS) e bulbo rostroventrolateral (RVLM) nos grupos SHR e WKY sedentários (S) e treinados (T) ao final dos protocolos experimentais. Significâncias $(\mathrm{P}<0,05):{ }^{*} v s$. WKY † vs. Sedentário.

Figura 29 - Comparação da porcentagem de extravasamento do corante FITC-Dextran no núcleo hipoglosso nos grupos SHR e WKY sedentários (S) aos 3 meses de idade.

Figura 30 - Comparação de imagens obtidas por microscopia de fluorescência (140x) no PVN, NTS e RVLM de SHR treinados por 14 dias consecutivos e infundidos simultaneamente com salina (SAL) e angiotensina II (ANGII) intracerebroventricular. Vermelho $=$ ROD 70kDa, verde $=$ FITC 10kDa, branco = co-localização da ROD 70kDa e FITC 10kDa. Nos painéis abaixo apresentamos quantificação do extravasamento do FITC (valores percentuais) nas respectivas áreas após infusão de ANGII e sAL. Significância $(\mathrm{P}<0,05): \Delta v s$. SAL.

Figura 31 - Comparação da marcação imunofluorescência para o antígeno de barreira endotelial (EBA) entre o núcleo do trato solitário comissural (NTSc) e a área postrema (AP), área bastante vascularizada na qual há completa ausência de marcação. Anticorpo utilizado (SMI-71, diluição 1:2000). cc - canal central. 66

Figura 32 - Comparação da expressão do antígeno de barreira endotelial (EBA, anticorpo SMI-71, diluição 1:2000) no núcleo paraventricular do hipotálamo (PVN) de WKY e SHR sedentários nas semanas 0 (S0) e 3 (S3). Os SHR foram também treinados por 3 semanas na ausência (T3) e na presença de infusão i.c.v. concomitante de angiotensina II (T3+ANGII). Painéis superiores: Fotomicrografias ilustrativas da expressão de SMI 71 no PVN. 3V - terceiro ventrículo. Painéis inferiores: Quantificação da expressão de SMI $71 \mathrm{em}$ diferentes subnúcleos do PVN. Significâncias $(\mathrm{P}<0,05){ }^{*} v s$. WKY † vs. sedentário \# vs. semana $0 \bullet v s$. T3... 67

Figura 33 - Comparação da expressão do antígeno de barreira endotelial (EBA, anticorpo SMI-71, diluição 1:2000) no núcleo do trato solitário (NTS) de WKY e SHR sedentários nas semanas 0 (S0) e 3 (S3). Os SHR foram também treinados por 3 semanas na ausência (T3) e na presença de infusão i.c.v. concomitante de angiotensina II (T3+ANGII). Painéis superiores: Fotomicrografias ilustrativas da expressão de SMI 71 no NTS. cc, canal central Painéis inferiores: Quantificação da expressão de SMI 71 em toda a extensão do NTS. Significâncias $(\mathrm{P}<0,05)$ : $†$ vs. sedentário \# vs. semana 0 . 
Figura 34 - Comparação da expressão do antígeno de barreira endotelial (EBA, anticorpo SMI-71, diluição 1:2000) na região rostro-ventrolateral do Bulbo (RVLM) de WKY e SHR sedentários nas semanas 0 (S0) e 3 (S3). Os SHR foram também treinados por 3 semanas na ausência (T3) e na presença de infusão i.c.v. concomitante de angiotensina II (T3+ANGII). Painéis superiores: Fotomicrografias ilustrativas da expressão de SMI 71 no RVLM. Painéis inferiores: Quantificação da expressão de SMI 71 no RVLM.

Figura 35 - Comparação da expressão do IBA-1 (marcador de microglia) no núcleo paraventricular do hipotálamo (PVN) de WKY e SHR sedentários nas semanas 0 (S0) e 3 (S3). Os SHR foram também treinados por 3 semanas na ausência (T3) e na presença de infusão i.c.v. concomitante de angiotensina II (T3+ANGII). Painéis superiores: Fotomicrografias ilustrativas da expressão de IBA-1 no PVN. 3V - terceiro ventrículo. Painéis inferiores: Quantificação da expressão de IBA-1 em diferentes subnúcleos do PVN. Significâncias $(\mathrm{P}<0,05):{ }^{*} v s$. WKY † vs. sedentário \# vs. semana $0 \bullet v s$. T3

Figura 36 - Comparação da expressão do IBA-1 (marcador de microglia) no núcleo do trato solitário (NTS) de WKY e SHR sedentários nas semanas 0 (S0) e 3 (S3). Os SHR foram também treinados por 3 semanas na ausência (T3) e na presença de infusão i.c.v. concomitante de angiotensina II (T3+ANGII). Painéis superiores: Fotomicrografias ilustrativas da expressão de IBA-1 no NTS, cc, canal central. Painéis inferiores: Quantificação da expressão de IBA-1 em toda a extensão do NTS. Significâncias $(\mathrm{P}<0,05):{ }^{*} v s . \mathrm{WKY} \dagger v s$. sedentário \# vs. semana 0.

Figura 37 - Comparação da expressão do IBA-1 (marcador de microglia) no bulbo rostroventrolateral (RVLM) de WKY e SHR sedentários nas semanas 0 (S0) e 3 (S3). Os SHR foram também treinados por 3 semanas na ausência (T3) e na presença de infusão i.c.v. concomitante de angiotensina II (T3+ANGII). Painéis superiores: Fotomicrografias ilustrativas da expressão de IBA-1 no RVLM. Painéis inferiores: Quantificação da expressão de IBA-1 no RVLM. Significância $(\mathrm{P}<0,05)$ : \# vs. semana 0 .

Figura 38 - Comparação da estrutura da microglia característica do PVN De um SHR treinado por 3 semanas (SHR-T3) e de outro treinado que recebeu simultaneamente a infusão de ANGII intracerebroventricular (T3+ANGII).

Figura 39 - Fotomicrografias de PVN obtidas por imunofluorescência para receptor AT1 (vermelho) e neurônios (verde). Na primeira imagem observa-se marcação vermelha de processos/ramificações que não condizem com a forma e estrutura de neurônios. Na segunda imagem observamos o resultado da soma das imagens de AT1 e neurônio. Na terceira imagem tem-se como resultado final apenas receptores AT1 presentes em neurônios.

Figura 40 - Comparação da expressão de receptores AT1 no núcleo paraventricular do hipotálamo (PVN) de WKY e SHR sedentários nas semanas 0 (S0) e 3 (S3). Os SHR foram também treinados por 3 semanas na ausência (T3) e na presença de infusão i.c.v. concomitante de angiotensina II (T3+ANGII). Painéis superiores: Fotomicrografias ilustrativas da expressão de receptores AT1 no PVN. 3V - terceiro ventrículo. Painéis inferiores: Quantificação da expressão 
de receptores AT1 em diferentes subnúcleos do PVN. Significâncias $(\mathrm{P}<0,05)$ : † vs. Sedentário, \# vs. semana $0, \bullet v s$. T3.

Figura 41 - Comparação da expressão de receptores AT1 no núcleo do trato solitário (NTS) de WKY e SHR sedentários nas semanas 0 (S0) e 3 (S3). Os SHR foram também treinados por 3 semanas na ausência (T3) e na presença de infusão i.c.v. concomitante de angiotensina II (T3+ANGII). Painéis superiores: Fotomicrografias ilustrativas da expressão de receptores AT1 em toda a extensão do NTS. cc, canal central. Painéis inferiores: Quantificação da expressão de receptores AT1 no NTS. Significâncias $(\mathrm{P}<0,05):^{*} v s$. WKY, † vs. Sedentário, $\bullet v s$. T3.

Figura 42 - Comparação da expressão de receptores AT1 no bulbo rostro-ventrolateral (RVLM) de WKY e SHR sedentários nas semanas 0 (S0) e 3 (S3). Os SHR foram também treinados por 3 semanas na ausência (T3) e na presença de infusão i.c.v. concomitante de angiotensina II (T3+ANGII). Painéis superiores: Fotomicrografias ilustrativas da expressão de receptores AT1 no RVLM. Painéis inferiores: Quantificação da expressão de receptores AT1 no RVLM.

Figura 43 - Comparação da expressão do GFAP (glial fibrillary acidic protein) no núcleo paraventricular do hipotálamo (PVN) de WKY e SHR sedentários nas semanas 0 (S0) e 3 (S3). Os SHR foram também treinados por 3 semanas na ausência (T3) e na presença de infusão i.c.v. concomitante de angiotensina II (T3+ANGII). Painéis superiores: Fotomicrografias ilustrativas da expressão de GFAP no PVN. 3V - terceiro ventrículo. Painéis inferiores: Quantificação da expressão de GFAP em diferentes subnúcleos do PVN. Significâncias $(\mathrm{P}<0,05):{ }^{*} v s$. WKY † vs. sedentário \# vs. semana $0^{\bullet} v s$. T3

Figura 44 - Comparação da expressão do GFAP (glial fibrillary acidic protein) no núcleo do trato solitário (NTS) de WKY e SHR sedentários nas semanas 0 (S0) e 3 (S3). Os SHR foram também treinados por 3 semanas na ausência (T3) e na presença de infusão i.c.v. concomitante de angiotensina II (T3+ANGII). Painéis superiores: Fotomicrografias ilustrativas da expressão de GFAP no NTS. cc, canal central. Painéis inferiores: Quantificação da expressão de GFAP em diferentes subnúcleos do NTS. Significâncias $(\mathrm{P}<0,05)$ : $^{*} v s$. WKY † vs. sedentário \# vs. semana $0^{\bullet}$ vs. T3.

Figura 45 - Comparação da expressão do GFAP (glial fibrillary acidic protein) no bulbo rostroventrolateral (RVLM) de WKY e SHR sedentários nas semanas 0 (S0) e 3 (S3). Os SHR foram também treinados por 3 semanas na ausência (T3) e na presença de infusão i.c.v. concomitante de angiotensina II (T3+ANGII). Painéis superiores: Fotomicrografias ilustrativas da expressão de GFAP no RVLM. Painéis inferiores: Quantificação da expressão de GFAP no RVLM. Significâncias $(\mathrm{P}<0,05)$ : †vs. sedentário \# vs. semana $00^{\bullet} v s$. T3. 


\section{LISTA DE TABELAS}

Tabela 1 - Lista de dados para realização do teste de esforço máximo, correlacionando o

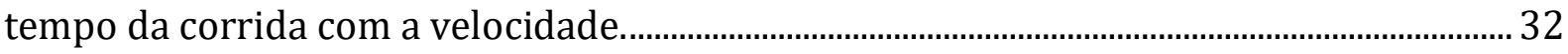

Tabela 2 - Grupos experimentais divididos por linhagem (SHR e WKY), condição (S ou T) e tempo $(0,1,2,4$ e 8 semanas $)$. 


\section{SUMÁRIO}

1 REVISÃO DE LITERATURA ..............................................................................22

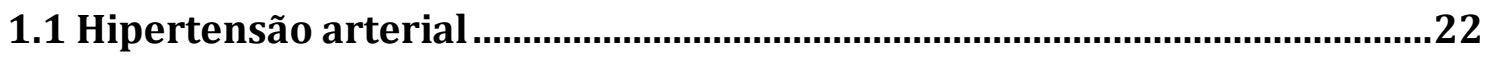

1.2 Barreira hematoencefálica e a hipertensão arterial ..................................23

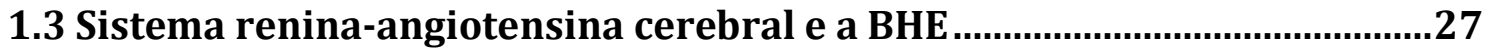

1.4 Treinamento aeróbio de baixa intensidade e o SRA.........................................28

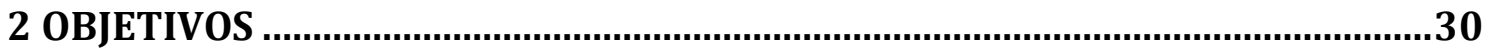

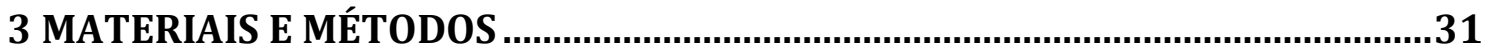

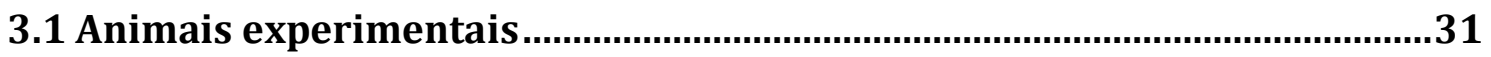

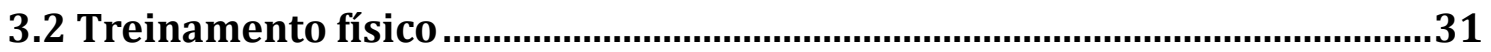

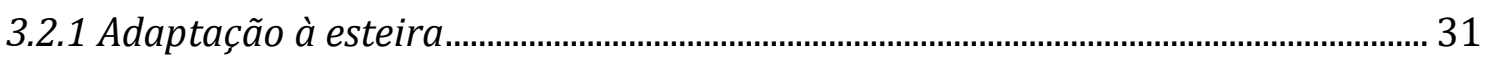

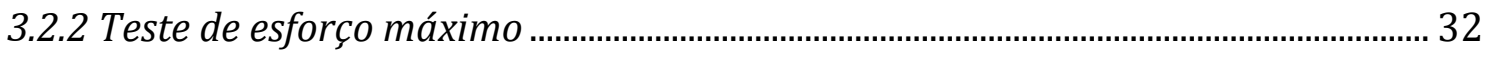

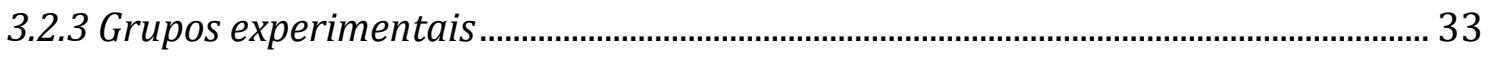

3.2.4 Protocolo de treinamento aeróbio de baixa intensidade ............................................ 33

3.3 Procedimentos cirúrgicos e registro direto da PA e FC .................................34

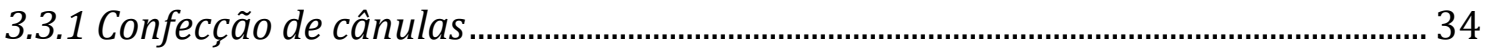

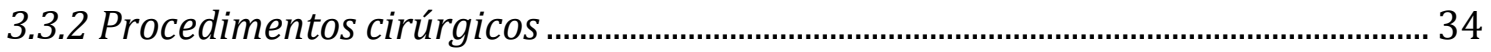

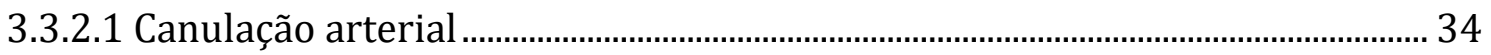

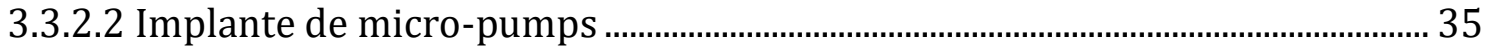

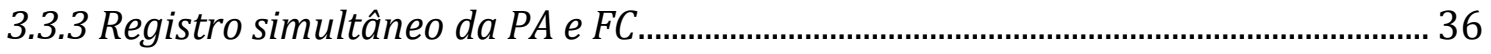

3.4 Análise espectral de parâmetros cardiovasculares...........................................37

3.5 Injeção intravascular de corantes fluorescentes e análise da integridade

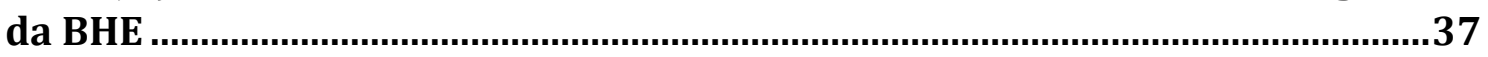

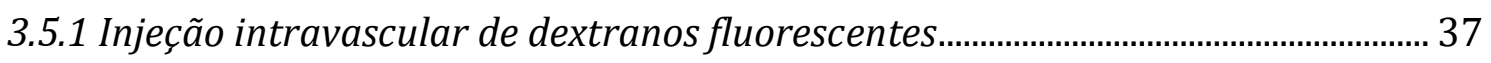

3.5.2 Aquisição de imagens por microscopia de fluorescência ........................................... 38

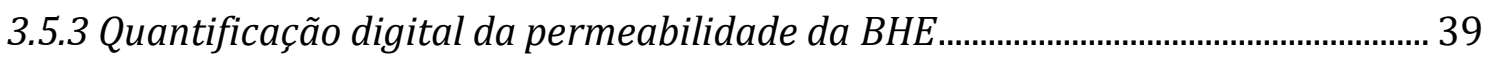

3.6 Ensaios de imunofluorescência ...................................................................

4 RESULTADOS OBTIDOS

4.1 Eficácia do treinamento nos grupos SHR e WKY..............................................43

4.2 Evolução do peso corporal nos grupos SHR e WKY.......................................44

4.3 Efeitos do treinamento e sedentarismo sobre a hemodinâmica basal de

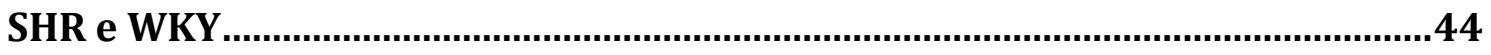


4.4 Efeitos do treinamento e sedentarismo sobre a variabilidade da pressão arterial e seus componentes espectrais nos grupos SHR e WKY ......................46 4.5 Efeitos da idade e do estabelecimento da hipertensão arterial sobre a integridade da BHE

4.6 Efeitos do treinamento e sedentarismo sobre a integridade da BHE nos grupos SHR e WKY

4.7 Efeitos da elevada disponibilidade de angiotensina II cerebral sobre a integridade da BHE no PVN, NTS e RVLM dos grupos SHR e WKY treinados..65

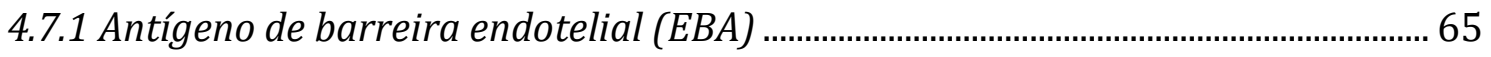

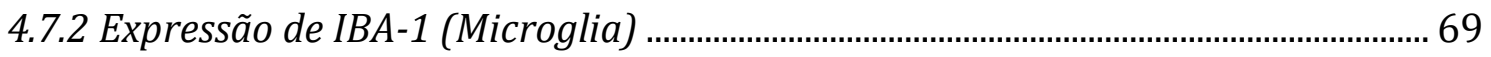

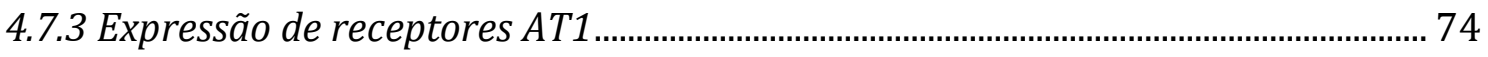

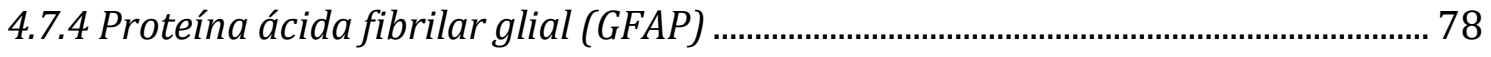

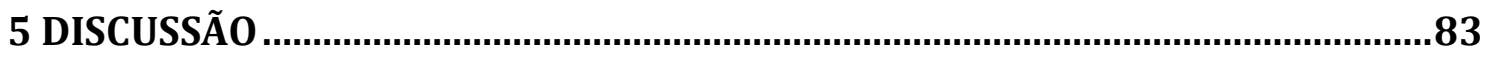

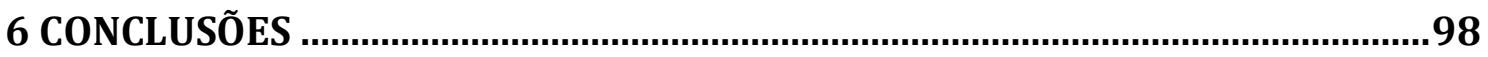

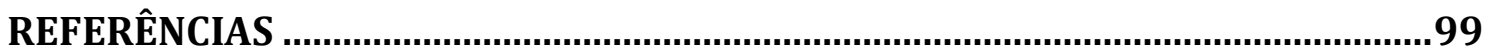




\section{REVISÃO DE LITERATURA}

\subsection{Hipertensão arterial}

A hipertensão arterial (HA) é uma condição clínica multifatorial caracterizada por níveis elevados e sustentados de pressão arterial (PA). Apesar de intensas pesquisas científicas e os avanços terapêuticos alcançados nas últimas décadas, a HA continua sendo o principal problema de saúde mundial. Ela triplica os riscos de doenças cardiovasculares, tais como infarto do miocárdio e insuficiência cardíaca e aumenta em cerca de seis vezes a predisposição ao acidente vascular cerebral (AVC). Com números ainda crescentes e a expectativa de atingir 1 bilhão em 2025, uma em cada três pessoas no mundo sofre de hipertensão arterial (PATON; RAIZADA, 2010; ZUBCEVIC et al., 2011). No Brasil, a HA representa a maior causa de mortalidade (aproximadamente $30 \%$ ) e é responsável por cerca de $11 \%$ de todas as internações hospitalares (DATASUS do Ministério da Saúde).

Atualmente, apesar da grande oferta de drogas anti-hipertensivas (diuréticos, vasodilatadores, simpatolíticos, bloqueadores de canais de cálcio, inibidores da renina e da enzima conversora de angiotensina, bloqueadores de receptores de angiotensina II, entre outros), cerca de 30\% dos pacientes são resistentes à medicação e não controlam eficientemente a pressão, apresentando a chamada hipertensão refratária. A maioria destes pacientes não responsivos possui tônus simpático aumentado, com vários componentes neurogênicos envolvidos na gênese desta patologia (PATON; RAIZADA, 2010; ZUBCEVIC et al., 2011). Diversos estudos na literatura científica têm demonstrado o papel fundamental do sistema nervoso simpático (SNS) (ANDERSON et al., 1989; COHEN et al., 1986; DiBONA, 2004; ESLER et al., 1988; MATSUKAWA et al., 1993;) e de alterações na função barorreflexa (GRASSI et al., 1998; TAKESHITA et al., 1975; TRASHER, 2002; ZUBCEVIC et al., 2011) na etiologia da hipertensão neurogênica, a forma mais frequente de hipertensão arterial primária, presente em cerca de 90-95\% dos pacientes hipertensos.

A HA é acompanhada de hipertrofia do ventrículo esquerdo (HEAGERTY et al., 1993; KANNEL, 1992) e caracteriza-se, a nível vascular, por hipertrofia de artérias e arteríolas em praticamente todos os tecidos periféricos (HEAGERTY et al., 1993; SIHM et al., 1995), além de intensa rarefação de capilares (ANTONIOS et al., 1999). No sistema 
nervoso central (SNC), a hipertensão também cursa com respostas adaptativas em macro vasos cerebrais, os quais apresentam hipertrofia e remodelamento vascular com aumento da razão parede/luz de artérias e arteríolas (BAUMBACH et al., 2003; HART et al., 1980; HEISTAD et al., 1992), além de maior propensão à aterosclerose. Estas alterações constituem importantes fatores de risco para o AVC, redução cognitiva e a demência, podendo também contribuir para a patogênese de outras doenças neurodegenerativas como o mal de Alzheimer (CAPONE et al., 2011; KUCUK et al., 2002; ZHANG et al., 2010). A hipertensão crônica também causa alterações em microvasos: há disfunção endotelial, com destruição das junções oclusivas levando a aumento da permeabilidade na barreira hematoencefálica (BHE) e a seu consequente rompimento (LAWTHER et al., 2011).

\subsection{Barreira hematoencefálica e a hipertensão arterial}

A BHE, que se encontra completamente formada ao nascimento (ARMULIK et al., 2010; KRUEGER et al., 2013), tem fundamental importância para a homeostase do SNC. É formada por um sistema celular complexo, composto por células endoteliais, membrana basal, astrócitos e pericitos (ABBOTT et al., 2006; BRADBURY, 1985) (Figura 1).

As células endoteliais que constituem os capilares encefálicos formam, devido às junções oclusivas entre as células endoteliais adjacentes (inset na Figura 1), uma barreira física permitindo apenas o transporte transcelular entre o capilar e o interstício, bloqueando o transporte paracelular que ocorre na maioria dos demais endotélios (ABBOTT et al., 2006). As junções oclusivas são formadas por três proteínas integrais transmembrana - a claudina, a ocludina e moléculas de adesão juncional - bem como proteínas citoplasmáticas acessórias (como as proteínas zonula occludens - ZO1/2/3). As proteínas citoplasmáticas ligam as proteínas de membrana à actina (proteína primária do citoesqueleto) mantendo a estrutura e integridade funcional do endotélio (LAWTHER et al., 2011).

Os astrócitos perivasculares formam processos especializados (podócitos Figura 1) intimamente sobrepostos à superfície externa dos capilares, separando os capilares dos neurônios. Os astrócitos possuem funções especializadas na regulação da BHE: durante o desenvolvimento, servem como arcabouços que guiam neurônios e 
direcionam os capilares da BHE, além de terem importante papel na indução e manutenção do fenótipo da BHE (ABBOTT et al., 2006; LAWTHER et al., 2011).

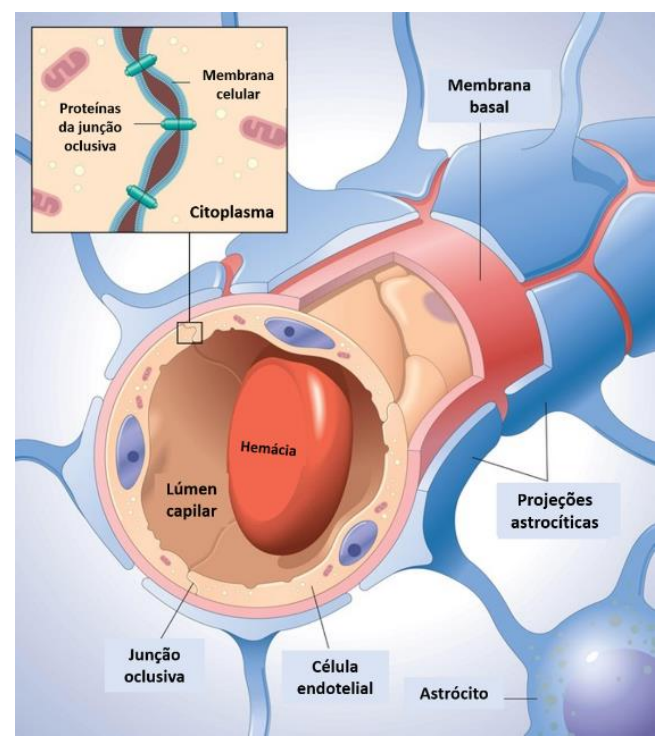

Figura 1 - Esquema representativo da barreira hematoencefálica (BHE) com seus principais constituintes. Modificado de https://cias.rit.edu/faculty-staff/101/faculty/340.

A membrana basal encontra-se interposta entre o endotélio e os astrócitos (Figura 1) e possui em sua constituição colágeno, proteoglicanos, laminina, fibronectina e outras proteínas da matriz extracelular. Ela fornece suporte mecânico para a fixação celular via integrinas (proteínas de receptor transmembrana), agindo como barreira para passagem de macromoléculas. Na membrana basal encontram-se embebidos os pericitos. Estas células enviam projeções, as quais penetram na lâmina basal fixando-se a intervalos irregulares à membrana abluminal do endotélio e cobrindo aproximadamente $30 \%$ da circunferência microvascular. Evidências sugerem que os pericitos possuem a habilidade de induzir estreitamento da BHE por regular proliferação de células endoteliais, além da diferenciação e formação das junções oclusivas. Além disso, os pericitos possuem capacidade fagocítica, a qual se encontra envolvida em respostas neuroimunes (DE VRIES et al., 1997; FLEEGAL-DE-MOTTA et al., 2009; LAWTHER et al., 2011; WILHELM et al., 2011).

As células da microglia ou microgliócitos (macrófagos residentes do SNC) funcionam em estreita associação com a BHE. Em condições basais, a microglia caracteriza-se morfologicamente por processos celulares largamente ramificados, os quais realizam um contínuo monitoramento de SNC. Sua função mais característica é 
uma rápida ativação em resposta a estímulos patológicos no SNC (NIMMERJAHN et al., 2005; KREUTZBERG, 1996;). Estão criticamente envolvidas em lesões, doenças neurodegenerativas, AVC e tumores cerebrais (NIMMERJAHN et al., 2005). Em resposta à injúria, isquemia e/ou estímulos inflamatórios, essas células são ativadas e assumem um fenótipo característico (redução do número de processos celulares, aumento da densidade nuclear e indução de formato ameboide) associado à sua proliferação, migração às proximidades do local de injúria, fagocitose de resíduos celulares e síntese de fatores tanto neurotróficos, quanto neurotóxicos (GARDEN; MÖLLER, 2006; KREUTZBERG, 1996). A ativação da microglia também promove a produção local de espécies reativas de oxigênio e citocinas pró-inflamatórias (SHI et al., 2010; ZUBCEVIC et al., 2011). Células da microglia ativadas podem destruir microrganismos invasores, remover detritos potencialmente deletérios, promover reparo tecidual por secretar fatores de crescimento e facilitar o retorno à homeostase tecidual. Sabe-se também que a microglia tem importante papel na manutenção da integridade endotelial, por facilitar seu reparo em condições patológicas (KELLER, 2013; OBERMEIER, 2013).

A comunicação cruzada entre todos os tipos celulares descritos acima modula a função da barreira e forma a chamada unidade neurovascular, na qual cada um dos diferentes tipos celulares contribui para a sua função (FLEEGAL-DE-MOTTA et al., 2009). A BHE é dinâmica, possuindo dupla função, de barreira e de carreador. A função de barreira ocorre pela restrição à passagem de substâncias tóxicas e potencialmente danosas do sangue para o encéfalo (ABBOTT et al., 2006; WILHELM et al., 2011). Esta função é alcançada através de:

1- Uma barreira paracelular, formada pelas junções oclusivas interendoteliais, que restringem o movimento de substâncias hidrossolúveis entre sangue e tecido neural através das células endoteliais adjacentes;

2- Uma barreira transcelular, composta pelos baixos níveis de endocitose, característica de células endoteliais encefálicas (diferente de outras células endoteliais) desta forma inibindo o transporte de substâncias através do citoplasma;

3- Uma barreira enzimática, provida de um complexo conjunto de enzimas, incluindo acetilcolinesterase, fosfatase alcalina, transpeptidase gama-glutamil, 
monoamina oxidases, e outras enzimas metabolizadoras de drogas capazes de degradar diferentes compostos químicos.

Pequenas moléculas lipossolúveis como o óxido nítrico e os gases sanguíneos como oxigênio e dióxido de carbono difundem-se facilmente pela BHE. Por outro lado, nutrientes essenciais como a glicose e aminoácidos precisam de transportadores específicos na membrana celular para atingir o encéfalo. A função carreadora da BHE é realizada por proteínas de transporte específicas inseridas na membrana celular, as quais são responsáveis pelo transporte de nutrientes, bem como pela remoção de produtos do metabolismo celular (ABBOTT et al., 2006; DE VRIES et al., 1997; FLEEGALDE-MOTTA et al., 2009; WILHELM et al., 2011).

As funções da BHE são bastante prejudicadas pela hipertensão arterial (FARACO; IADECOLA, 2013). Sabe-se que a desregulação do fluxo sanguíneo cerebral e trocas anormais através da barreira, decorrentes da HA, podem resultar no seu rompimento (FLEEGAL-DE-MOTTA et al., 2009; ZHANG et al., 2010). A abertura da BHE, por sua vez, é crítica no desenvolvimento e progressão de várias doenças que afetam o SNC (DE VRIES et al., 1997; JUHLER et al., 1985; KUCUK et al., 2002; LAWTHER et al., 2011).

Os mecanismos através dos quais a HA afeta o funcionamento da BHE ainda estão por ser determinados e muitas questões permanecem em aberto (HOM et al., 2007; ZHANG et al., 2010). Sabe-se, porém, que a disfunção endotelial induzida pela hipertensão crônica destrói as junções oclusivas, sendo responsável pelo aumento da permeabilidade na BHE e seu consequente rompimento (FARACO; IADECOLA, 2013; LAWTHER et al., 2011). Estudos com a linhagem de ratos espontaneamente hipertensos (SHR) sugeriram que fatores hemodinâmicos, além de fatores estruturais, possam estar envolvidos na gênese da disfunção endotelial (KUCUK et al., 2002). Demonstrou-se, posteriormente, que a angiotensina II (ANGII), via receptores $\mathrm{AT}_{1}$, tem papel importante nesta patologia, modulando diretamente a função das células endoteliais da BHE e alterando sua permeabilidade (CAPONE et al., 2011; FLEEGAL-DE-MOTTA et al., 2009).

Zhang et al., (2010) mostraram que a infusão subcutânea prolongada de ANGII, em dose subpressora, causava inflamação dos vasos cerebrais, levando a aumento na permeabilidade da BHE, a qual se encontrava associada a aumento da circulação encefálica, adesão leucocitária e estresse oxidativo (CAPONE et al., 2011; TOYUZ; SCHIFFRIN, 2008; ZHANG et al., 2010). Ito et al., (2000) também demonstraram que a 
inibição dos receptores $\mathrm{AT}_{1}$ bloqueava o aumento da permeabilidade celular e reduzia o edema cerebral relacionados com a hipertensão arterial, mesmo na ausência da redução da pressão arterial, sugerindo um papel do sistema renina-angiotensina (SRA), e em especial da ANGII, em modular o funcionamento da BHE. Realmente a ANGII é considerada o principal efetor do SRA, desempenhando importante papel na manutenção da pressão arterial (PA) e na homeostase de fluidos corporais, através de ações tanto a nível periférico quanto central (FLEEGAL-DE-MOTTA et al., 2009).

\subsection{Sistema renina-angiotensina cerebral e a BHE}

A presença de um SRA cerebral, distinto do plasmático, mas funcionalmente integrado a este, encontra-se bem estabelecido na literatura (GANONG, 1984; HOFFMAN et al., 1976; MACKINLEY et al., 2003; PHILLIPS et al., 1979). Vários núcleos autonômicos, conhecidos por participar do controle dos reflexos cardiovasculares e por estarem envolvidos com a gênese e manutenção da hipertensão neurogênica, possuem alta densidade de receptores $\mathrm{AT}_{1}$. Dentre esses núcleos autonômicos podemos destacar o núcleo paraventricular do hipotálamo (PVN) (SAWCHENKO; SWANSON, 1982), e as áreas bulbares do núcleo do trato solitário (NTS) (SPYER, 1990) e do bulbo rostroventrolateral (RVLM) (DAMPNEY, 1994; SPYER, 1990), os quais participam ativamente da integração do reflexo barorreceptor e são de fundamental importância para o controle cardiovascular. O SRA é essencial para o bom funcionamento das áreas de controle autonômico, mas sua hiperatividade leva a disfunções graves. Por sua vez a HA é acompanhada de importante hiperatividade do SRA cerebral (MARC; LLORENSCORTES, 2011; PHILLIPS; DE OLIVEIRA, 2008; VEERASINGHAM; RAIZADA, 2003), a qual lesa a BHE comprometendo a atividade de neurônios pré-autonômicos centrais e levando à hipertonia simpática, à perda da sensibilidade do barorreflexo e à perpetuação da hipertensão arterial (YAO; MAY, 2013).

Recentemente Biancardi et al., (2014) mostraram em SHR e em ratos submetidos à hipertensão renovascular que a ANGII circulante, e não o aumento da PA, promovia prejuízo à integridade da $\mathrm{BHE}$, uma vez que o bloqueio dos receptores $\mathrm{AT}_{1}$ com losartan, mas não a redução da PA pelo vasodilatador hidralazina, promovia redução nos danos causados à BHE pela hipertensão. Estes experimentos sugeriam que a redução da 
atividade do SRA poderia ser uma forma eficaz de proteger a integridade da BHE em indivíduos hipertensos.

Estudando o envolvimento do SRA cerebral na gênese/manutenção assim como na reversão da hipertensão arterial, experimentos de nosso laboratório têm demonstrado que o treinamento aeróbio de baixa intensidade, da mesma forma que o bloqueio crônico dos receptores $\mathrm{AT}_{1}$, é uma eficiente conduta terapêutica para reduzir a expressão e atividade do SRA cerebral (BEZERRA et al., 2001; CHAAR et al., 2015; FELIX; MICHELINI, 2007; SANGALETI et al., 2004; SANTOS et al., 1995; 1998).

\subsection{Treinamento aeróbio de baixa intensidade e o SRA}

Felix e Michelini (2007) demonstraram que o treinamento aeróbio de baixa intensidade reduz significativamente a expressão de mRNA do angiotensinogênio (Aogen), o precursor da cascata das angiotensinas, em áreas bulbares de controle cardiovascular, como o NTS e a área postrema, e que esta redução se encontrava correlacionada com a queda da PA induzida pelo treinamento em animais hipertensos. Estudando a sequência temporal de alteração de diferentes componentes do SRA em áreas centrais de controle autonômico Chaar et al., (2015) observaram que o treinamento aeróbio causava redução da expressão de mRNA de Aogen no PVN, NTS/DMV e RVLM de SHR, com sequência temporal distinta: após 2 semanas de treinamento no PVN e NTS, mas após 4 semanas no RVLM. Observou-se também redução da expressão de receptores $\mathrm{AT}_{1}$ no PVN e NTS/DMV dos SHR, a qual foi observada apenas após 12 semanas de treinamento, sem alterar a expressão destes receptores no RVLM (CHAAR et al., 2015). Por outro lado, o treinamento aumentava transitoriamente a expressão de receptores Mas no PVN (entre as semanas 4 e 8), sem a alterar no NTS/DMV e no RVLM.

O treinamento aeróbio de baixa intensidade mostrou-se também eficaz em reduzir a atividade do SRA em vasos periféricos, no tecido renal e plasma (SILVA JR et al., 2015), assim como a atividade do SRA cardíaco (MICHELINI; SILVA JUNIOR; CASARINI, dados não publicados). Outros estudos de nosso laboratório em ratos submetidos à hipertensão por coarctação subdiafragmática da aorta (hipertensão de origem mecânica) e tratados cronicamente com losartan (antagonista de receptores $\mathrm{AT}_{1}$ ) também demonstraram que independentemente dos níveis de PA, o bloqueio do 
SRA normaliza a expressão de Aogen e de $\mathrm{AT}_{1}$ em áreas de controle autonômico (SANGALETI et al., 2004), corrigindo completamente os déficits funcionais (como o ganho reduzido do nervo depressor aórtico, o desbalanço autonômico ao coração com predomínio do simpático, a hiperatividade do simpático vascular e a depressão do barorreflexo) apresentados pelos animais hipertensos não tratados (BEZERRA et al., 2001; SANTOS et al., 1995, 1998). Em trabalho recente observamos também que a correção da disfunção barorreflexa e do balanço autonômico ao coração induzida pelo treinamento em SHR acontecia em 2 semanas de treinamento e era mediado pela redução do estresse oxidativo e do perfil pró-inflamatório no PVN, os quais caracterizam a hipertensão arterial neste modelo experimental (MASSON et al., 2014).

Em conjunto estas observações sugerem que o treinamento aeróbio de baixa intensidade, assim como o bloqueio farmacológico das ações teciduais da Angiotensina II, corrige a disfunção autonômica dos SHR por reduzir a expressão/atividade do SRA local e normalizar tanto o estresse oxidativo quanto a inflamação em áreas autonômicas. Por outro lado, estes dados em conjunto com as observações de que a HA cursa com lesão da BHE e que o bloqueio de receptores $\mathrm{AT}_{1}$ reverte a lesão da BHE e reduz o edema cerebral (BIANCARDI et al., 2014; CAPONE et al., 2011; FARACO; IADECOLA, 2013; ITO et al., 2000) evidenciam que o treinamento aeróbio também possa corrigir o controle autonômico em hipertensos por melhorar a integridade/funcionamento da BHE. Esta é, justamente, nossa hipótese de trabalho. Pretendemos, portanto, investigar em SHR os efeitos simultâneos do treinamento aeróbio sobre o controle autonômico da circulação e sobre a permeabilidade da BHE em áreas encefálicas envolvidas com a gênese dos tônus vagal e simpático ao coração e vasos de resistência. Sabendo-se ainda que os efeitos do treinamento aeróbio sobre a expressão/funcionalidade dos diferentes componentes SRA cerebral e sobre o conteúdo de espécies reativas de oxigênio e citocinas próinflamatórias ocorrem em diferentes tempos experimentais, pretendemos investigar nas diferentes áreas autonômicas a sequência temporal com que a permeabilidade da BHE é alterada pelo exercício aeróbio. Neste projeto contamos com a participação do Dr. Javier Stern, do Medical College of Georgia, USA, nosso colaborador de longa data e que tem trabalhado com a lesão da BHE na hipertensão (BIANCARDI et al., 2014). 


\section{OBJETIVOS}

Foram 2 os objetivos principais deste estudo:

- Avaliar em SHR a evolução da integridade da BHE em áreas autonômicas encefálicas (PVN, NTS, RVLM) desde a fase pré-hipertensiva ( $\sim 1$ mês de idade) até a fase crônica da hipertensão ( $\sim 5$ meses de idade);

- Avaliar a eficácia do treinamento aeróbio de baixa intensidade iniciado na fase mantida da hipertensão em corrigir os efeitos deletérios da hipertensão sobre a integridade da BHE em áreas de controle autonômico e se estas alterações são ou não acompanhadas de melhora do controle cardiovascular nos SHR.

Como controle experimental foram utilizados ratos WKY pareados por idade e submetidos aos mesmos protocolos experimentais.

Nossos objetivos específicos foram:

- Quantificar nos SHR e WKY os efeitos idade-dependente e hipertensão-dependente sobre a integridade e/ou lesão da BHE;

- Quantificar e comparar nos SHR e WKY os efeitos sequenciais do treinamento e do sedentarismo (semanas experimentais $0,1,2,4$ e 8) sobre o extravasamento de corante fluorescente para o espaço extravascular encefálico no PVN, NTS e RVLM;

- Quantificar nas mesmas áreas, nos tempos experimentais, os efeitos do treinamento ou sedentarismo sobre diferentes parâmetros cardiovasculares, procurando correlacionar a maior ou menor integridade da BHE com a função cardiovascular;

- Comprovar o envolvimento da ANGII cerebral como possível mecanismo determinante da lesão e/ou reversão da BHE em SHR através da infusão exógena de dose subpressora de ANGII no PVN durante o treinamento aeróbio;

- Avaliar nesta área nos mesmos tempos experimentais os efeitos do treinamento ou sedentarismo sobre a expressão de alguns dos componentes da BHE, como a proteína ácida glial fibrilar (GFAP), o antígeno de barreira endotelial (EBA), a microglia (IBA-1), e sobre a expressão de receptores $\mathrm{AT}_{1}$. 


\section{MATERIAIS E MÉTODOS}

\subsection{Animais experimentais}

Nesse estudo foram utilizados ratos (Rattus norvegicus) pertencentes às linhagens SHR e Wistar Kyoto (WKY) com peso aproximado de 200-250 g e 12-14 semanas de idade no início dos protocolos de treinamento/sedentarismo, bem como animais das mesmas linhagens com 20-22 dias de idade. SHR e WKY, provenientes do Biotério Central do Instituto de Ciências Biomédicas da Universidade de São Paulo (ICB/USP) foram alojados no Biotério de Experimentação Animal do Departamento de Fisiologia e Biofísica e mantidos em ambiente com temperatura controlada $\left(22{ }^{\circ} \mathrm{C}\right.$ e 25 ${ }^{\circ} \mathrm{C}$ ), ciclo claro-escuro (12 horas), com livre acesso à água e alimentação. Todos animais foram pesados semanalmente para se acompanhar a evolução da massa corpórea. Todos os procedimentos cirúrgicos e protocolos realizados estão de acordo com o Manual Institucional para Experimentação Animal e aprovados pelo Comitê de Bioética do ICB (Protocolo n. 197, folha 116 do livro 02).

\subsection{Treinamento físico}

O treinamento aeróbio foi realizado em esteira ergométrica (Inbramed, Millenium) adaptada para ratos, com 10 raias de acrílico transparente, pintadas de preto em sua porção frontal, criando um ambiente escuro para o qual os ratos são atraídos durante as sessões de corrida, o que facilita a atividade física do animal, evitando o uso de choques elétricos. 0 protocolo de treinamento e o período prévio de adaptação encontram-se descritos a seguir.

\subsubsection{Adaptação à esteira}

As duas semanas iniciais foram destinadas ao período de adaptação. A primeira semana serviu para a adaptação ao novo ambiente (Biotério do Departamento de Fisiologia Cardiovascular), e a segunda à corrida na esteira (cinco sessões de 0,4-0,7 $\mathrm{km} / \mathrm{h}, 0 \%$ inclinação, 10 minutos/dia). Os animais considerados inaptos a andar/correr na esteira foram excluídos dos protocolos experimentais. 


\subsubsection{Teste de esforço máximo}

A capacidade aeróbia máxima dos animais foi medida individualmente através do teste de esforço máximo (TEM). 0 teste em esteira ergométrica consistiu em identificar a velocidade e tempo máximo em que o animal consegue correr até atingir a exaustão. 0 teste teve início com $0,3 \mathrm{~km} / \mathrm{h}$, sendo acrescidos a cada 3 minutos de mais $0,3 \mathrm{~km} / \mathrm{h}$ até a exaustão do animal (Quadro 1).

Tabela 1 - Lista de dados para realização do teste de esforço máximo, correlacionando o tempo da corrida com a velocidade.

$\begin{array}{cc}\text { Tempo de corrida } & \text { Velocidade } \\ 0-3 \mathrm{~min} & 0,3 \mathrm{~km} / \mathrm{h} \\ 3 \mathrm{~min} 1 \mathrm{~s}-6 \mathrm{~min} & 0,6 \mathrm{~km} / \mathrm{h} \\ 6 \mathrm{~min} 1 \mathrm{~s}-9 \mathrm{~min} & 0,9 \mathrm{~km} / \mathrm{h} \\ 9 \mathrm{~min} 1 \mathrm{~s}-12 \mathrm{~min} & 1,2 \mathrm{~km} / \mathrm{h} \\ 12 \mathrm{~min} 1 \mathrm{~s}-15 \mathrm{~min} & 1,5 \mathrm{~km} / \mathrm{h} \\ 15 \mathrm{~min} 1 \mathrm{~s}-18 \mathrm{~min} & 1,8 \mathrm{~km} / \mathrm{h} \\ 18 \min 1 \mathrm{~s}-21 \mathrm{~min} & 2,1 \mathrm{~km} / \mathrm{h}\end{array}$

Cada animal realizou o teste de esforço 3 vezes durante os protocolos experimentais. A primeira vez, no início do protocolo de treinamento, foi utilizada para determinar a capacidade aeróbia de cada animal, permitindo alocar-se animais com igual desempenho aos grupos experimentais sedentário e treinado (descritos a seguir) e para se determinar a intensidade do treinamento. 0 segundo teste máximo, realizado após a $4^{\underline{a}}$ semana de treinamento, foi utilizado para determinar nova capacidade máxima e readequar-se o protocolo de treinamento. 0 terceiro teste foi realizado ao final dos experimentos (8 ${ }^{a}$ semana) e prestou-se à comparação do desempenho entre os grupos e à quantificação da eficácia do treinamento nos grupos normotensos e hipertensos.

Os animais dos grupos sedentários foram mantidos por período equivalente de tempo e colocados uma vez por semana na esteira por 5 minutos a $0,4-0,7 \mathrm{~km} / \mathrm{h}$, para se manter a adaptação ao manuseio, à esteira e ao exercício. Estes também realizaram teste de esforço máximo nos mesmos períodos que os animais treinados. 


\subsubsection{Grupos experimentais}

WKY e SHR foram divididos nos grupos: sedentário (S) e treinado (T). Vários subgrupos de $\mathrm{S}$ e $\mathrm{T}$ foram formados: $\mathrm{S}_{0}$ - animal sedentário no início do protocolo experimental; $\mathrm{S}_{8}$ - animal sedentário no final do protocolo experimental (8 semanas); $\mathrm{T}_{1}$ - animal após 1 semana de treinamento; $\mathrm{T}_{2}$ - animal após 2 semanas de treinamento; $\mathrm{T}_{4}$ - animal após 4 semanas de treinamento; $\mathrm{T}_{8}$ - animal após 8 semanas de treinamento. Foram formados, portanto, 12 subgrupos experimentais (Quadro 2).

Tabela 2 - Grupos experimentais divididos por linhagem (SHR e WKY), condição (S ou T) e tempo $(0,1,2,4$ e 8 semanas $)$.

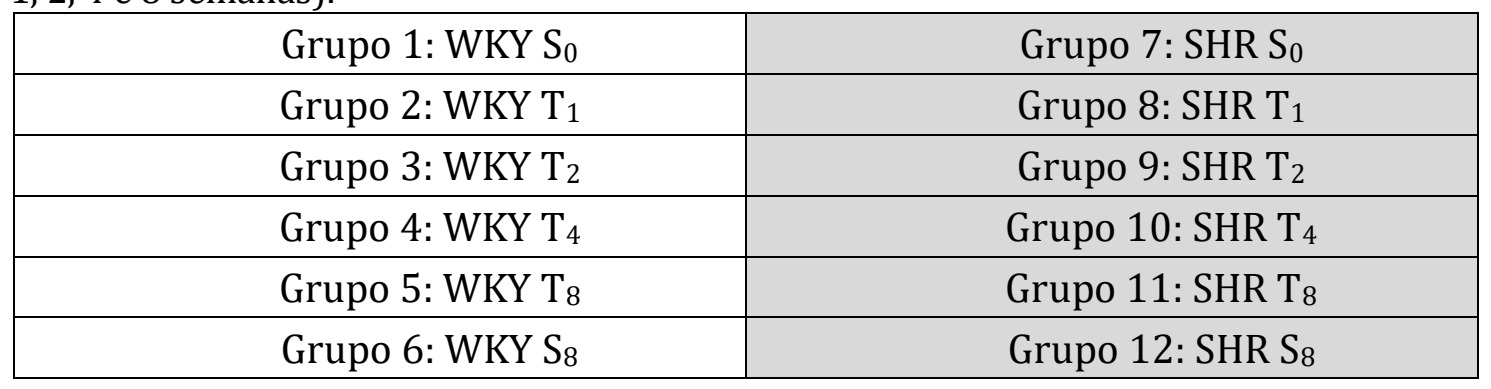

Para acessarmos os efeitos da instalação da hipertensão sobre a lesão da BHE, utilizamos, além dos grupos acima identificados, outros grupos de SHR de 4 semanas de idade (e seus controles WKY, pareados por idade), período em que os SHR ainda se encontram na fase pré-hipertensiva. Como o objetivo desta investigação era avaliar o estado funcional da BHE desde a fase de normotensão até a fase crônica da hipertensão, estes grupos de animais não foram submetidos ao treinamento.

\subsubsection{Protocolo de treinamento aeróbio de baixa intensidade}

0 protocolo de treinamento de baixa intensidade (50-60\% da carga máxima atingida no teste de esforço) compreendeu um programa de exercício repetitivo realizado durante no máximo uma hora ao dia, cinco dias por semana durante 8 semanas. A intensidade escolhida (50-60\% da velocidade máxima) tem sido indicada como intensidade ideal para obtenção de efeitos benéficos do treinamento sobre o sistema cardiovascular de hipertensos, como a redução da pressão arterial e da hiperatividade do SRA, e, a melhoria do controle autonômico da circulação (CERONI et 
al., 2009; FELIX; MICHELINI, 2007; MELO et al., 2003). A intensidade do exercício foi aumentada gradativamente pela combinação da velocidade e duração do exercício até atingir a intensidade estabelecida.

\subsection{Procedimentos cirúrgicos e registro direto da PA e FC}

Nos períodos previamente definidos $\left(\mathrm{S}_{0}, \mathrm{~T}_{1}, \mathrm{~T}_{2}, \mathrm{~T}_{4}, \mathrm{~T}_{8}\right.$ e $\left.\mathrm{S}_{8}\right)$ os animais foram conduzidos ao Laboratório de Fisiologia Cardiovascular para canulação arterial, registro dos parâmetros cardiovasculares, injeção de corantes fluorescentes e posterior coleta dos tecidos. Para tanto foram inseridas cânulas na artéria femoral e carótida, implantadas 24 horas antes da realização dos experimentos funcionais.

\subsubsection{Confecção de cânulas}

As cânulas arteriais foram confeccionadas com tubos de Tygon (Critchley, Austrália), sendo mais fina a parte proximal a ser introduzida na luz vascular (diâmetro interno: externo = 0,28: 0,61 mm) com $4 \mathrm{~cm}$ de extensão (artéria femoral) e 2,5 cm de extensão (carótida). Estas cânulas foram soldadas, por aquecimento, à parte distal de maior calibre (diâmetro interno: externo $=0,50: 1,50 \mathrm{~mm}$ ) com aproximadamente $17 \mathrm{~cm}$ de comprimento (artéria femoral) e $8 \mathrm{~cm}$ de comprimento (carótida). As cânulas foram preenchidas com solução salina 0,9\% e ocluídas com pino de metal.

\subsubsection{Procedimentos cirúrgicos}

\subsubsection{Canulação arterial}

Para canulação arterial, os animais foram previamente anestesiados com 100 $\mathrm{mg} / \mathrm{Kg}$ de cloridrato de cetamina e $20 \mathrm{mg} / \mathrm{Kg}$ de cloridrato de xilazina. Para a realização das cirurgias foram utilizados procedimentos assépticos e lupa cirúrgica (Surgical Microscope - DFV - M90), com os animais mantidos em mesa cirúrgica aquecida $\left(37^{\circ} \mathrm{C}\right)$. Para canulação da artéria femoral, foram realizadas tricotomia das regiões interna do membro posterior esquerdo e da região cervical. Através de incisão na altura da articulação coxofemoral foi localizado o tronco vásculo-nervoso e isolada artéria femoral 
onde foi introduzida e fixada a parte proximal mais fina da cânula de Tygon preenchida com solução fisiológica heparinizada $(20 \mu \mathrm{L} / \mathrm{mL})$. A extremidade distal foi exteriorizada através do espaço subcutâneo na região cervical e fixada com fio de algodão. Para canulação da carótida, foi realizada uma incisão na região ventral do pescoço para localização e isolamento da carótida esquerda. Outra cânula de Tygon também preenchida com solução salina foi inserida na luz do vaso, em direção rostral e a outra extremidade exteriorizada através do espaço subcutâneo na região cervical e fixada com fio de algodão. Após realização dos procedimentos cirúrgicos os animais receberam doses adequadas de analgésico (2 mg/Kg cetoprofeno - Merial, SC) e antibiótico (24.000 UI/Kg pentabiótico Veterinário - Fort Dodge, SC) e mantidos, após recuperação cirúrgica, em gaiolas individuais.

\subsubsection{Implante de micro-pumps}

Para avaliação dos efeitos da ANGII e do treinamento aeróbio sobre os componentes da BHE nos núcleos estudados, nós realizamos implante de micro-pumps intracerebroventricular (i.c.v.) em animais hipertensos que foram em seguida treinados por 3 semanas. Para isso, 2 semanas após de adaptação à esteira, 12 animais da linhagem SHR, pesando entre 250-280g foram anestesiados com $100 \mathrm{mg} / \mathrm{Kg}$ de cloridrato de cetamina e $20 \mathrm{mg} / \mathrm{Kg}$ de cloridrato de xilazina e após tricotomizados na região dorsal da cabeça e escápula, colocados no aparelho estereotáxico (David-Kopf, Tujunga, CA, EUA) e, com o auxílio de um protetor auricular, a cabeça foi colocada em posição plana (coordenada da barra do incisivo: $-3,3 \mathrm{~mm}$ ) e fixada por meio das barras auriculares do aparelho estereotáxico. A seguir foi injetado, subcutaneamente, um anestésico local com vasoconstrictor (cloridrato de lidocaína a 3\% com bitartarato de norepinefrina 1:50.000), na região do escalpo a ser aberta, a fim de se evitar sangramentos após a incisão cirúrgica. Logo após a assepsia da pele com solução de álcool iodado, foi feita uma incisão longitudinal na pele e tecido subcutâneo, expondo-se a região da calota craniana, a qual foi posteriormente tratada com solução fisiológica e água oxigenada para a completa assepsia da área. Kits de infusão encefálica (Brain infusion kit 2, ALZET, Cupertino, CA, USA) acoplados à micro-pumps (Micro-osmotic pump modelo $1002-0,25 \mu \mathrm{L} / \mathrm{h}$ por 14 dias, ALZET, Cupertino, CA, USA) foram fixados na torre do estereotáxico e colocadas na posição vertical (angulação zero) com a cabeça do 
animal ajustada até que os pontos das suturas sagitais (bregma) e occipital (lambda) da calota craniana ficassem no mesmo nível horizontal e, então, foram feitas as leituras dos parâmetros anteroposterior (AP), lateral (L) e dorsoventral (DV) a partir do Bregma. Através um orifício feito com auxílio de uma broca odontológica o kit de infusão foi inserido em direção ao ventrículo lateral encefálico a partir das coordenadas estereotáxicas do Atlas de Paxinos e Watson (2005) ( -1,6 mm lateral ao Bregma, -1 mm anteroposterior e $-4,5 \mathrm{~mm}$ ventral). 0 kit foi então fixado ao crânio com resina acrílica de uso odontológico (Artigos Odontológicos Clássico, Campo Limpo Paulista, SP, Brasil) e a pele suturada. As micro-pumps contendo ANGII ou veículo (salina) foram inseridas subcutaneamente na região escapular e a pele foi em seguida suturada. As micro-pumps foram previamente preenchidas com um volume e concentração de ANGII de forma que cada animal recebesse por hora uma dose de $50 \mathrm{ng} / \mu \mathrm{L}$ da solução. Esses cálculos foram realizados a partir de software ALZET e para concentração escolhida, considerada subpressora, tendo como base o trabalho prévio de Pan et al. (2006). Como medida profilática pós-cirúrgica, foram injetados $0,1 \mathrm{ml}$ de Pentabiótico Veterinário e analgésico Biofen 1\% (Biofarm Química e Farmacêutica LTDA, Jaboticabal, SP, Brasil) ambos por via subcutânea. Em seguida os animais foram colocados em caixas individuais, com água e ração "ad-libitum"e mantidos em salas com temperatura, umidade e luminosidade controladas, por um período de 14 dias e treinados diariamente, segundo protocolo descrito acima. Metade dos animais do grupo foram destinados ao grupo de imunofluorescência e outra metade à injeção de corantes e análise da integridade da BHE.

\subsubsection{Registro simultâneo da PA e FC}

Os registros basais da PA e FC foram realizados com o animal acordado e com livre movimentação, na própria gaiola, pelo menos 24 horas após os procedimentos cirúrgicos. A cânula da artéria femoral foi conectada a um transdutor de pressão (Modelo CDX III, Cobe Labs, Lakewood, CO, USA), acoplado a um amplificador (ML224 Quad Bridge Amp, ADInstruments, New South Wales, Austrália) e ao sistema de aquisição de dados digital (PowerLab, ADInstruments, New South Wales, Austrália) para registro da PA pulsátil e média. A frequência de amostragem para aquisição dos 
parâmetros hemodinâmicos foi de 2000 Hertz/canal. Após estabilização dos parâmetros cardiovasculares, os valores basais de PA pulsátil foram registrados por 40 minutos. A FC e PA média (PAM) foram derivadas do intervalo de pulso da pressão arterial, batimento a batimento.

Os registros funcionais dos animais do grupo $\mathrm{S}$ ocorreram no início $\left(\mathrm{S}_{0}\right)$ e no final $\left(\mathrm{S}_{8}\right)$ do protocolo (controle temporal) e os dados dos animais do grupo $\mathrm{T}$ foram coletados com 1, 2, 4 e 8 semanas experimentais $\left(\mathrm{T}_{1}, \mathrm{~T}_{2}, \mathrm{~T}_{4}\right.$ e $\left.\mathrm{T}_{8}\right)$ (efeitos do treinamento). Para ambos os grupos, os valores de PA e FC de repouso apresentados correspondem à média destes valores durante 30 minutos do registro basal.

\subsection{Análise espectral de parâmetros cardiovasculares}

A análise espectral dos parâmetros cardiovasculares no domínio da frequência foi realizada como descrito anteriormente por Soares et al., (2004). Resumidamente, as análises, abrangendo tanto o domínio do tempo quanto o da frequência, foram avaliadas em condição de repouso para cada animal, utilizando-se um período de 5 min de registro contínuo, selecionado após a estabilização dos parâmetros cardiovasculares. A densidade da análise espectral foi obtida através da transformação rápida de Fourier pelo método de Welch e janelas de Hanning com sobreposição de 50\%. Os componentes da análise espectral para as bandas very low- (VLF, <0,20 Hz), low- (LF, 0,20-0,75 Hz) e high-frequency (HF, >0.75 Hz) foram obtidos pelas médias da integração das densidades dos espectros dentro da largura das bandas de frequência, utilizando-se uma rotina customizada (MATLAB R2012a, Mathworks, Natick, MA, USA).

\subsection{Injeção intravascular de corantes fluorescentes e análise da integridade da BHE}

\subsubsection{Injeção intravascular de dextranos fluorescentes}

Depois de realizadas as medidas funcionais, os ratos foram anestesiados com uma mistura de cloridrato de cetamina e cloridrato de xilazina - $60 \mathrm{mg}$ e $8 \mathrm{mg} / \mathrm{mL}$, respectivamente, e submetidos à injeção intracarotídea do corante fluorescente rodamina dextran (70 kDa - ROD) e isotiocianato de fluoresceína dextran (10 kDa FITC) (10 mg/mL, 2,86 $\mu \mathrm{L} / \mathrm{g} / \mathrm{cada})$, através da cânula carotídea previamente inserida. 
Após 20 minutos, os ratos foram decapitados e seus encéfalos rapidamente coletados e pós-fixados por $48 \mathrm{~h}$ em parafolmaldeído 4\% (4\% PFA), seguido por crioproteção em tampão fosfato de sódio 0,1 M (0,01 M PBS) contendo $30 \%$ de sacarose, por 3 dias a $4{ }^{\circ} \mathrm{C}$. Cortes de $30 \mu \mathrm{m}$ de espessura do hipotálamo contendo toda a extensão do PVN, e, do tronco cerebral englobando tanto o NTS quanto o RVLM, segundo coordenadas de Paxinos e Watson (1986)) foram obtidos em criostato Leica (CM3050, Germany), coletados em 4 poços de placa de cultura contendo PBS $0,1 \mathrm{M}$, sendo os cortes de um desses poços imediatamente colocados em lâmina gelatinizada e montados em lâminas previamente gelatinizadas (solução contendo 0,5\% de gelatina de pele bovina, 0,05\% de $\left.\mathrm{CrK}\left(\mathrm{SO}_{4}\right)\right)$. As lâminas foram montadas com o meio de montagem Slowfade ${ }^{\circledR}$ Gold Antifade Reagent, Life Technologies, CA, EUA) e lamínula, evitando-se a formação de bolhas.

\subsubsection{Aquisição de imagens por microscopia de fluorescência}

As imagens do núcleo paraventricular do hipotálamo (PVN), bulbo rostroventrolateral (RVLM) e núcleo do trato solitário (NTS) foram examinados e fotografados com o microscópio fluorescente LEICA DMLB (Leica Microsystems, Germany) acoplado a uma câmera ExiBlue (Imaging, Canada). As fotomicrografias obtidas através do software Image-Pro Plus v. 7.01 (Media Cybernetics, USA) (Figura 2) foram processadas pelo software ImageJ (NIH, USA), para análise de extravasamento da BHE.
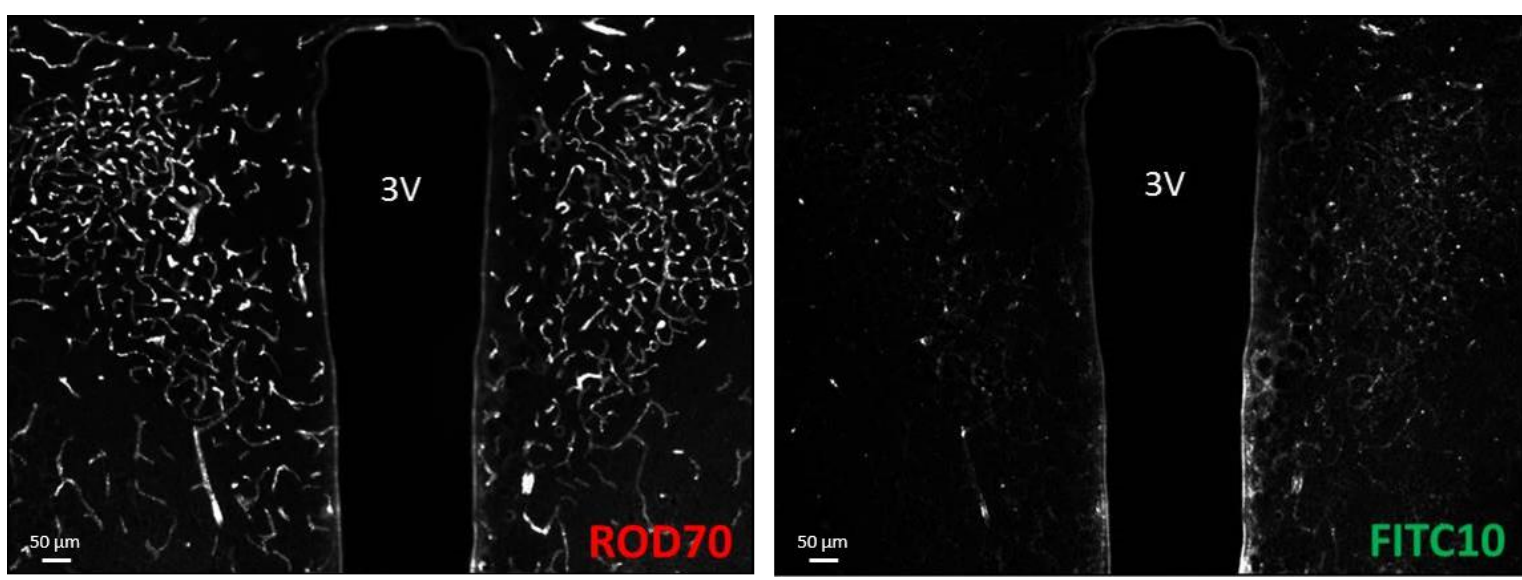

Figura 2 - Exemplo de fotomicrografias obtidas em microscópio de fluorescência com os filtros para o corante Rodamina-Dextran de 70 kDa (ROD, vermelho) e FITC-Dextran de 10 kDa (FITC, verde). 


\subsubsection{Quantificação digital da permeabilidade da BHE}

0 estado de permeabilidade da barreira hematoencefálica foi mensurado pela habilidade das pequenas moléculas de FITC em extravasar parcialmente do leito intravascular para o parênquima encefálico, caso haja algum tipo de lesão/rompimento da BHE. Esta técnica de quantificação foi idealizada por nosso colaborador, o Prof. Dr. Javier Stern (Georgia Health Sciences University, USA) (BIANCARDI et al., 2014), mas precisou ser padronizada para nossas condições experimentais (microscopia e câmera de fluorescência e software de aquisição Image-Pro Plus 3D v7.01, Media Cybernetics).

A figura 3 exemplifica passo-a-passo o procedimento para a análise de extravasamento dos corantes realizada. As figuras $3 \mathrm{a}$ e $3 \mathrm{~b}$ representam o mesmo corte unilateral esquerdo do PVN de um animal SHR-S da semana 0, fotografado com filtros para a ROD e FITC, respectivamente. Após procedimento para remoção do background, o qual consiste no cálculo do threshold para as imagens co-localizadas, restam imagens binárias para a ROD (3c) e o FITC (3d). Estas foram então co-localizadas no software formando as imagens 3e e $3 \mathrm{f}$ (em 32 bits e 8 bits, respectivamente). A imagem em 32 bits não é utilizada para o cálculo, apenas serve para termos uma ideia visual do extravasamento do FITC (a cor vermelha representa a ROD, a cor verde, o FITC e o branco a co-localização dos dois corantes). Da imagem co-localizada em 8 bits, subtraímos a imagem 3d (FITC binário) e temos como resultado a imagem 3g, que representa apenas o FITC extravasado. Através do comando measure do software, obtivemos automaticamente o valor de porcentagem de área de FITC extravasado para a imagem analisada (3h).

Esse procedimento foi realizado em todos os cortes, para os lados direito e esquerdo do PVN, NTS e RVL. Os valores utilizados para comparação entre os grupos são das médias aritméticas para todos os cortes de cada animal. Foram analisados de 7 a 9 cortes do PVN de cada animal, 12 a 14 cortes do NTS e 4 cortes do RVLM. Além disso, elencamos o núcleo hipoglosso como região inespecífica para comparação do extravasamento com as áreas de controle cardiovascular. Analisamos 3 cortes deste núcleo, em SHR e WKY, no início dos protocolos (semana 0). 

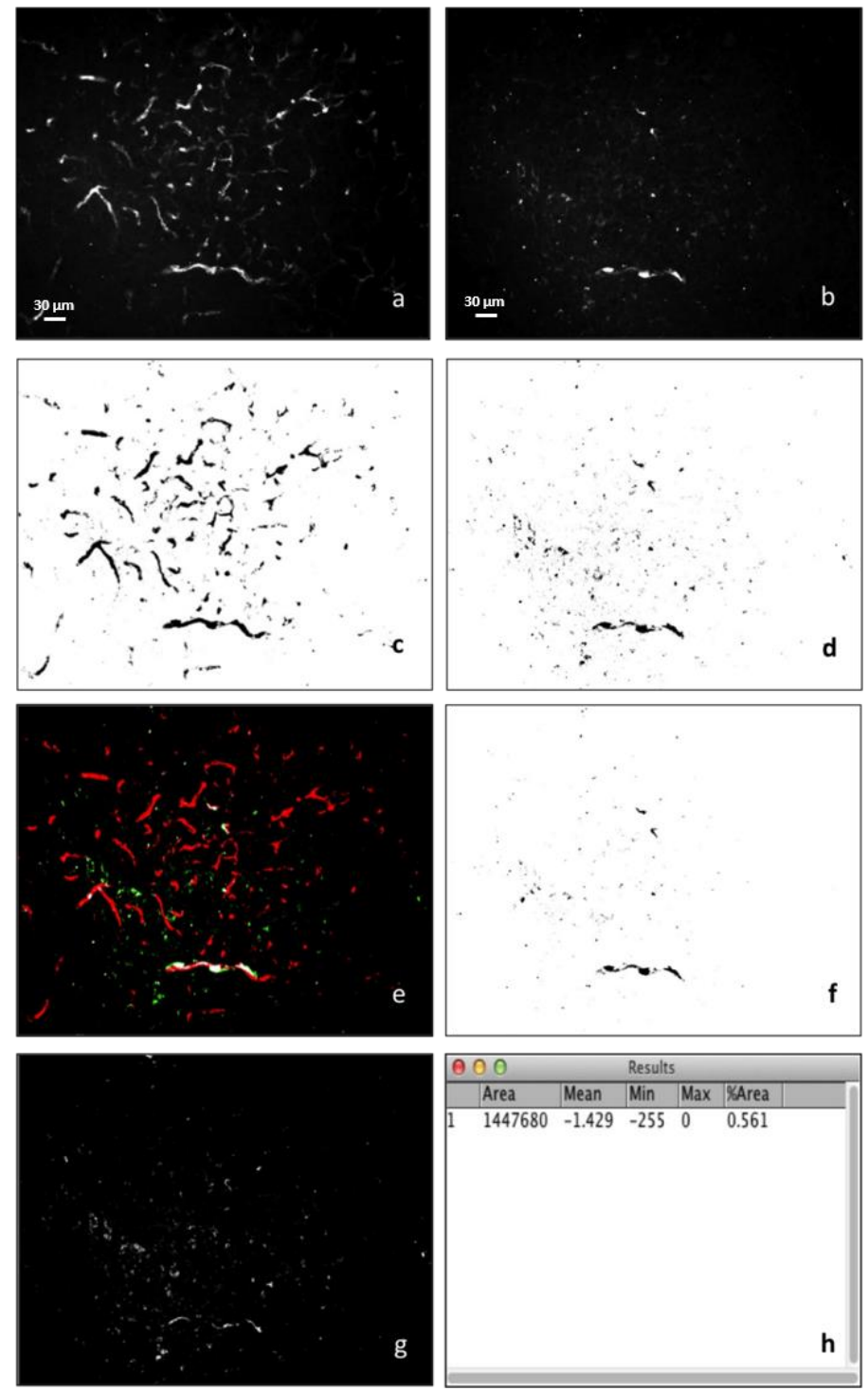

Figura 3 - Diferentes passos do processo de quantificação do extravasamento de FITC. a- PVN com filtro para ROD; b- PVN com filtro para o FITC; c- imagem binária para a ROD; d- imagem binária para o FITC; e- co-localização da ROD e FITC (imagem em 32 bits), o vermelho corresponde a ROD, o verde o FITC e o branco é a co-localização dos dois corantes; f- colocalização de ROD e FITC (imagem em 8 bits); g- resultado da subtração das imagens co-localizada e FITC 8 bits; $\mathbf{h}$ - resultado da porcentagem de área extravasada pelo FITC.

\subsection{Ensaios de imunofluorescência}

\subsubsection{Obtenção dos tecidos encefálicos}

Os animais foram anestesiados profundamente e, imediatamente após a parada respiratória, perfundidos em bomba peristáltica a uma taxa de aproximadamente 20 $\mathrm{ml} / \mathrm{min}$, via ventrículo esquerdo. Primeiramente foi utilizada uma solução salina estéril e tamponada por cerca de 5 minutos, seguida por perfusão com uma solução de PFA a $4 \%$ por aproximadamente 20 minutos. Os animais foram então decapitados para a 
retirada dos encéfalos, os quais foram pós-fixados por 4 horas em PFA 4\% e em seguida crioprotegidos em solução sacarose a $30 \%$ por três dias a $4{ }^{\circ} \mathrm{C}$. Os encéfalos foram armazenados em freezer $-80^{\circ} \mathrm{C}$ até o processamento das reações de imunofluorescência.

\subsubsection{Padronização dos anticorpos}

Com o objetivo verificar os efeitos da hipertensão e do treinamento aeróbio na expressão de alguns dos componentes da BHE, padronizamos os anticorpos para a técnica de imunofluorescência. Cortes coronais sequenciais de $30 \mu \mathrm{m}$ de espessura abrangendo toda a extensão dos núcleos de interesse (PVN, NTS e RVLM - segundo coordenadas de Paxinos e Watson (1986)) foram cortados em criostato Leica (CM3050, Germany), coletados e armazenados em solução PBS $0,1 \mathrm{M}$ a $4{ }^{\circ} \mathrm{C}$. Antes da incubação com os anticorpos específicos, os cortes passaram por um pré-tratamento em solução contendo 1\% de peróxido de hidrogênio, 10\% de metanol diluído em PBS 0,1M, por 30 min a $4{ }^{\circ} \mathrm{C}$. Após 3 lavagens de 10 min em PBS 0,1M, os cortes foram pré-incubados em soro normal donkey 2\% (S30-10ML, Millipore Temceula, CA, EUA) por $1 \mathrm{~h}$ e a seguir incubados com os seguintes anticorpos primários: 1) mouse anti-rat blood-brain barrier (SMI 71) monoclonal antibody (1:2000; Covance, CA, EUA); 2) rabbit anti-glial fibrillary acidic protein (GFAP) (1:300, Sigma-Aldrich, MO, EUA); 3) rabbit anti-mouse IBA-1 (1:1000; Wako, Osaka, Japan); 4) rabbit anti-angiotensin type 1 receptor (AT1 (306):sc579) (1:50, Santa Cruz Biotechnology, CA, EUA); 5) mouse anti-neuronal nuclei (NeuN) (1:1000; Millipore, Darmstadt, German). Todos os anticorpos primários foram diluídos em PBS 0,1M contendo 0,1\% de Triton X-100 (detergente para quebrar os lipídios de membrana facilitando a ligação dos anticorpos com as proteínas). A seguir os cortes foram incubados com anticorpos secundários Alexa 594 donkey anti-rabbit (Alexa Fluor 594-conjugated AffiniPure donkey anti-rabbit IgG $(\mathrm{H}+\mathrm{L})$ Jackson Immunoresearch Laboratories Inc., MD, EUA), Alexa 488 donkey anti-mouse (Alexa Fluor 488-conjugated AffiniPure Donkey Anti-Mouse IgG (H+L) Jackson Immunoresearch Laboratories Inc., MD, EUA) ou Alexa 488 donkey anti-rabbit (Alexa Fluor 488-conjugated AffiniPure donkey anti-mouse $\operatorname{Ig} G(\mathrm{H}+\mathrm{L})$ Jackson Immunoresearch Laboratories Inc., MD, EUA) todos com uma concentração de 1:500 por 1 h. Após 3 outras lavagens de 10 min em PBS 0,1M, os cortes foram montados em lâminas previamente gelatinizadas (solução contendo 0,5\% de gelatina de pele bovina e $0,05 \%$ de $\left.\mathrm{CrK}\left(\mathrm{SO}_{4}\right)\right)$. As lâminas foram montadas no meio 
de montagem Slowfade Gold Antifade reagente (Life Technologies, CA, EUA) e lamínula, evitando-se a formação de bolhas e armazenadas a $4{ }^{\circ} \mathrm{C}$ no escuro

\subsubsection{Análise histológica}

Os cortes sequenciais do PVN, NTS e RVLM foram analisados (microscópio LEICA DMLB, Leica Microsystems, Germany, acoplado a uma câmera ExiBlue, Imaging, Canada) para localização das áreas de interesse, as quais foram fotografadas em diferentes aumentos. As fotomicrografias obtidas pela microscopia de fluorescência foram analisadas pelos softwares Image-Pro Plus v. 7.01 (Media Cybernetics, USA) e ImageJ (NIH, USA).

\subsection{Análise estatística}

Os resultados apresentados são expressos como média \pm EPM (erro padrão da média). O desempenho em esteira e a evolução do peso corporal foram analisados pela ANOVA de 3 fatores para medidas repetidas (grupo, condição e tempo). Para demais variáveis funcionais, análise espectral e quantificação de extravasamento pela BHE, utilizamos ANOVA de 2 fatores, comparando o efeito de 8 semanas de treinamento (grupo e tempo) e os efeitos do treinamento ou sedentarismo (grupo e condição). Com relação a densidade integrada obtida pela imunofluorescência dos componentes BHE, comparando-se entre os grupos (WKY e SHR) e sedentarismo nos tempos (0 e 3) também foi realizada a ANOVA de 2 fatores e para comparação dos animais do grupo SHR com relação à infusão de ANGII foi utilizada a análise ANOVA ONE WAY. Para analisar os efeitos da infusão de ANGII ou salina sobre os efeitos do treinamento na integridade da BHE utilizamos teste-t não pareado. Foram considerados como grupo, SHR e WKY, como condição o sedentarismo e o treinamento e como tempo, as semanas 0, 1, 2, 4 e 8 . 0 teste post hoc utilizado foi o Fisher LSD. Para estas análises foi utilizado o software STATISTIC 12 (Stat Soft Inc). 0 nível de significância foi fixado em $p \leq 0,05$. 


\section{RESULTADOS OBTIDOS}

\subsection{Eficácia do treinamento nos grupos SHR e WKY}

Os animais SHR e WKY encontravam-se com 3 meses de idade no início dos experimentos. 0 treinamento aeróbio de baixa intensidade ou o sedentarismo iniciaramse após um período de 2 semanas de adaptação dos ratos à esteira ergométrica. 0 cálculo da intensidade do treinamento bem como a evolução do desempenho em esteira dos SHR e WKY foram obtidos através de 3 testes de esforço máximo (TEM) realizados no início (semana 0), metade (semana 4) e ao final (semana 8) dos protocolos de treinamento ou sedentarismo.

No início dos protocolos experimentais, os SHR apresentavam melhor desempenho em esteira do que os WKY (Figura 4), mas os grupos hipertensos (SHR-S e SHR-T) e normotensos (WKY-S e WKY-T) iniciaram os protocolos com mesma capacidade máxima $(1,5 \pm 0,2 \mathrm{Km} / \mathrm{h}$ e $1,1 \pm 0,1 \mathrm{Km} / \mathrm{h}$, respectivamente). Enquanto ambos os ratos treinados apresentaram ganho de desempenho ao longo do protocolo (SHR-T: $2,3 \pm 0,1 \mathrm{Km} / \mathrm{h}$ na semana 4 e $2,5 \pm 0,2 \mathrm{Km} / \mathrm{h}$ na semana 8 ; WKY-T: $1,7 \pm 0,1$ na semana 4 e $1,9 \pm 0,2$ na semana 8), os SHR-S exibiram redução de desempenho $(1,1 \pm 0,2 \mathrm{Km} / \mathrm{h}$ na semana 4 e 0,9 $\pm 0,1 \mathrm{Km} / \mathrm{h}$ na semana 8), sem alteração significativa do desempenho nos WKY-S $(1,2 \pm 0,1 \mathrm{Km} / \mathrm{h}$ na semana 4 e 1,0 $\pm 0,03 \mathrm{Km} / \mathrm{h}$ na semana 8$)$. Observamos ainda que o melhor desempenho dos SHR vs. WKY foi mantido durante o protocolo de treinamento com diferenças significativas nos três testes de esforço realizados $(1,5 \pm 0,1$ $\mathrm{Km} / \mathrm{h}$ vs. $1,1 \pm 0,1 \mathrm{Km} / \mathrm{h}$ na semana $0 ; 2,3 \pm 0,1 \mathrm{Km} / \mathrm{h}$ vs. $1,7 \pm 0,1 \mathrm{Km} / \mathrm{h}$ na semana $4 \mathrm{e}$ $2,6 \pm 0,2 \mathrm{Km} / \mathrm{h}$ vs. $1,9 \pm 0,2 \mathrm{Km} / \mathrm{h}$ na semana 8). Não houve diferenças significativas quanto ao desempenho em esteira entre SHR-S e WKY-S nas semanas 4 e 8 dos protocolos experimentais (Figura 4).
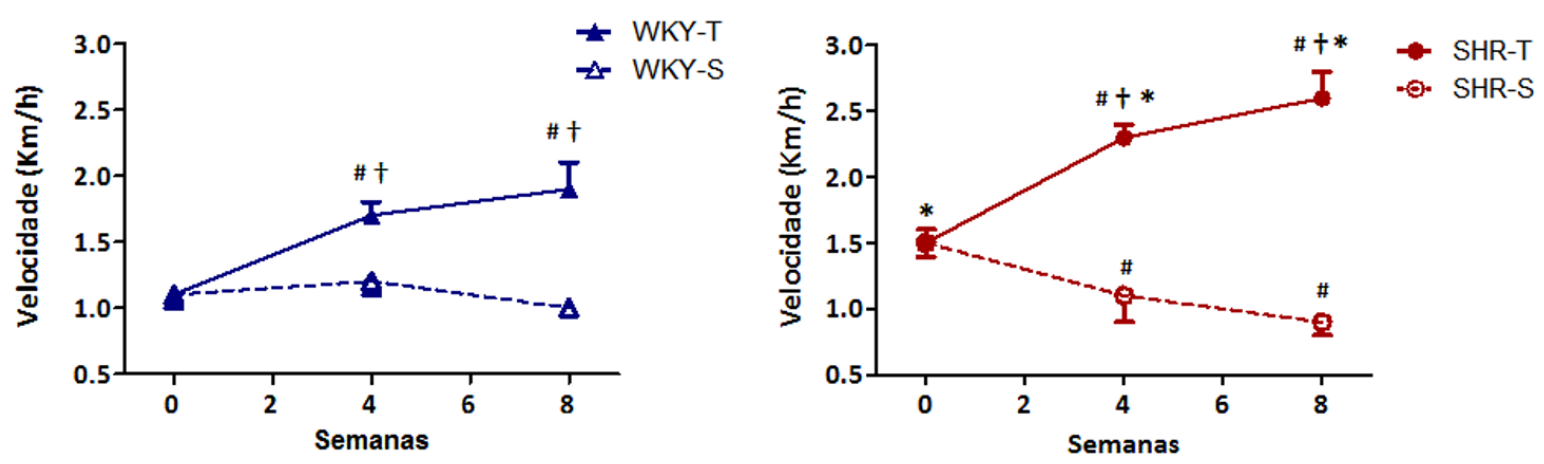

Figura 4 - Evolução temporal do desempenho em esteira $(\mathrm{Km} / \mathrm{h})$ dos grupos treinados (SHR-T e 
WKY-T) e sedentários (SHR-S e WKY-S) ao longo dos protocolos experimentais nas semanas 0, 4 e 8. Significâncias $(\mathrm{P}<0,05) * v s$. WKY † vs. sedentário \# vs. semana 0.

\subsection{Evolução do peso corporal nos grupos SHR e WKY}

A evolução do peso corporal durante os protocolos de treinamento e sedentarismo é apresentada na Figura 5. No início dos protocolos, SHR e WKY, normotensos e hipertensos, apresentavam peso similar (SHR: 266 \pm 1 g e WKY: 265 \pm 5 g). Ao longo das oito semanas experimentais todos os grupos exibiram aumento gradual de peso em relação à semana 0 (SHR-T: $294 \pm 4$ g na semana 4, 305 \pm 5 g na semana 8 , SHR-S: $303 \pm 5 \mathrm{~g}$ na semana 4 e $331 \pm 5 \mathrm{~g}$ na semana 8 vs. $266 \pm 1 \mathrm{~g}$ na semana 0 ; WKY-T: $303 \pm 9 \mathrm{~g}$ na semana $4,317 \pm 11 \mathrm{~g}$ na semana 8 , WKY-S: $298 \pm 9 \mathrm{~g}$ na semana $4,304 \pm 8 \mathrm{~g}$ na semana 8 vs. $265 \pm 5$ g na semana 0), o que atesta a higidez dos animais. Interessante observar que o treinamento físico foi eficiente em reduzir o peso dos SHR (de $261 \pm 2 \mathrm{~g}$ na semana 0 para $294 \pm 4$ g na semana 4 e $305 \pm 5$ g na semana $8 v s$. SHR-S de mesma idade, figura 5), ao passo que o treinamento não alterou significativamente o peso corporal dos WKY. Observamos também que os SHR-S apresentaram peso superior aos WKY-S na oitava semana.
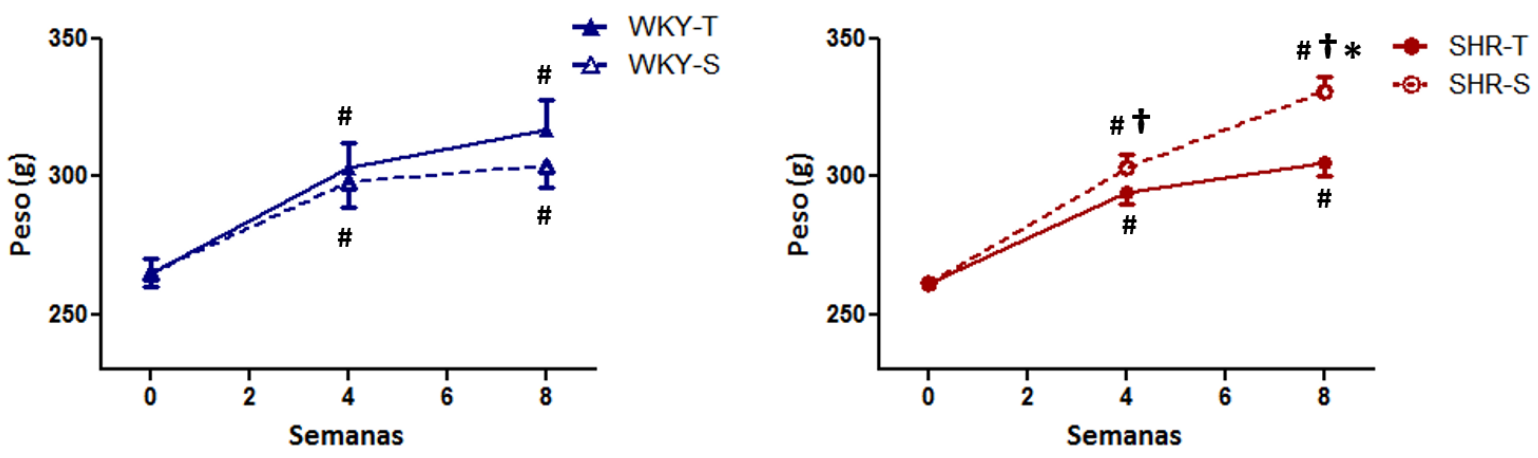

Figura 5 - Evolução do peso corporal dos SHR e WKY durante os protocolos de treinamento (T) ou sedentarismo $(\mathrm{S})$ nas semanas 0,4 e 8 dos protocolos experimentais. Significâncias $(\mathrm{P}<0,05){ }^{*} v s$. WKY † vs. sedentário \# vs. semana 0 .

\subsection{Efeitos do treinamento e sedentarismo sobre a hemodinâmica basal de SHR $\mathrm{e}$ WKY}

No início dos protocolos os SHR já se encontravam na fase estabelecida de hipertensão arterial (PAM $=175 \pm 7 \mathrm{mmHg}$ ) e taquicárdicos ( $\mathrm{FC}=404 \pm 11 \mathrm{~b} / \mathrm{min}$, Figuras 
6 e 7, respectivamente). Observamos que os SHR-T mostraram tendência à queda da PAM já a partir da semana 1, a qual atingiu níveis de significância na quarta semana

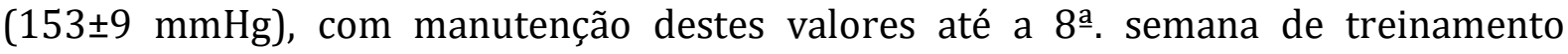
(153 \pm 6 mmHg na semana 8). Observou-se, no entanto, que embora reduzidos, os níveis pressóricos dos SHR não foram normalizados pelo treinamento (cerca de $127 \pm 5 \mathrm{mmHg}$ nos WKY). Nenhuma alteração pressórica foi observada nos WKY ao longo das 8 semanas experimentais (Figura 6).
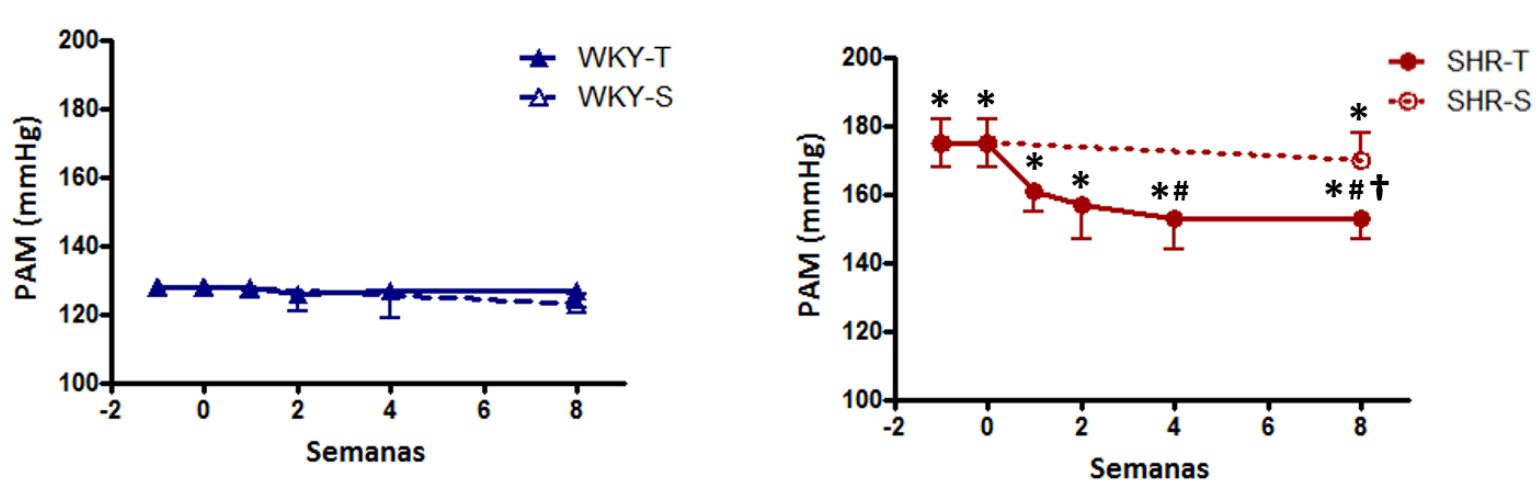

Figura 6 - Evolução dos valores basais de pressão arterial média (PAM) ao longo dos protocolos de treinamento (T) ou sedentarismo $(\mathrm{S})$ nos grupos SHR e WKY. Significâncias $(\mathrm{P}<0,05) * v s$. WKY † vs. sedentário \# vs. semana 0.

O treinamento físico também reduziu a FC basal de SHR, com quedas significativas a partir da quarta semana de treinamento (SHR-T $=351 \pm 11 \mathrm{~b} / \mathrm{min}$ na semana 4 vs. $404 \pm 11 \mathrm{~b} / \mathrm{min}$ na semana 0 ). A bradicardia de repouso foi mantida até a última semana de treinamento $(355 \pm 5 \mathrm{~b} / \mathrm{min}$ na semana 8 , correspondendo à redução de $10 \%$ em relação aos SHR-S. Figura 7). Observou-se também que estes valores não diferiam dos níveis de FC basal apresentada pelos WKY na semana 0 (363 $\pm 18 \mathrm{~b} / \mathrm{min})$. Os animais WKY também apresentaram bradicardia de repouso, já a partir da primeira semana de treinamento (de $363 \pm 18 \mathrm{~b} / \mathrm{min}$ na semana 0 para $320 \pm 11 \mathrm{~b} / \mathrm{min}$ na semana 1), a qual se manteve até o final do protocolo (354 $\pm 14 \mathrm{~b} / \mathrm{min}$ na semana 8 , figura 7$)$. Comparando-se os SHR-T aos WKY-T, a FC de repouso dos SHR ainda se mostrava mais elevada que a de seus controles até a $4^{\text {a }}$. semana, com completa normalização na semana 8. 

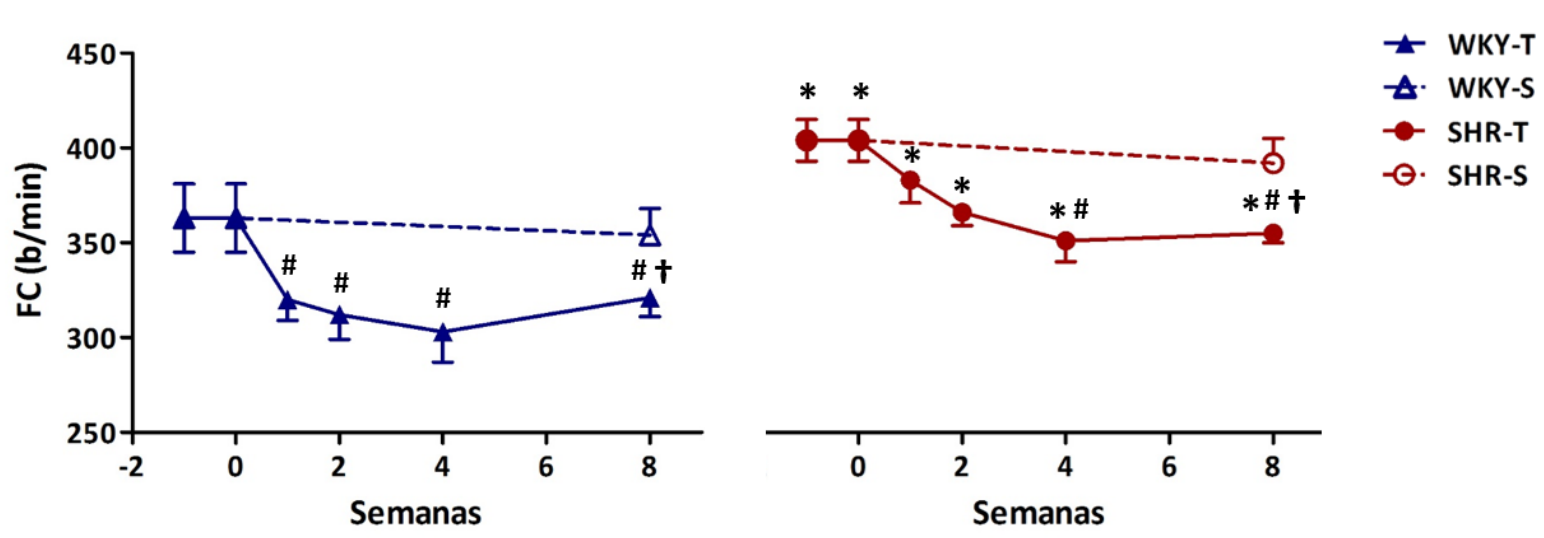

Figura 7 - Evolução dos valores basais de frequência cardíaca (FC) ao longo dos protocolos de treinamento $(\mathrm{T})$ ou sedentarismo $(\mathrm{S})$ nos grupos SHR e WKY. Significâncias $(\mathrm{P}<0,05)$ : * vs. WKY † vs. sedentário \# vs. semana 0.

Ao final dos protocolos evidenciamos a eficácia do treinamento em reduzir significativamente a PAM (Figura 8A) e FC (Figura 8B) basais dos SHR quando comparados com os SHR-S, normalizando inclusive a FC dos SHR-T aos valores dos WKY.
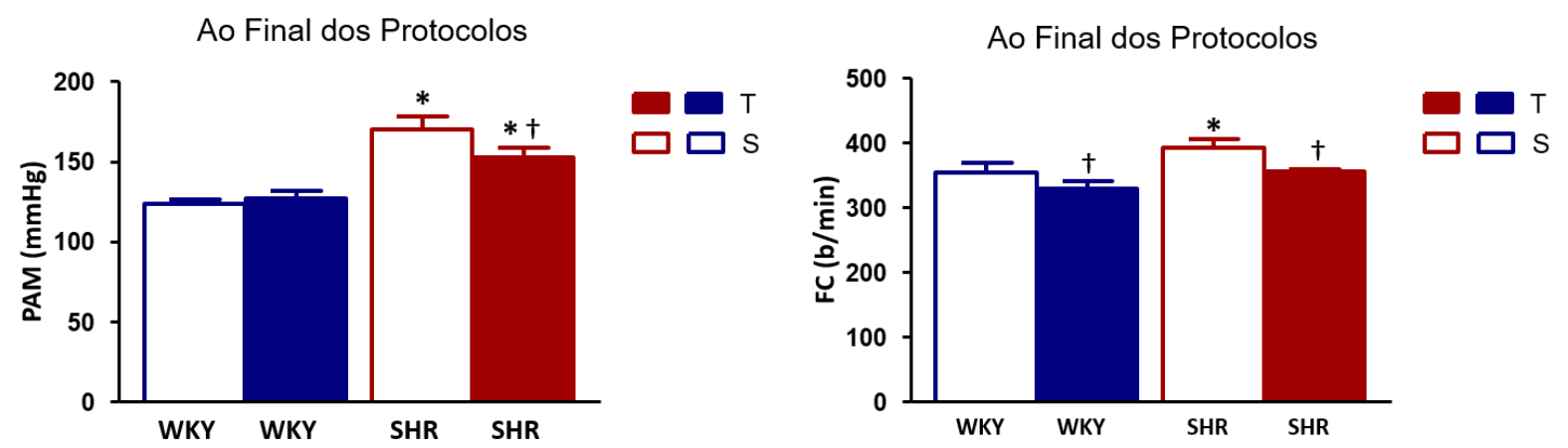

Figura 8 - Comparação dos valores basais de pressão arterial média (PAM) e frequência cardíaca (FC) ao final dos protocolos de treinamento (T) ou sedentarismo (S) nos grupos SHR e WKY. Significâncias $(\mathrm{P}<0,05):{ }^{*} v s$. WKY $† v s$. sedentário.

\subsection{Efeitos do treinamento e sedentarismo sobre a variabilidade da pressão arterial e seus componentes espectrais nos grupos SHR e WKY}

Conforme informado no relatório anterior (item Justificativas), tivemos dificuldades na análise espectral da FC (variabilidade do IP analisada pelo MatLab) quando analisamos registros sequenciais de 20 min de duração. A variabilidade e os componentes espectrais da FC apresentaram erros enormes, inviabilizando a análise 
estatística, de forma que deixamos de apresentar estes dados. Procurando identificar as causas destes erros contatamos o idealizador da rotina, o prof. Dr. Pedro Paulo da Silva Soares, da Universidade Federal do Rio de Janeiro, e ele nos orientou a utilizar para esta análise trechos menores, de aproximadamente 5 minutos do registro sequencial, ao invés dos 20 min que havíamos usado anteriormente. Refizemos, portanto, toda a análise espectral em séries temporais de FC assim como os da PAS, cujos dados são apresentados a seguir (Figuras 9 a 14). Embora os valores absolutos da variabilidade da PAS sejam pouco diferentes daqueles apresentados no relatório anterior, as alterações induzidas pela hipertensão e treinamento se fizeram no mesmo sentido.

No início dos protocolos experimentais a variabilidade da PAS encontrava-se significativamente elevada nos SHR-S quando comparada a seus controles normotensos (SHR-S0: $59 \pm 7 \mathrm{mmHg}^{2}$ vs. $40 \pm 3 \mathrm{mmHg}^{2}$ nos WKY-S0, figura 9). 0 treinamento não foi eficaz em reduzir significantemente a variabilidade dos SHR-T mas causou ligeira redução destes valores que, a partir da oitava semana de treinamento, não mais diferiam daqueles apresentados pelo grupo WKY (SHR-T8: $46 \pm 5 \mathrm{mmHg}^{2}$ vs. WKY: $\sim 31 \pm 3$ $\mathrm{mmHg}^{2}$ ). Interessante observar-se que o treinamento preveniu o intenso aumento apresentado pelos SHR-S durante as 8 semanas experimentais (de $59 \pm 7 \mathrm{mmHg}^{2}$ para $128 \pm 20 \mathrm{mmHg}^{2}$ ). Não houve diferença significativa entre os grupos WKY-T e WKY-S, os quais mantiveram ao longo dos protocolos seus níveis baixos de variabilidade da PAS (Figura 9).
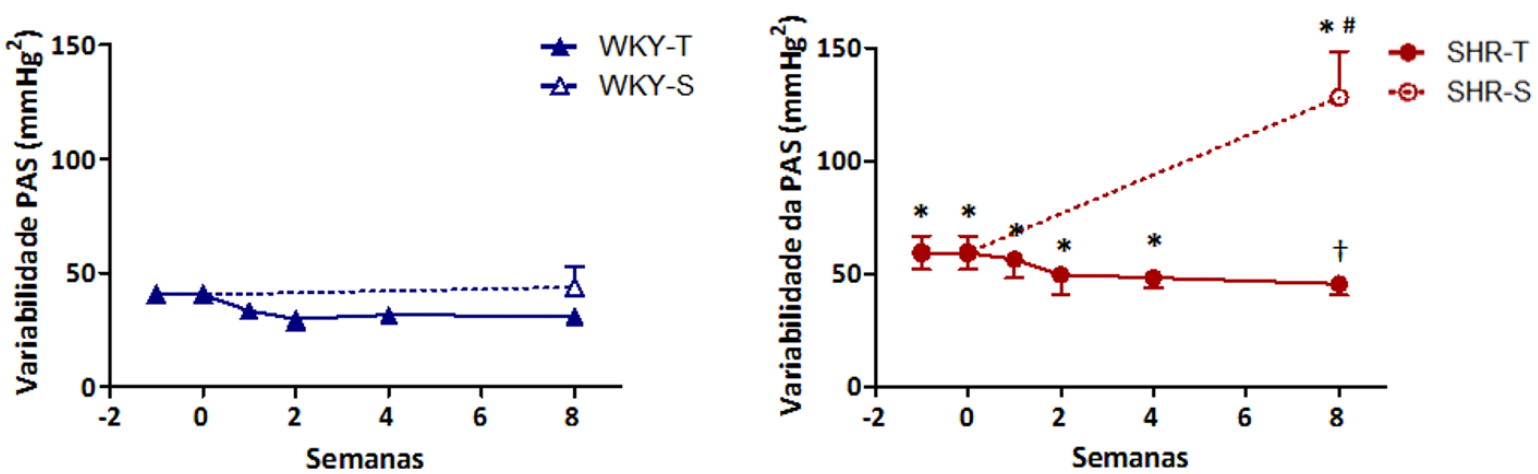

Figura 9 - Evolução da variabilidade da pressão arterial sistólica (PAS) ao longo dos protocolos de treinamento (T) ou sedentarismo (S) nos grupos SHR e WKY. Significâncias $(\mathrm{P}<0,05)$ : * vs. WKY † vs. sedentário \# vs. semana 0 .

O componente low frequency (LF) da PAS dos SHR-S também se mostrou mais elevado que o dos WKY-S no início dos protocolos experimentais $\left(18 \pm 3 \mathrm{mmHg}^{2}\right.$ vs. $5 \pm 1$ 
$\mathrm{mmHg}^{2}$, figura 10). Da mesma forma que o observado para a variabilidade da PAS, o componente LF foi significativamente aumentado nos SHR-S durante as 8 semanas experimentais. O treinamento determinou redução do LF nos SHR, com diferenças significativas observadas já na primeira semana (de $18 \pm 3 \mathrm{mmHg}^{2}$ para $11 \pm 2 \mathrm{mmHg}^{2}$ ), mas mesmo assim não foi eficaz em normalizar seus valores uma vez que SHR-T8 ainda se mostrava elevado em relação aos valores de LF apresentados pelos WKY. Nem o treinamento físico nem o sedentarismo alteraram os valores de LF da PAS no grupo normotenso (Figura 10).
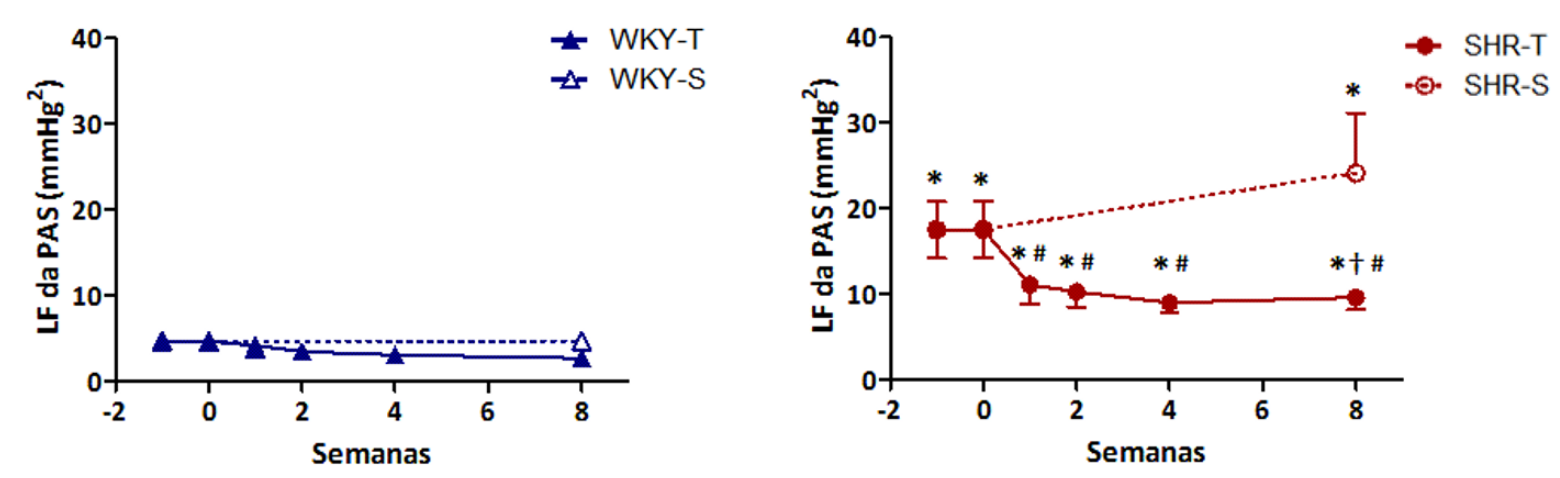

Figura 10 - Evolução do componente low frequency (LF) da pressão arterial sistólica (PAS) ao longo dos protocolos de treinamento $(\mathrm{T})$ ou sedentarismo (S) nos grupos SHR e WKY. Significâncias $(\mathrm{P}<0,05):{ }^{*} v s$. WKY e \# vs. semana 0.

Por sua vez o componente high frequency (HF) da PAS não exibiu diferenças significativas entre as linhagens hipertensa e normotensa no início do protocolo $(13 \pm 3$ $\mathrm{mmHg}^{2}$ vs. $8 \pm 2 \mathrm{mmHg}^{2}$ - Figura 11), mas se mostrava aumentado nos SHR-S na oitava semana $\left(14 \pm 3 \mathrm{mmHg}^{2}\right)$ quando comparado aos animais normotensos e aos SHR treinados da oitava semana $\left(6 \pm 2 \mathrm{mmHg}^{2}\right)$. $\mathrm{O}$ treinamento físico foi eficaz em reduzir este componente a partir da segunda semana de treinamento nos SHR e na oitava semana nos WKY $\left(6 \pm 2 \mathrm{mmHg}^{2}\right.$ e $2 \pm 1 \mathrm{mmHg}^{2}$, respectivamente). A condição sedentarismo determinou ligeira redução sem, no entanto, alterar significativamente os valores de HF do grupo WKY (Figura 11). 

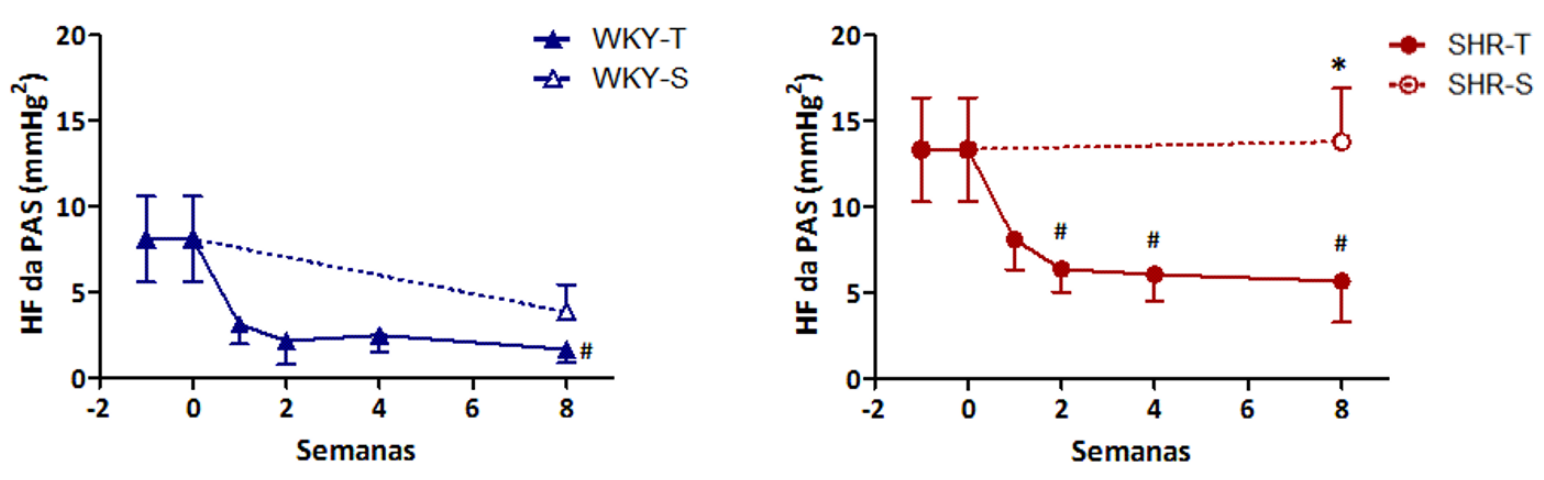

Figura 11 - Evolução do componente high frequency (HF) da pressão arterial sistólica (PAS) ao longo dos protocolos de treinamento (T) ou sedentarismo (S) nos grupos SHR e WKY. Significâncias $(\mathrm{P}<0,05):{ }^{*} v s$. WKY e \# vs. semana 0.

Quando analisado em séries temporais de $5 \mathrm{~min}$, o componente very low frequency (VLF) da PAS dos SHR mostrava-se ligeiramente mais elevado, mas não apresentou em nenhum dos tempos experimentais diferenças significativas em relação aos WKY. Também não foram observadas em ambas as linhagens diferenças entre treinados e sedentários (Figura 12).
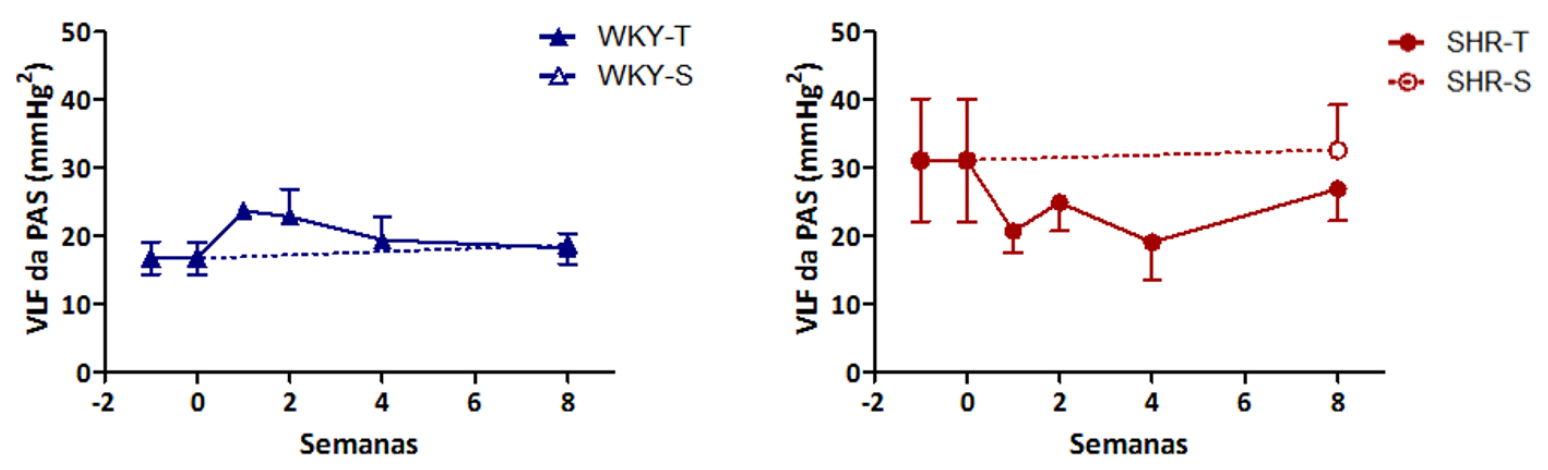

Figura 12 - Evolução do componente very low frequency (VLF) da pressão arterial sistólica (PAS) ao longo dos protocolos de treinamento (T) ou sedentarismo (S) nos grupos SHR e WKY. Significâncias $(\mathrm{P}<0,05):{ }^{*} v s$. WKY e \# vs. semana 0.

Ao final dos protocolos experimentais observamos uma grande redução na variabilidade da PAS dos SHR-T quando comparados aos SHR-S, inclusive com normalização desses valores aos níveis dos grupos dos animais WKY (Figura 13A). Esta redução da variabilidade da PAS foi acompanhada por redução significativa de seu 
componente LF (Figura 13B). O treinamento não teve efeitos significativos nos componentes HF nem VLF em nenhuma das linhagens (Figuras 13C e 13D, respectivamente).
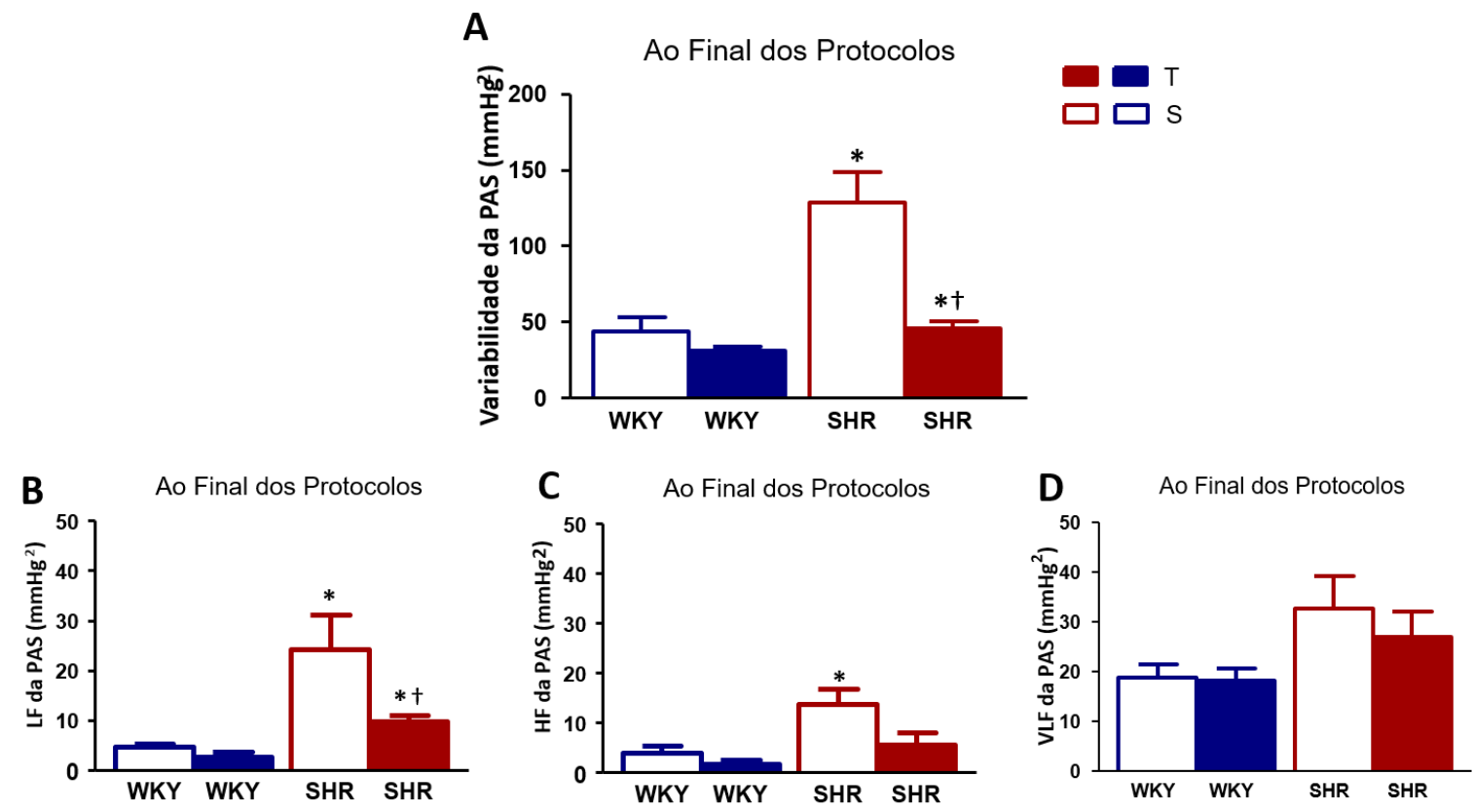

Figura 13 - Comparação dos valores de A- variabilidade da pressão arterial sistólica (PAS); B componente low frequency (LF) da PAS; C - componente high frequency (HF) da PAS e D componente very low frequency (VLF) da PAS ao final dos protocolos de treinamento (T) ou sedentarismo (S) nos grupos SHR e WKY. Significâncias $(\mathrm{P}<0,05):{ }^{*} v s$. WKY †vs. sedentário.

A variabilidade do intervalo de pulso (IP), não exibia diferenças significativas entre SHR e WKY no início dos protocolos $\left(24 \pm 4 \mathrm{~ms}^{2} v s .39 \pm 12 \mathrm{~ms}^{2}\right.$, respectivamente Figura 14). 0 treinamento aumentou significativamente a variabilidade do IP em ambas

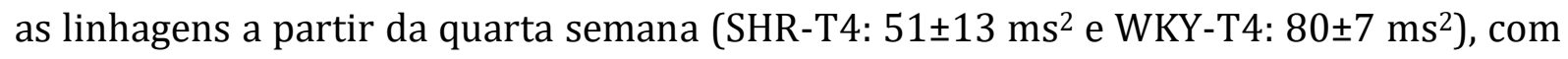
aumento adicional na oitava semana no grupo SHR (SHR-T8: 106 $\pm 18 \mathrm{~ms}^{2}$ ). Não houve alterações na variabilidade do IP nos SHR-S e WKY-S, o que determinou na oitava semana aumentos significativos nos grupos treinados vs. respectivos controles

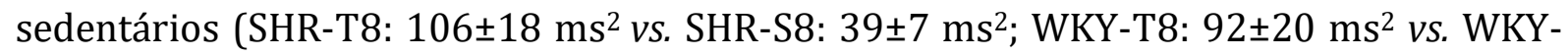
S8: $52 \pm 8 \mathrm{~ms}^{2}, \mathrm{P}<0.05$, figura 14 ). 

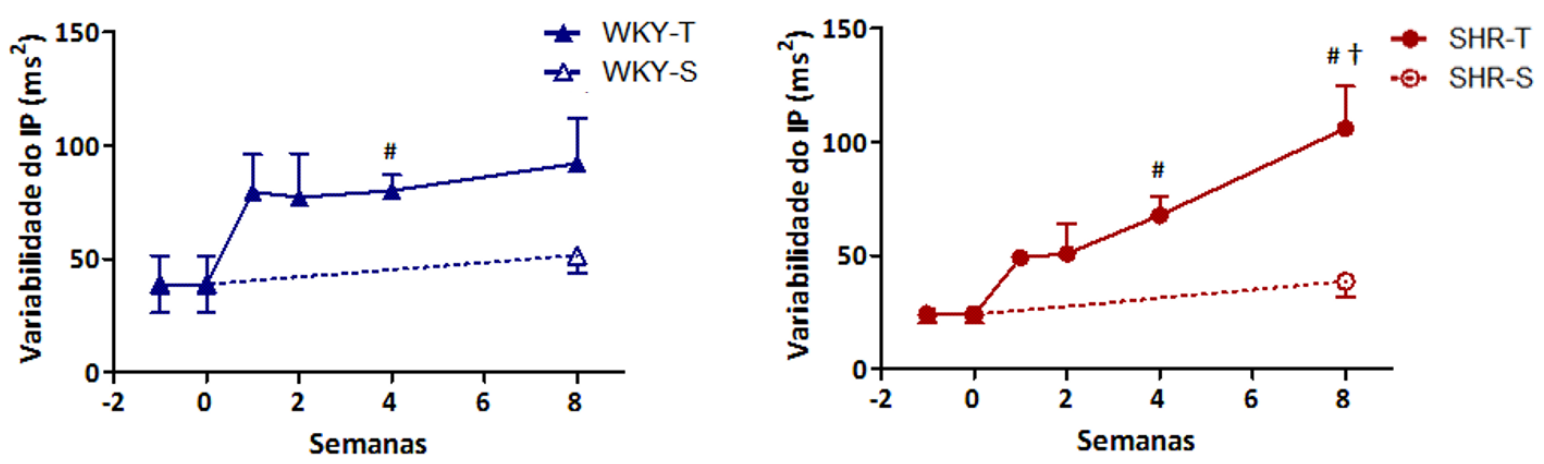

Figura 14 - Evolução da variabilidade do intervalo de pulso (IP) ao longo dos protocolos de treinamento $(\mathrm{T})$ ou sedentarismo $(\mathrm{S})$ nos grupos SHR e WKY. Significâncias $(\mathrm{P}<0,05)$ : *vs. WKY e \# vs. semana 0.

O componente LF do IP também não diferia entre SHR-S e WKY-S no início dos protocolos (SHR-S0: $1 \pm 0 \mathrm{~ms}^{2}$ e WKY-S0: $2 \pm 0 \mathrm{~ms}^{2}$ - Figura 15). Nem o treinamento físico nem o sedentarismo alteraram significativamente o LF do IP no grupo SHR. Por outro lado observamos nos WKY na oitava semana experimental redução significativa do componente LF nos WKY-T, com aumento significativo nos WKY-S (WKY-T8: $1 \pm 0 \mathrm{~ms}^{2} v s$. WKY-S8: $3 \pm 0 \mathrm{~ms}^{2}$ ).
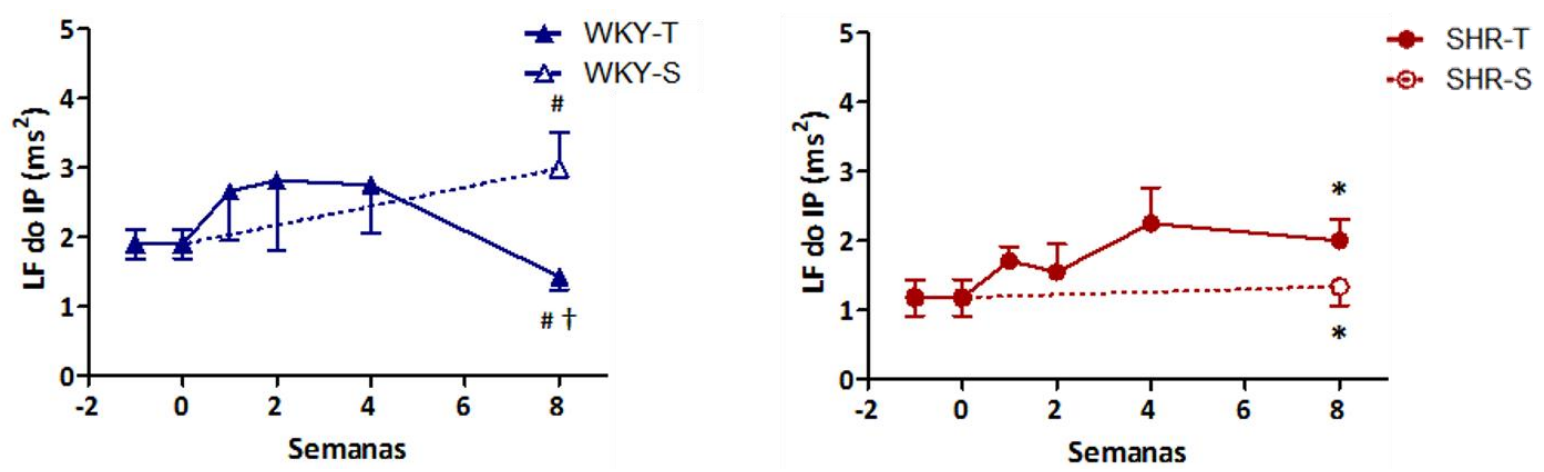

Figura 15 - Evolução do componente low frequency (LF) da frequência cardíaca (FC) ao longo dos protocolos de treinamento (T) ou sedentarismo (S) nos grupos SHR e WKY. Significâncias $(\mathrm{P}<0,05):{ }^{*} v s$. WKY e \# vs. semana 0 .

Em relação ao componente HF do IP, observamos que não haver diferenças entre SHR-S e WKY-S no início dos protocolos (SHR-S0: $6 \pm 1 \mathrm{~ms}^{2}$ e WKY-S0: $10 \pm 1 \mathrm{~ms}^{2}$, figura 16) e que o treinamento aumentou o componente HF apenas nos SHR, a partir da quarta semana, com aumento ligeiro aumento entre a quarta e oitava semanas (SHR-T4: $13 \pm 2$ ms ${ }^{2}$ e SHR-T8: $16 \pm 4 \mathrm{~ms}^{2}$ ). 0 sedentarismo não alterou esse parâmetro em nenhuma das linhagens estudadas. Também não houve diferenças entre WKY-T e WKY-S. (Figura 16). 

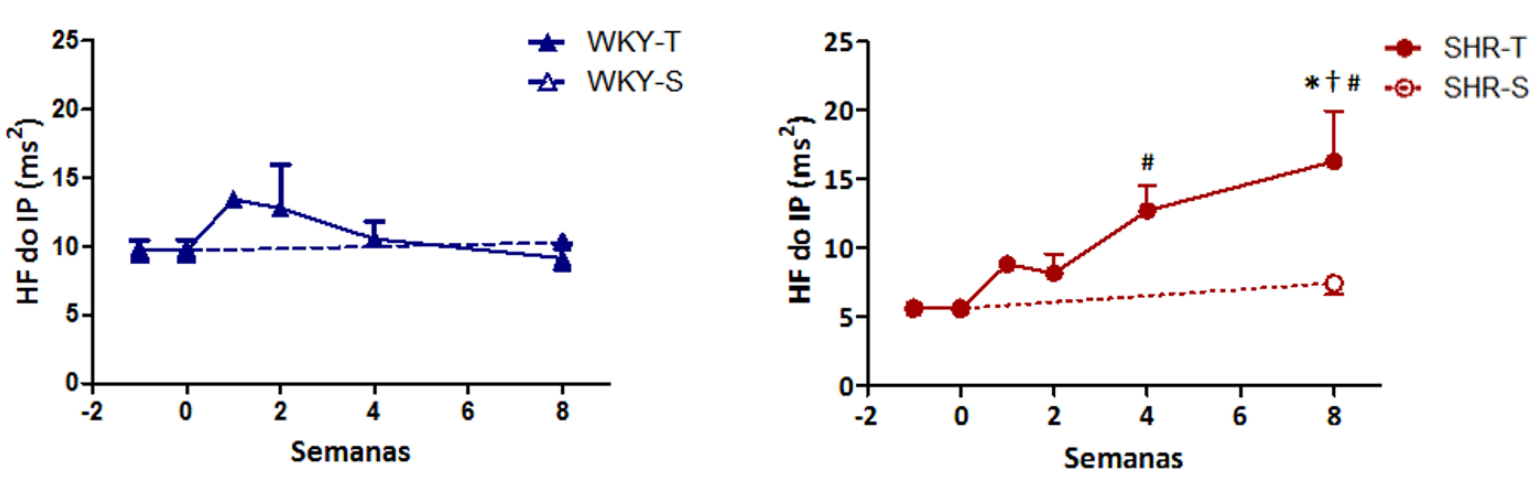

Figura 16 - Evolução do componente high frequency (HF) da frequência cardíaca (FC) ao longo dos protocolos de treinamento (T) ou sedentarismo (S) nos grupos SHR e WKY. Significâncias $(\mathrm{P}<0,05):{ }^{*} v s$. WKY e \# vs. semana 0 .

Ao final dos protocolos observamos um significante aumento na variabilidade do IP em SHR e WKY treinados quando comparados com os grupos mantidos sedentários. Esse aumento em WKY foi acompanhado pela redução do componente LF e nos SHR por um aumento no componente HF (Figura 17).
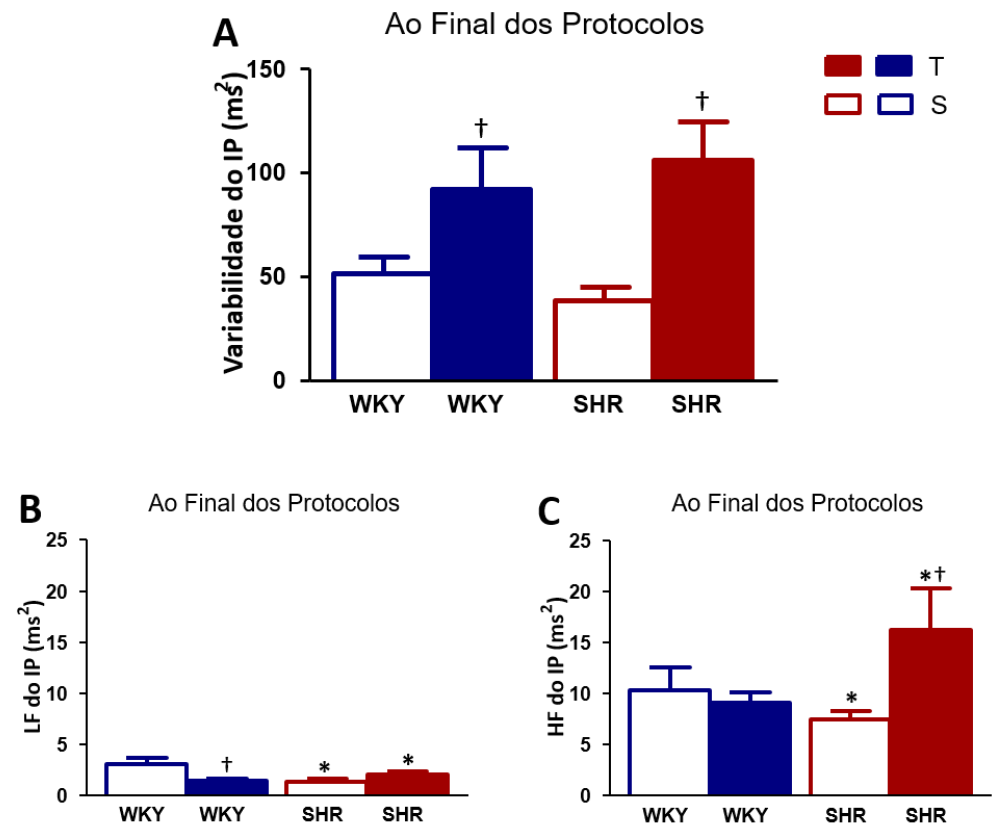

Figura 17 - Comparação dos valores de A- variabilidade do intervalo de pulso (IP); B - componente low frequency (LF) do IP; C - componente high frequency (HF) do IP ao final dos protocolos de treinamento $(\mathrm{T})$ ou sedentarismo $(\mathrm{S})$ nos grupos SHR e WKY. Significâncias $(\mathrm{P}<0,05)$ : * $v s$. WKY † vs. sedentário.

Em todos os tempos experimentais analisamos também, através das séries 
temporais de PAS e FC, o barorreflexo espontâneo, conforme calculado pelos índices alfa LF $(\alpha \mathrm{LF})$ e alfa HF $(\alpha H F)$, cujos valores são apresentados nas Figuras 18 e 19. Observamos que o índice $\alpha \mathrm{LF}$ apresentava valores reduzidos nos SHR-S quando comparados aos WKY-S $\quad\left(0,24 \pm 0,03 \mathrm{~ms}^{2} / \mathrm{mmHg}^{2}\right.$ vs. $0,65 \pm 0,09 \mathrm{~ms}^{2} / \mathrm{mmHg}^{2}$, respectivamente - Figura 18). Embora não significativo este parâmetro teve uma tendência a aumentar com o treinamento nos SHR-T (SHR-T1: 0,41 $\pm 0,09 \mathrm{~ms}^{2} / \mathrm{mmHg}$, SHR-T2: 0,41 $\pm 0,08 \mathrm{~ms}^{2} / \mathrm{mmHg}$, SHR-T4: 0,50 $\pm 0,09 \mathrm{~ms}^{2} / \mathrm{mmHg}$ e SHR-T8: 0,51 $\pm 0,07$ $\mathrm{ms}^{2} / \mathrm{mmHg}$ ). 0 sedentarismo não alterou significativamente o $\alpha \mathrm{LF}$ do grupo SHR sedentário durante as oito semanas (SHR-T8: 0,33 $\pm 0,05 \mathrm{~ms}^{2} / \mathrm{mmHg}$ ). Nos WKY-T o $\alpha \mathrm{LF}$ foi mantido elevado, com aumentos significativos na primeira e oitava semana de treinamento (WKY-T1: 1,16 $\pm 0,28 \mathrm{~ms}^{2} / \mathrm{mmHg}$, WKY-T8: $1,09 \pm 0,14 \mathrm{~ms}^{2} / \mathrm{mmHg} v s$. WKYS0: 0,65 $\pm 0,09 \mathrm{~ms}^{2} / \mathrm{mmHg}$ ). Também nos WKY, o sedentarismo não alterou

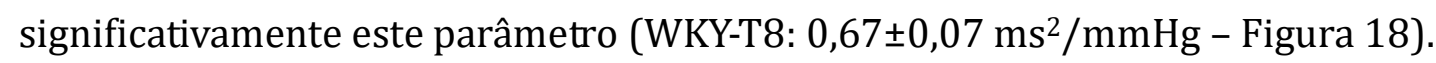
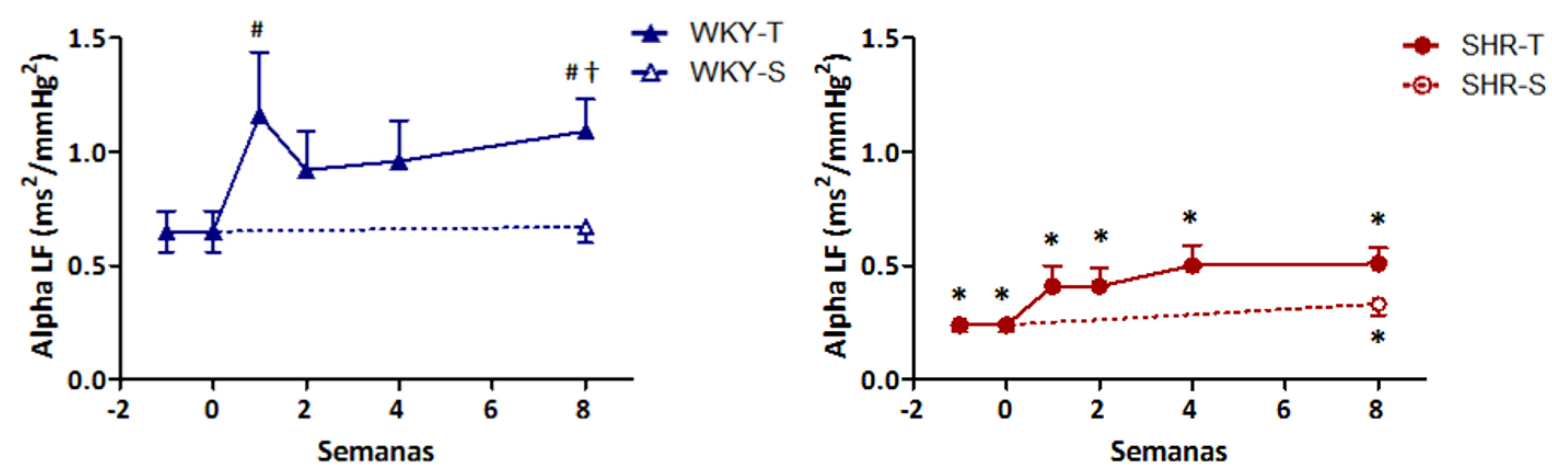

Figura 18 - Evolução do índice alfa do componente low frequency (LF) ao longo dos protocolos de treinamento $(\mathrm{T})$ ou sedentarismo $(\mathrm{S})$ nos grupos SHR e WKY. Significância $(\mathrm{P}<0,05)$ : * vs. WKY.

O cálculo do $\alpha H F$, não mostrou diferenças significativas entre SHR-S e WKY-S no início dos protocolos $\left(1,01 \pm 0,28 \mathrm{~ms}^{2} / \mathrm{mmHg}\right.$ e 1,59 $\pm 0,55 \mathrm{~ms}^{2} / \mathrm{mmHg}$, respectivamente Figura 19). Em ambas as linhagens, houve aumento dessa variável durante o protocolo de treinamento, os SHR atingindo valores significativos na oitava semana (SHR-T8: 2,15 $\pm 0,54$ $\mathrm{ms}^{2} / \mathrm{mmHg} v$ s. SHR-S0: $1,01 \pm 0,20 \mathrm{~ms}^{2} / \mathrm{mmHg}$ ) e os WKY na segunda e oitava semana de

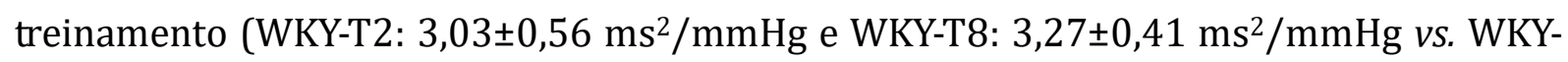
S0: $\left.1,59 \pm 0,55 \mathrm{~ms}^{2} / \mathrm{mmHg}\right)$. O sedentarismo não alterou o $\alpha H F$ em nenhuma das linhagens (SHR-S8: 0,88 $\pm 0,13 \mathrm{~ms}^{2} / \mathrm{mmHg}$ vs. SHR-S0: $1,01 \pm 0,20 \mathrm{~ms}^{2} / \mathrm{mmHg}^{2}$ e WKY-S8: 

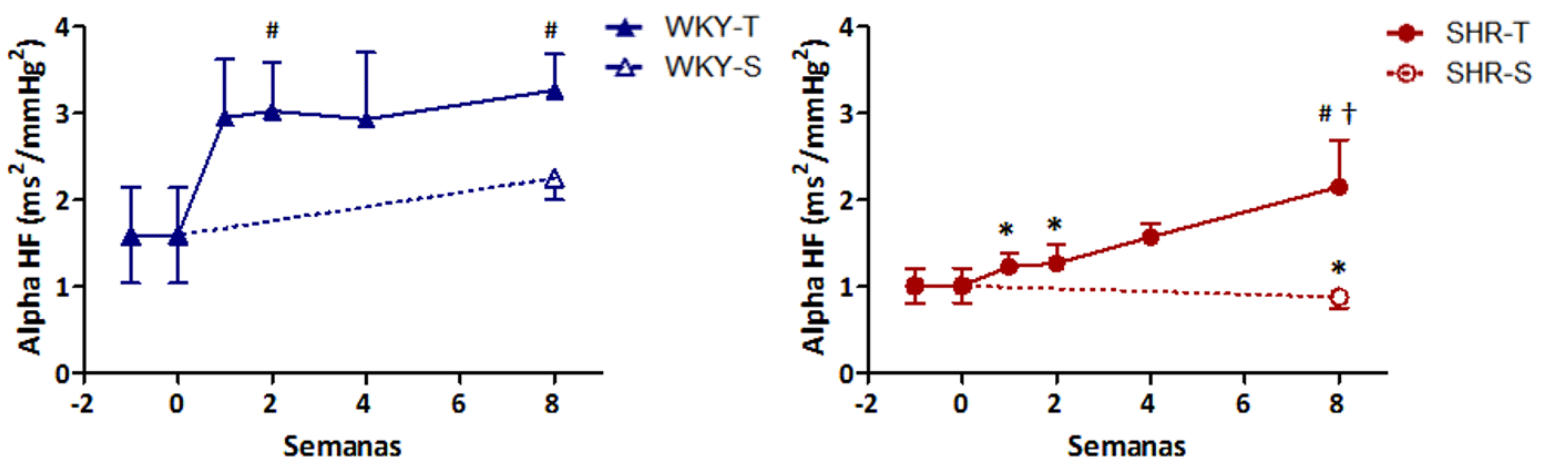

Figura 19 - Evolução do índice alfa do componente high frequency (HF) ao longo dos protocolos de treinamento (T) ou sedentarismo $(\mathrm{S})$ nos grupos SHR e WKY. Significância $(\mathrm{P}<0,05)$ : * vs. WKY.

Ao final dos protocolos, observamos uma redução significativa do alfa LF nos WKY-T quando comparados aos WKY-S (Figura 20A) mas nenhuma alteração nos grupos SHR-T e SHR-S, que continuaram com valores menores para esse parâmetro quando comparados com os WKY (Figura 20A). Os SHR-T, porém, tiveram aumento do componente alfa HF, quando comparados aos SHR-S (Figura 20B).
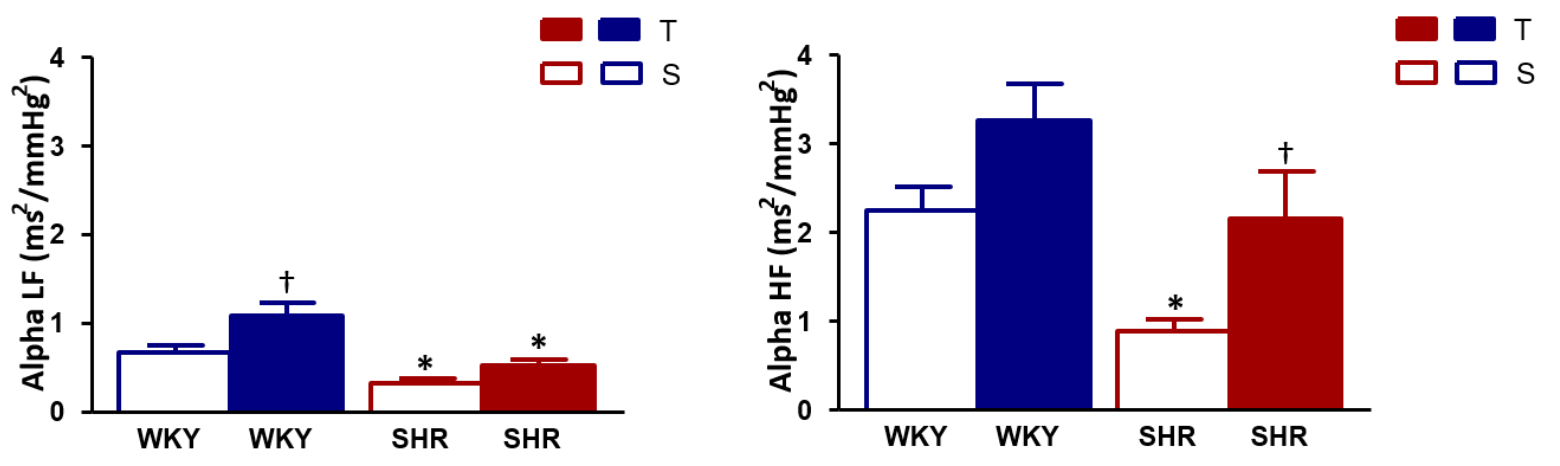

Figura 20 - Comparação do alfa dos componentes alpha LF e alpha HF ao final dos protocolos de treinamento (T) ou sedentarismo (S) nos grupos SHR e WKY. Significâncias $(\mathrm{P}<0,05)$ : * vs. WKY † vs. sedentário.

\subsection{Efeitos da idade e do estabelecimento da hipertensão arterial sobre a integridade da $\mathrm{BHE}$}

Com o objetivo de analisar a integridade da BHE em animais na fase préhipertensiva, realizamos injeções de FITC e RODAMINA também em animais jovens, com cerca de 4 semanas de idade (WKY com 24 dias e SHR com 25 dias). Em ambos os 
grupos praticamente não houve nenhum extravasamento do FITC nesta idade quando os animais já apresentam a BHE completamente formada (ARMULIK et al., 2010). Como mostrado nas Figuras 21, 22 e 23, a quantificação não resultou em valores significativos de extravasamento em nenhuma das áreas e em nenhum dos grupos estudados: PVN = $0,16 \pm 0,03 \%$ nos WKY e $0,15 \pm 0,03 \%$ nos SHR (Figura 21); NTS $=0,15 \pm 0,03 \%$ nos WKY e 0,09 $\pm 0,03 \%$ nos SHR (Figura 22); RVLM = 0,03 $\pm 0,01 \%$ nos WKY e 0,02 $\pm 0,01 \%$ nos SHR (Figura 23).

Nos WKY houve pequena elevação do extravasamento aos 3 e 5 meses de idade, que, no entanto, não atingiu níveis de significância em nenhuma das áreas estudadas. Por outro lado, observamos nos SHR aumento significativo do extravasamento aos 3 e 5 meses de idade, que foi progressivo no PVN (3ํo. mês $=7,19 \pm 1,27 \%$; $5^{\circ}$. mês $=$ $12,37 \pm 0,86 \%$, Figura 21).

A

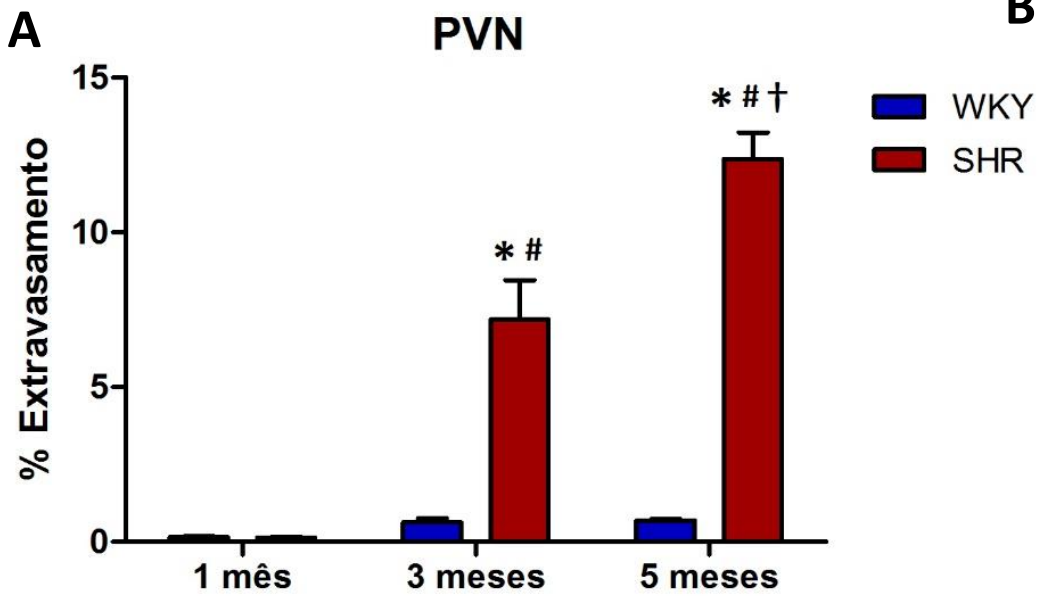

B
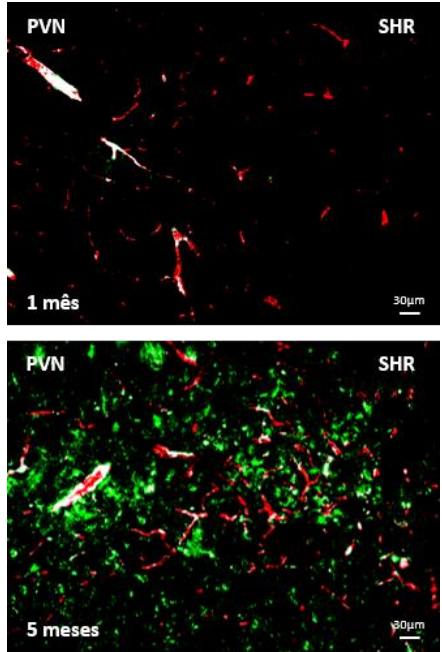

Figura 21 - A. Comparação da porcentagem de extravasamento do corante FITC-Dextran no núcleo paraventricular do hipotálamo (PVN) dos grupos SHR e WKY aos 1, 3 e 5 meses de idade. Significâncias $(\mathrm{P}<0,05): *$ vs. WKY, \# vs. 1 mês, $\dagger$ vs. 3 meses, $\mathrm{n}=4$ WKY e $\mathrm{n}=4$ SHR. B. Figuras ilustrativas do extravasamento do FITC (verde) nos SHR no1ํ. (acima) e 5ํ. mês de idade (abaixo).

Nos demais núcleos o extravasamento já apresentava valores máximos aos 3 meses, não se alterando significativamente entre o $3^{\circ}$. e $5^{\circ}$. meses de idade: NTS = $11,53 \pm 1,28 \%$ e $11,13 \pm 1,59 \%$ (Figura 22); RVLM = 5,77 \pm 0,84\% e 4,32 \pm 0,47\% (Figura 23), respectivamente. Observamos também no RVLM um menor extravasamento do FITC-Dextran quando comparado às demais áreas autonômicas. 

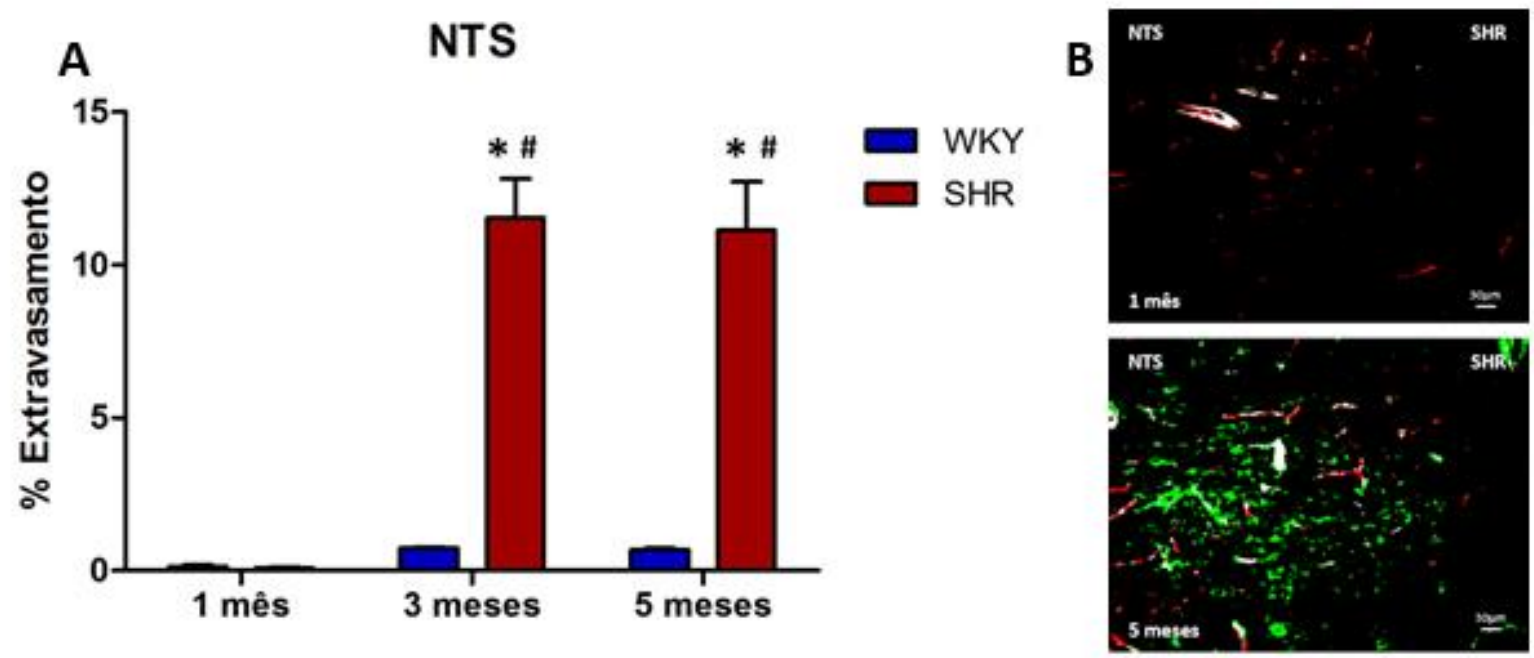

Figura 22 - Comparação da porcentagem de extravasamento do corante FITC-Dextran no núcleo do trato solitário (NTS) dos grupos SHR e WKY de 1, 3 e 5 meses de vida. Significâncias $(\mathrm{P}<0,05)$ : * vs. WKY, \# vs. 1 mês; $\mathrm{n}=4$ WKY e $\mathrm{n}=4$ SHR. B. Figuras ilustrativas do extravasamento do FITC (verde) nos SHR no1ํ. (acima) e 5ํo. mês de idade (abaixo).
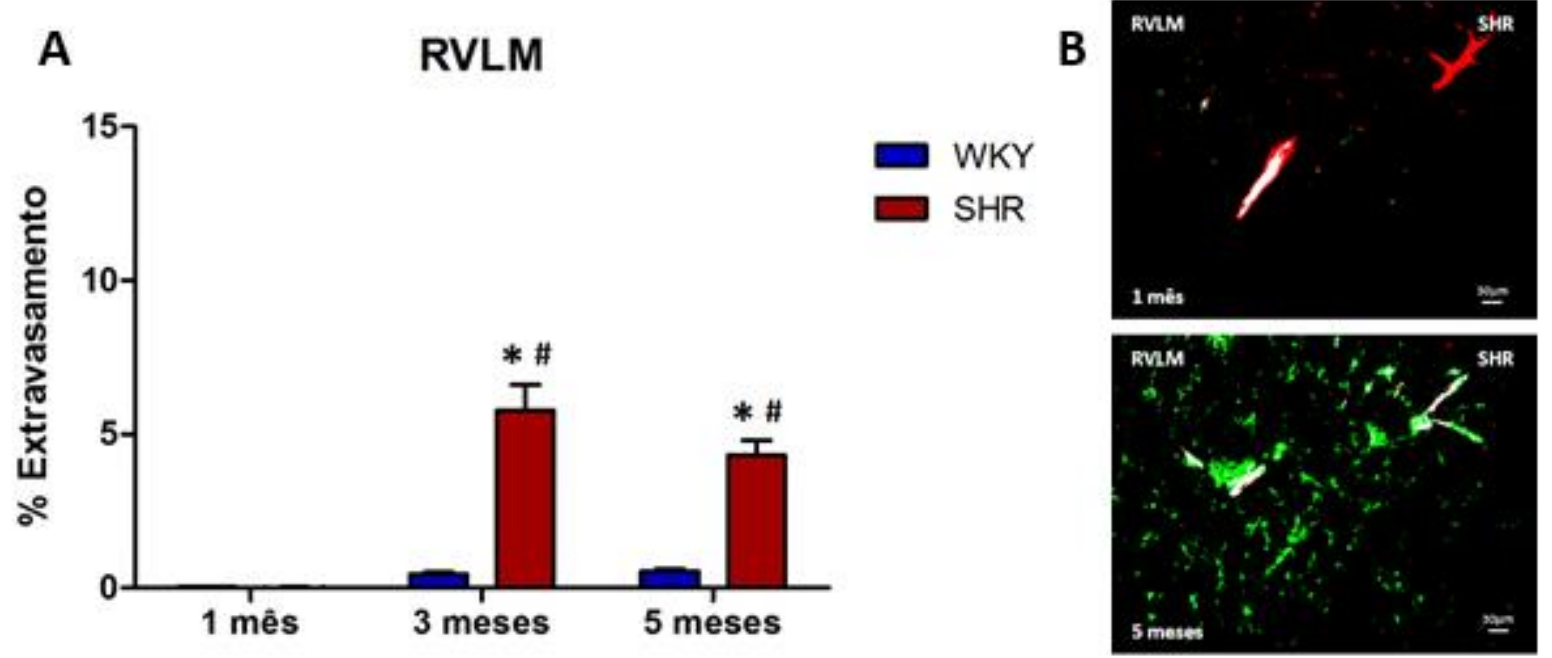

Figura 23 - Comparação da porcentagem de extravasamento do corante FITC-Dextran no bulbo rostro-ventrolateral (RVLM) dos grupos SHR e WKY de 1, 3 e 5 meses de vida. Significâncias $(\mathrm{P}<0,05):{ }^{*} v s$. WKY, \# vs. 1 mês; $\mathrm{n}=4 \mathrm{WKY}$ e $\mathrm{n}=4$ SHR. B. Figuras ilustrativas do extravasamento do FITC (verde) nos SHR no1ํ. (acima) e 5ํ․ mês de idade (abaixo).

\subsection{Efeitos do treinamento e sedentarismo sobre a integridade da BHE nos grupos SHR e WKY}

A Figura 24, comparando as imagens de fluorescência do FITC-Dextran e rodamina-dextran entre SHR e WKY sedentários aos 3 meses de idade, quando foram iniciados os protocolos de treinamento e sedentarismo (semana 0), mostra claramente 
que os SHR já apresentavam elevado extravasamento do FITC nos três núcleos estudados - PVN, NTS e RVLM - indicando importante lesão da BHE.

Dados quantitativos confirmaram estas observações. No PVN o extravasamento nos SHR-S era bastante superior ao apresentado pelos WKY-S pareados por idade $(7,19 \pm 1,27 \%$ vs. $0,63 \pm 0,13 \%$, respectivamente, Figura 25$)$. Interessante observar-se que o treinamento aeróbio foi eficaz em reduzir marcadamente o extravasamento do FITC, normalizando sua porcentagem já a partir da $2^{2}$ a. semana de treinamento (quando os valores dos SHR-T não mais diferiam daqueles apresentados pelos WKY) e impedindo o aumento gradual do extravasamento apresentado pelos SHR-S entre as semanas 0 e 8 dos protocolos experimentais Figura 25).

Também no NTS o extravasamento do FITC-dextran no início dos protocolos experimentais foi bastante elevado nos SHR-S quando comparado aos WKY-S $(11,53 \pm 1,28 \%$ vs. $0,74 \pm 0,03 \%$ na semana 0 , figura 26). Da mesma forma que o observado para o PVN, o treinamento aeróbio também determinou redução marcante da lesão da BHE no NTS com queda significativa já a partir da 1a․ semana experimental $(7,98 \pm 1,14 \%)$, atingindo valores similares aos apresentados pelos grupos WKY (entre

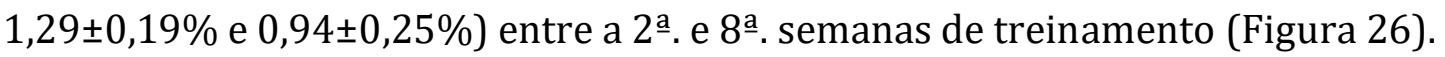

O extravasamento do FITC-dextran no RVLM dos SHR-S no início dos protocolos experimentais foi de menor magnitude que o observado nas demais áreas autonômicas, mas também significantemente elevado quando comparados aos WKY-S de mesma idade $(5,77 \pm 0,84 \%$ vs. 0,44 $\pm 0,06 \%$, respectivamente, figura 27). 0 treinamento aeróbio também determinou importante redução e normalização da lesão da BHE (de $0,96 \pm 0,22 \%$ a $0,76 \pm 0,53 \%$, valores similares aos observados nos grupos WKY) entre a $2^{\text {a }}$. e 8a․ semanas de treinamento (Figura 27). 

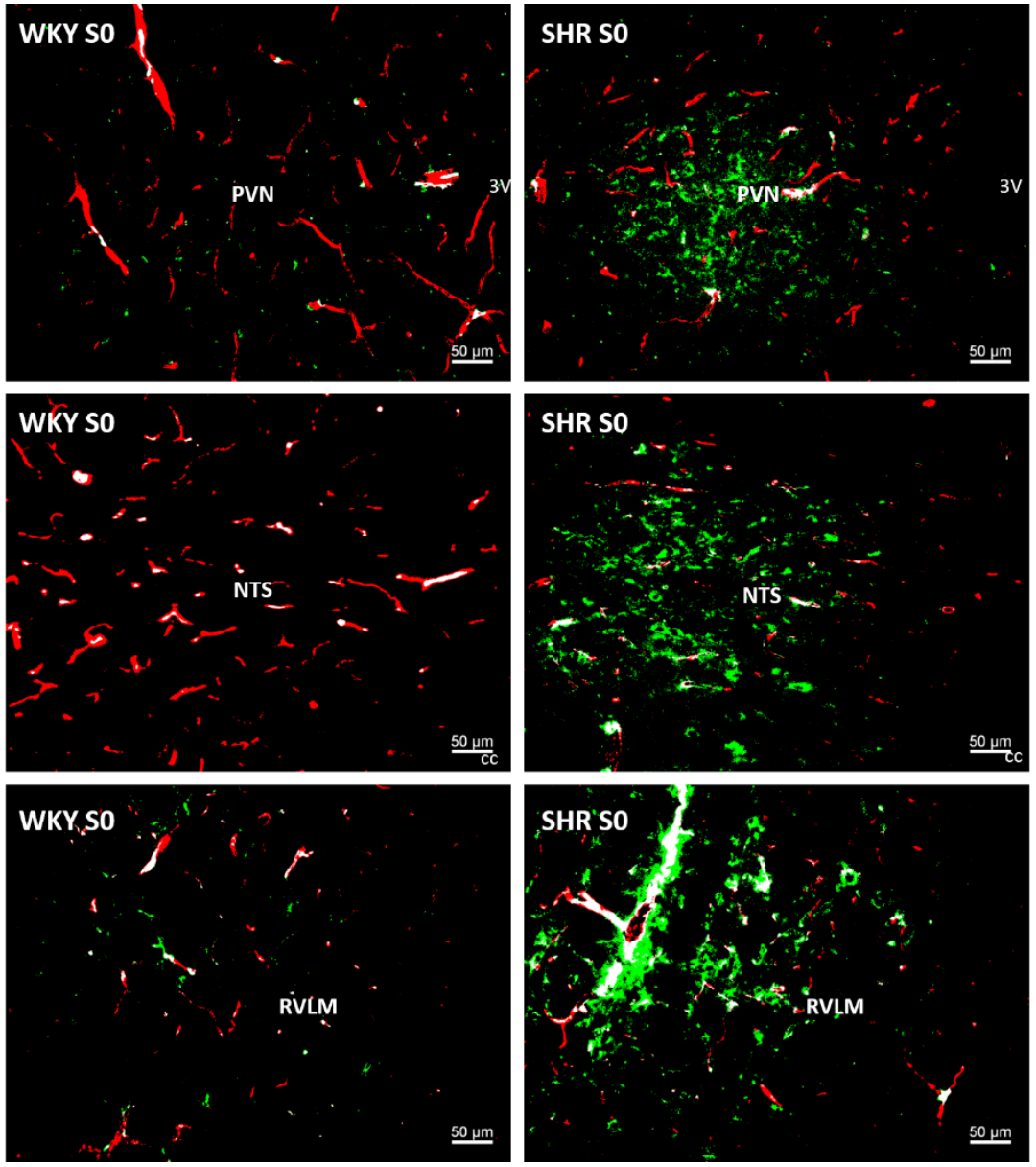

Figura 24 - Comparação de imagens obtidas por microscopia de fluorescência do núcleo paraventricular do hipotálamo (PVN), núcleo do trato solitário (NTS) e bulbo rostro-ventrolateral (RVLM) de SHR e WKY sedentários no início dos protocolos - semana 0 (S0). Vermelho = ROD $70 \mathrm{kDa}$, verde $=$ FITC $10 \mathrm{kDa}$, branco $=$ co-localização da ROD $70 \mathrm{kDa}$ e FITC $10 \mathrm{kDa}, 3 \mathrm{~V}=$ terceiro ventrículo e $\mathrm{cc}=$ canal central. 

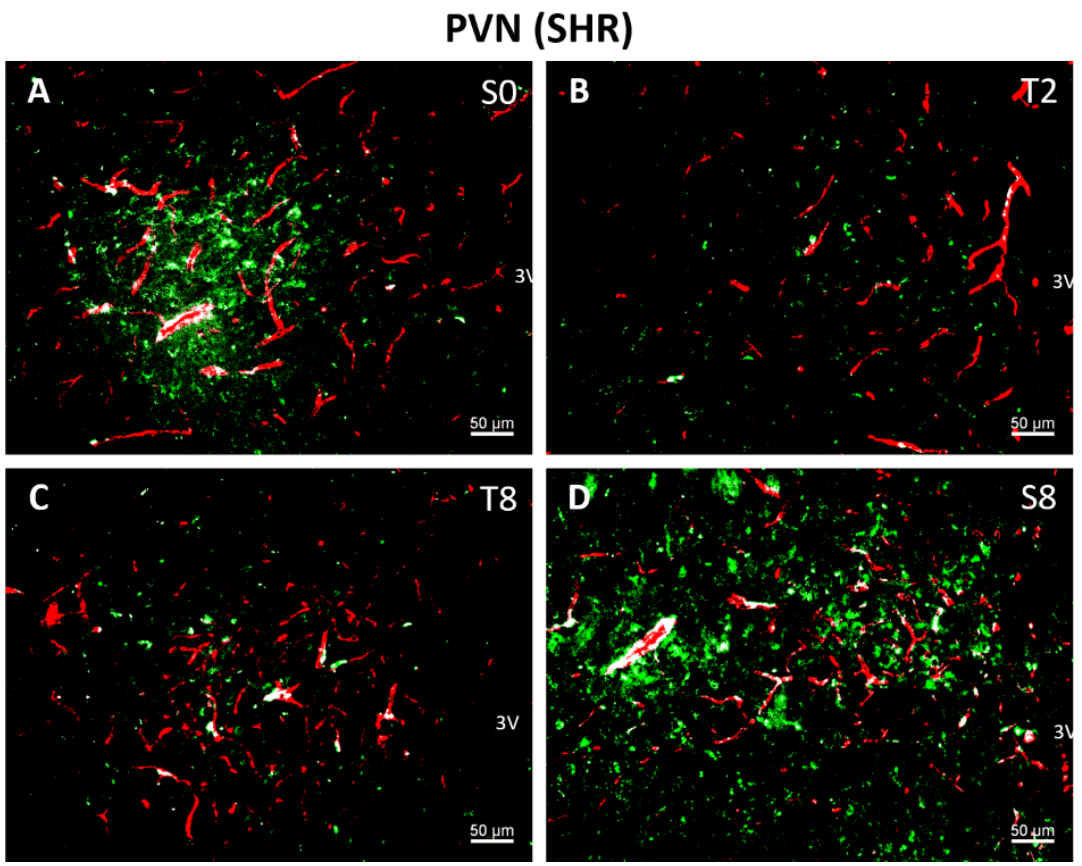

E
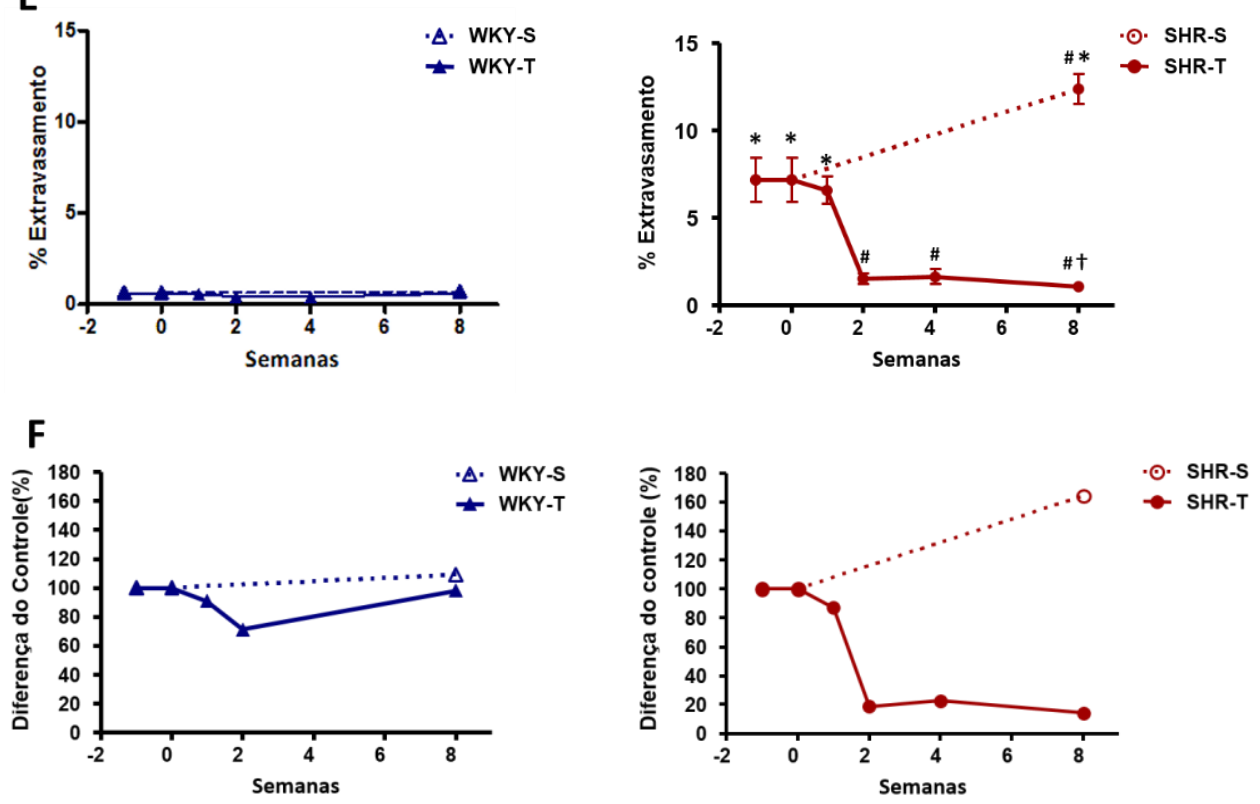

Figura 25 - Comparação de imagens obtidas por microscopia de fluorescência do núcleo paraventricular do hipotálamo (PVN) de SHR sedentários (S) nas semanas 0 (A) e 8 (D) e SHR treinados $(\mathrm{T})$ nas semanas $2(\mathbf{B})$ e $8(\mathbf{C})$. Vermelho $=$ ROD $70 \mathrm{kDa}$, verde $=$ FITC $10 \mathrm{kDa}$, branco $=$ co-localização da ROD $70 \mathrm{kDa}$ e FITC $10 \mathrm{kDa}$. Em E apresentamos a evolução temporal do extravasamento do FITC (valores percentuais) no PVN dos grupos SHR e WKY, S e T, ao longo das 8 semanas experimentais e em $\mathbf{F}$ comparamos ambos os grupos considerando o valor inicial na semana zero de WKY e SHR como 100\%. Significâncias $(\mathrm{P}<0,05):{ }^{*} v s$. WKY † vs. sedentário \# vs. semana 0 . 

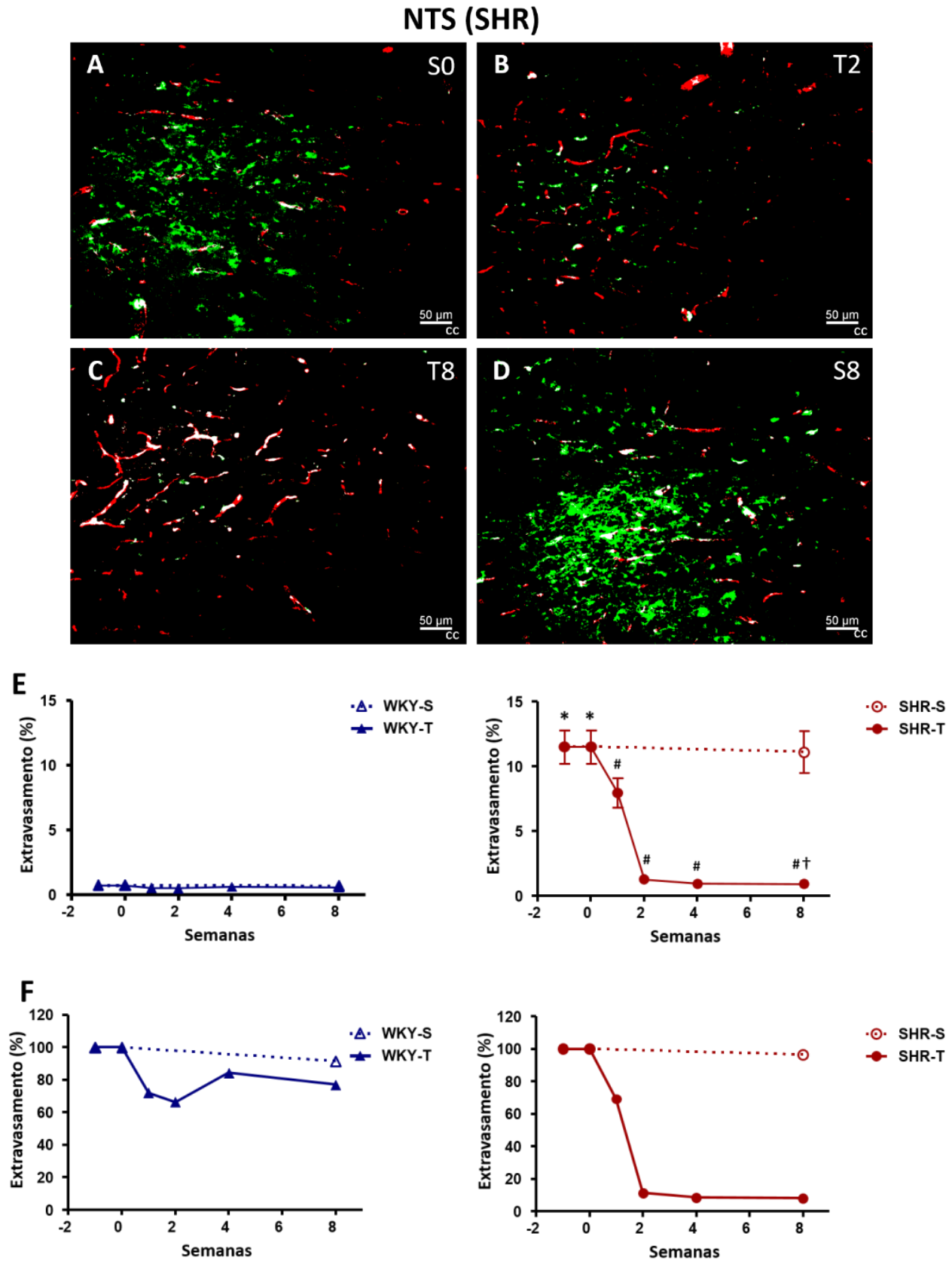

Figura 26 - Comparação de imagens obtidas por microscopia de fluorescência do núcleo do trato solitário (NTS) de SHR sedentários (S) nas semanas 0 (A) e 8 (D) e SHR treinados (T) nas semanas 2 (B) e 8 (C). Vermelho $=$ ROD 70kDa, verde $=$ FITC 10kDa, branco $=$ co-localização da ROD 70kDa e FITC 10kDa. Em E apresentamos a evolução temporal do extravasamento do FITC (valores percentuais) no PVN dos grupos SHR e WKY, S e T, ao longo das 8 semanas experimentais e em $\mathbf{F}$ comparamos ambos os grupos considerando o valor inicial na semana zero de WKY e SHR como 100\%. Significâncias $(\mathrm{P}<0,05):{ }^{*} v s$. WKY † vs. sedentário \# vs. semana 0. 


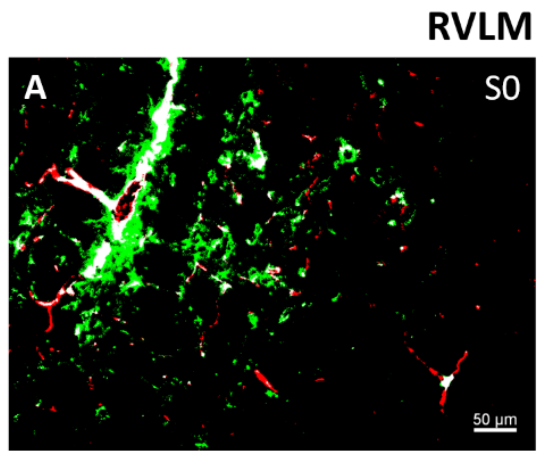

\section{(SHR)}
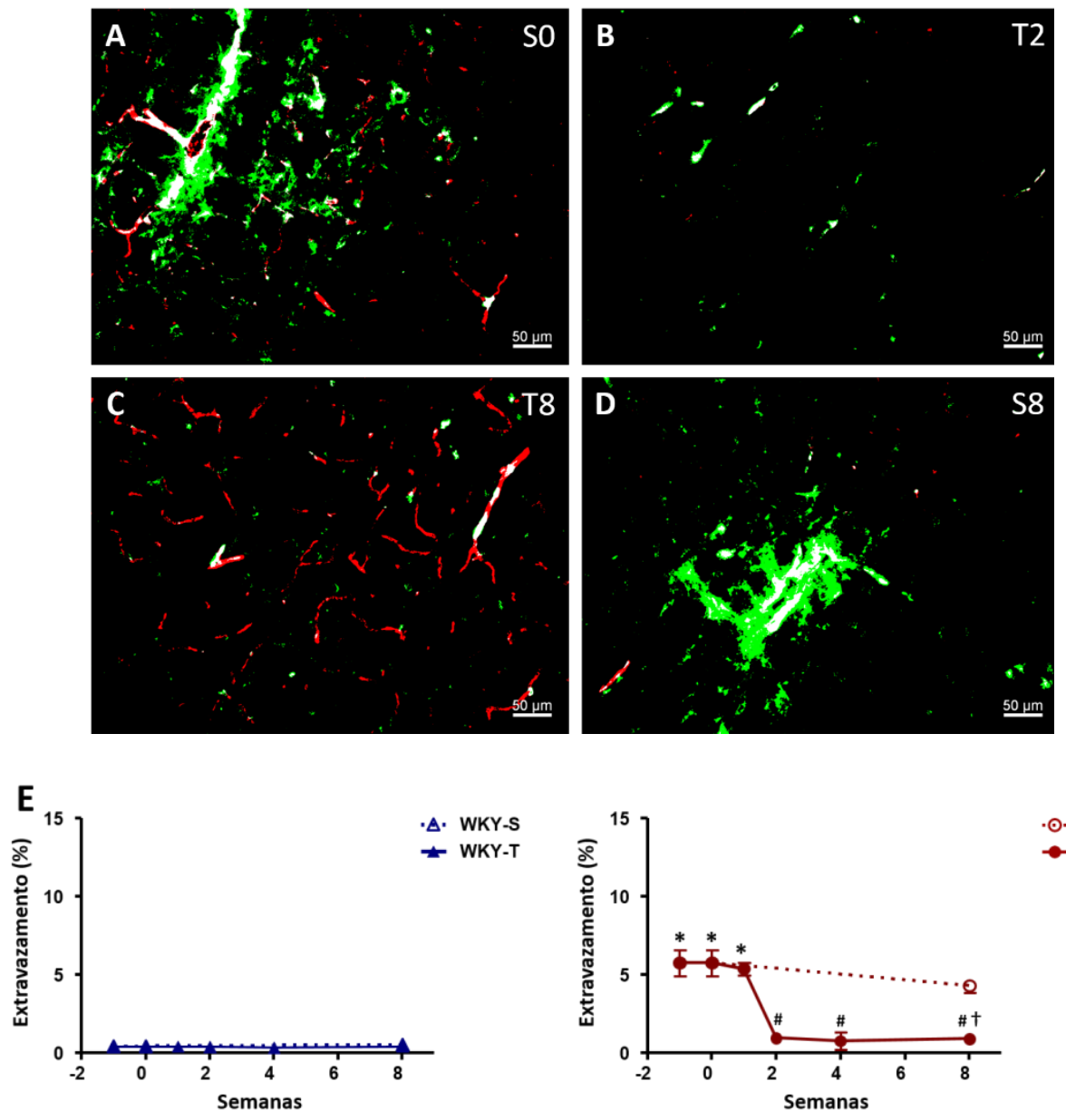

๑. SHR-S
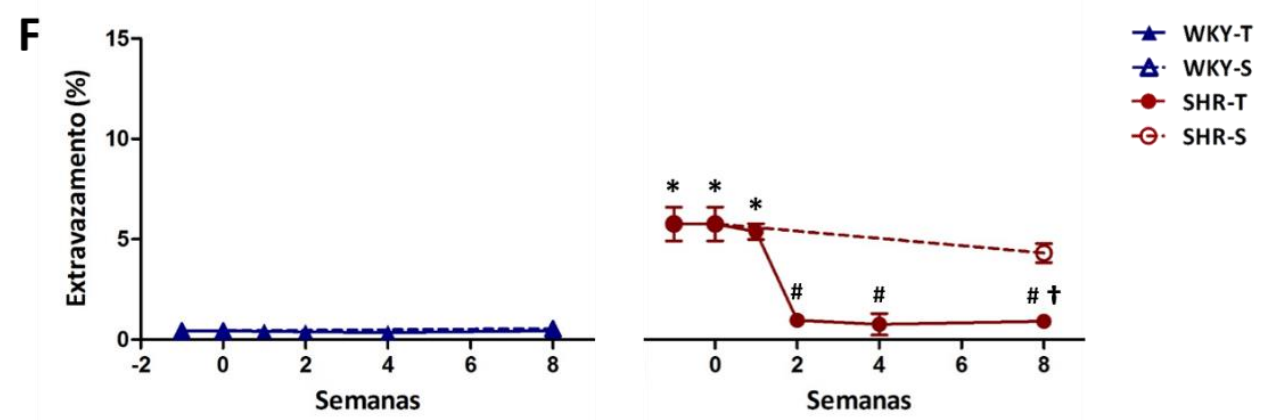

Figura 27 - Comparação de imagens obtidas por microscopia de fluorescência (140x) do bulbo rostro-ventrolateral (RVLM) de SHR sedentários (S) nas semanas 0 (A) e 8 (D) e SHR treinados (T) nas semanas 2 (B) e 8 (C). Vermelho $=$ ROD 70kDa, verde $=$ FITC 10kDa, branco = co-localização da ROD 70kDa e FITC 10kDa. Em E apresentamos a evolução temporal do extravasamento do FITC (valores percentuais) no PVN dos grupos SHR e WKY, S e T, ao longo das 8 semanas experimentais e em $\mathbf{F}$ comparamos ambos os grupos considerando o valor inicial na semana zero de WKY e SHR como 100\%. Significâncias $(\mathrm{P}<0,05):{ }^{*} v s$. WKY †vs. sedentário \# vs. semana 0. 
Ao final dos protocolos, notamos marcante redução na porcentagem de extravasamento de FITC nos três núcleos estudados dos SHR-T em relação aos SHR-S, sem alteração visível nos WKY-T quando comparados aos WKY-S (Figura 28). No entanto quando as quantificações nas semanas experimentais dos WKY-T foram representadas como alterações percentuais em relação à semana 0 (considerada 100\% veja painéis F nas Figuras 25, 26 e 27), observamos que o treinamento também foi eficaz em reduzir o extravasamento neste grupo experimental (reduções entre 20\% a 30\% nas 3 áreas estudadas), embora as alterações observadas fossem proporcionalmente menores que as apresentadas pelos SHT-T (reduções de 80\% a 90\% nas mesmas áreas). É importante notar que a marcante redução do extravasamento nos SHR-T praticamente normalizou a BHE, igualando seu funcionamento ao dos animais normotensos.
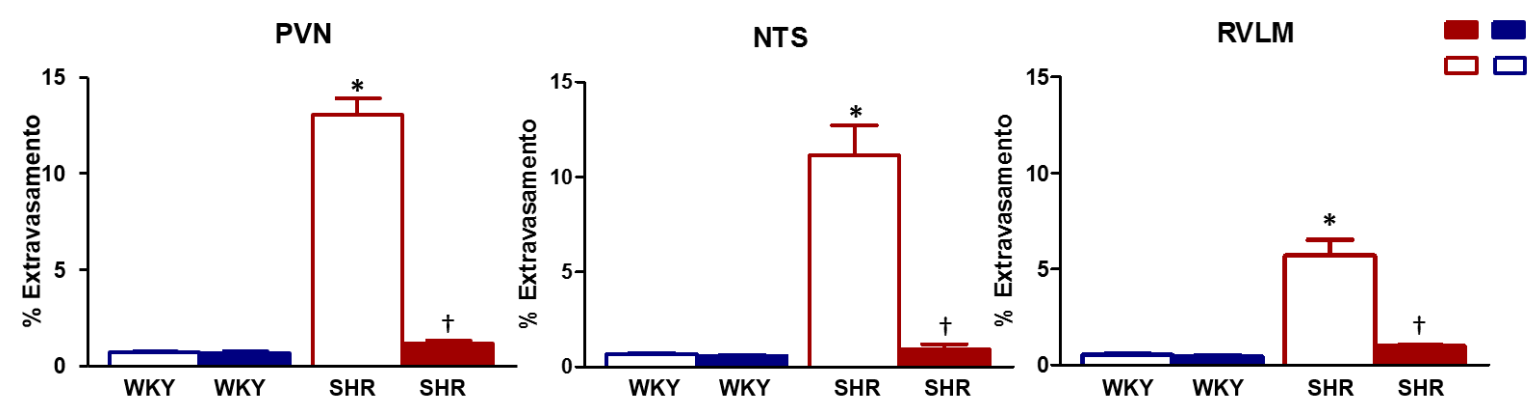

Figura 28 - Comparação da porcentagem de extravasamento do corante FITC-Dextran no núcleo paraventricular do hipotálamo (PVN), núcleo do trato solitário (NTS) e bulbo rostro-ventrolateral (RVLM) nos grupos SHR e WKY sedentários (S) e treinados (T) ao final dos protocolos experimentais. Significâncias $(\mathrm{P}<0,05):{ }^{*} v s . \mathrm{WKY}+v s$. Sedentário.

Com o objetivo de verificarmos se a lesão da BHE nos SHR-S era ou não específica a áreas autonômicas, analisamos também o extravasamento do FITC-dextran no núcleo hipoglosso (Figura 29), uma área inespecífica e não autonômica, que não participa diretamente do controle cardiovascular e não é afetada pelo treinamento aeróbio. Esta quantificação nos SHR e WKY foi realizada aos 3 meses de idade, ou seja, a mesma idade apresentada no início dos protocolos experimentais. Em ambos os grupos a porcentagem de extravasamento foi bastante reduzida (WKY=0,24 $\pm 0,05 \%$; SHR=0,24 $\pm 0,06 \%$ ), sendo inclusive similar entre hipertensos e normotensos (Figura 29). 

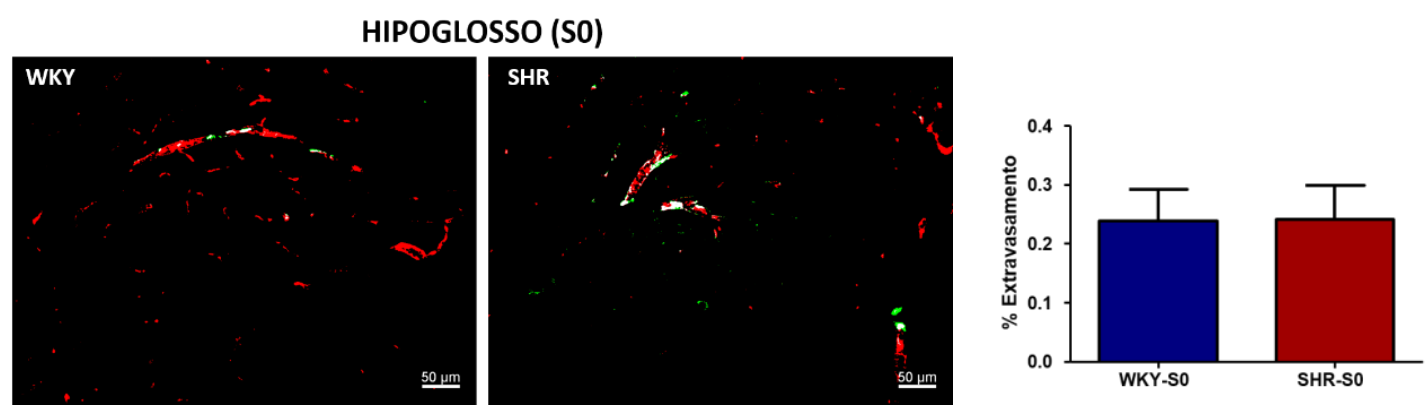

Figura 29 - Comparação da porcentagem de extravasamento do corante FITC-Dextran no núcleo hipoglosso nos grupos SHR e WKY sedentários (S) aos 3 meses de idade.

Como dados anteriores de nosso laboratório têm demonstrado que a melhora do controle autonômico da circulação induzido pelo treinamento em SHR é acompanhado de importante redução da atividade do sistema renina-angiotensina no PVN (Masson et al., 2014; 2015; Chaar et al., 2015) e dados da literatura têm indicado que a lesão da BHE em hipertensos encontra-se associada à elevada disponibilidade de ANGII circulante (Biancardi et al., 2014. 2015) investigarmos também a participação deste hormônio nas alterações de permeabilidade da BHE observadas durante o treinamento aeróbio. Para tanto SHR implantados com micro-pumps osmóticas e perfundidos com ANGII ou salina intracerebroventricular (i.c.v., 3ำ ventrículo) por 14 dias foram submetidos a 14 sessões diárias consecutivas de treinamento (equivalentes ao volume de treino atingido pelos SHR do grupo anterior entre as semanas experimentais 2 e 3, uma vez que esses animais treinavam 5 dias/semana). Ao final das 14 sessões metade dos SHR foram infundidos com rodamina e FITC-dextran para quantificação do extravasamento da BHE nestas condições e a outra metade eutanasiada para quantificação da expressão de receptores AT1 e outros marcadores da BHE.

A Figura 30 ilustra para o PVN, NTS e RVLM a porcentagem de extravasamento nos SHR-T que foram simultaneamente tratados com ANGII ou salina i.c.v. Observa-se que a infusão de salina não alterou o extravasamento em nenhuma das áreas autonômicas $(0,36 \pm 0,13 \%, 0,17 \pm 0,00 \%$ e $0,13 \pm 0,04 \%$ para PVN, NTS e RVLM, respectivamente, valores estes similares aos observados ao redor da $2^{2}$ a semana de treinamento nos SHR dos grupos anteriores - vide Figuras 25, 26 e 27), mas a infusão simultânea de uma dose subpressora de ANGII aumentou significativamente o extravasamento do FITC-dextran após 2 semanas de treinamento apenas no PVN dos SHR-T quando comparados aos infundidos com salina $(5,28 \pm 0,57 \%$ vs. $0,36 \pm 0,13 \%$, 
respectivamente Figura 30). Interessante observar-se que a infusão de ANGII não alterou significativamente a correção do extravasamento induzido pelo treinamento no NTS $(0,17 \pm 0,01 \%$ vs. $0,78 \pm 0,30 \%)$ e RVLM $(0,13 \pm 0,04 \%$ vs. $0,27 \pm 0,06 \%)$ (Figura 30$)$.
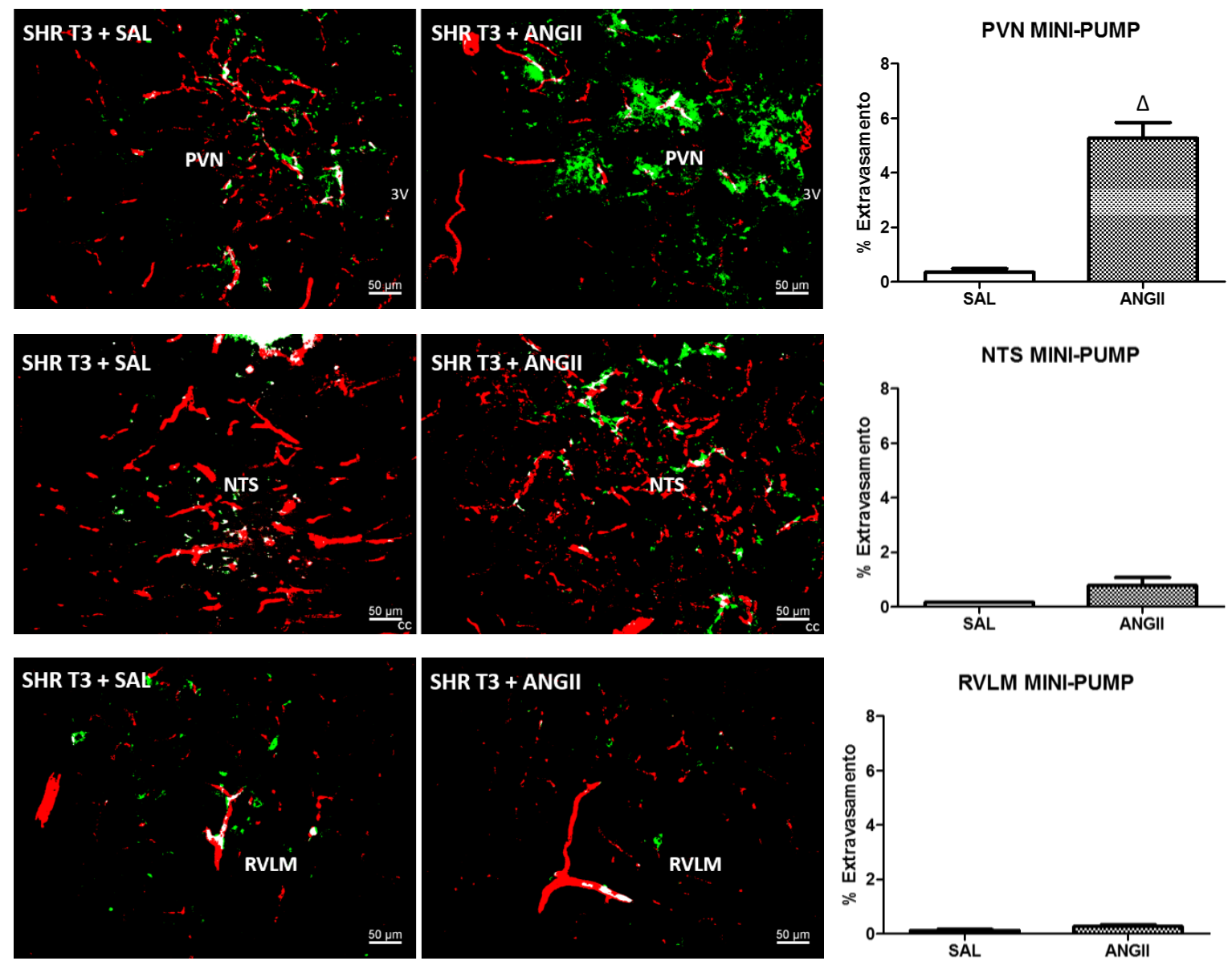

Figura 30 - Comparação de imagens obtidas por microscopia de fluorescência (140x) no PVN, NTS e RVLM de SHR treinados por 14 dias consecutivos e infundidos simultaneamente com salina (SAL) e angiotensina II (ANGII) intracerebroventricular. Vermelho $=$ ROD 70kDa, verde $=$ FITC $10 \mathrm{kDa}$, branco $=$ co-localização da ROD 70kDa e FITC 10kDa. Nos painéis abaixo apresentamos quantificação do extravasamento do FITC (valores percentuais) nas respectivas áreas após infusão de ANGII e sAL. Significância $(\mathrm{P}<0,05): \Delta v s$. SAL. 


\subsection{Efeitos da elevada disponibilidade de angiotensina II cerebral sobre a} integridade da BHE no PVN, NTS e RVLM dos grupos SHR e WKY treinados

Para investigar nos diferentes grupos experimentais os efeitos da hipertensão e da hipertensão associada ao treinamento sobre a integridade da BHE, utilizamos a técnica de imunofluorescência para avaliar qualitativamente a expressão de diferentes componentes da BHE. Conforme especificado no projeto inicial, era nosso objetivo analisar estes efeitos nas mesmas áreas dos mesmos encéfalos em que quantificamos o extravasamento (a coleta dos cortes sequenciais foi feita em diferentes poços), mas desconhecíamos (e a literatura não relata este fato) que o FITC e a ROD impregnam os cortes encefálicos, mascarando as reações de imunofluorescência para todos os anticorpos. Por orientação de professores do nosso Departamento tentamos, sem sucesso, remover o FITC e a Rod com lavagens sucessivas. Foi, portanto, necessário treinarmos outros grupos de animais para obtermos os tecidos cerebrais adequados a este processamento, o que atrasou sobremaneira a obtenção dos dados. Além disto, como os efeitos do treinamento sobre a correção da lesão da BHE foram, em todas as áreas estudadas, similares entre a $2^{\underline{a}}$. e a 8 8 $^{\mathrm{a}}$. semanas experimentais, os novos protocolos de treinamento e sedentarismo estenderam-se por 3 semanas facilitar a obtenção dos dados, mas assegurando a completa manifestação dos efeitos do treinamento em todos os animais analisados.

\subsubsection{Antígeno de barreira endotelial (EBA)}

O EBA é uma proteína presente na superfície luminal do endotélio, encontrada apenas em áreas com BHE (LIN et al., 2000; STERNBERGER; STERNBERGER, 1987). 0 anticorpo monoclonal contra o EBA (SMI 71, Covance, CA, EUA) não reage com o endotélio fenestrado, como também não o faz com regiões perivasculares. Realmente, como observado na Figura 31 para um corte do tronco cerebral dorsal, observamos marcação do SMI 71 apenas no NTS e não na área postrema, uma região desprovida de BHE. Importante observar que sua reatividade desaparece em lesões da BHE, com por exemplo na encefalomielite experimental (STERBERGER et al., 1989). O SMI 71 foi, portanto, utilizado para documentar os efeitos da hipertensão e do treinamento sobre a 
integridade da BHE nos capilares presentes no PVN, NTS e RVLM, como documentado nas Figuras 32, 33 e 34.

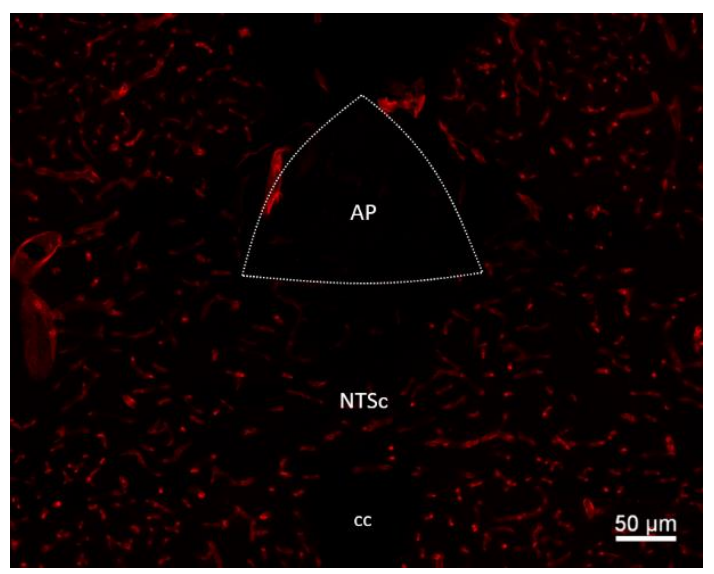

Figura 31 - Comparação da marcação imunofluorescência para o antígeno de barreira endotelial (EBA) entre o núcleo do trato solitário comissural (NTSc) e a área postrema (AP), área bastante vascularizada na qual há completa ausência de marcação. Anticorpo utilizado (SMI-71, diluição $1: 2000)$. cc - canal central.

A marcação para o EBA encontrava-se significativamente reduzida em todos os subnúcleos parvocelulares e magnocelular do PVN dos SHR-S no início dos protocolos (semana 0, fase em que os animais tinham cerca de 3 meses de idade) quando comparados aos respectivos controles (WKY-S pareados por idade - S0 na Figura 32). A manutenção do sedentarismo por mais 3 semanas determinou redução ainda mais pronunciada da integridade da BHE em ambos os grupos (S3 na Figura 32). Condizente com nossos resultados anteriores, observamos que o treinamento por 3 semanas aumentou significativamente a integridade da BHE, conforme indicada pela expressão

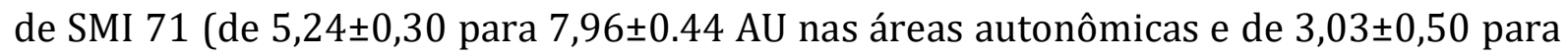
5.59 $\pm 0,91$ no magnocelular, figura 32). Por outro lado, a ANGII infundida no 3o. ventrículo simultaneamente ao treinamento bloqueou completamente seu efeito, mantendo em todos os subnúcleos do PVN a expressão do SMI 71 em níveis similares aos observados nos ratos sedentários (Figura 32). 

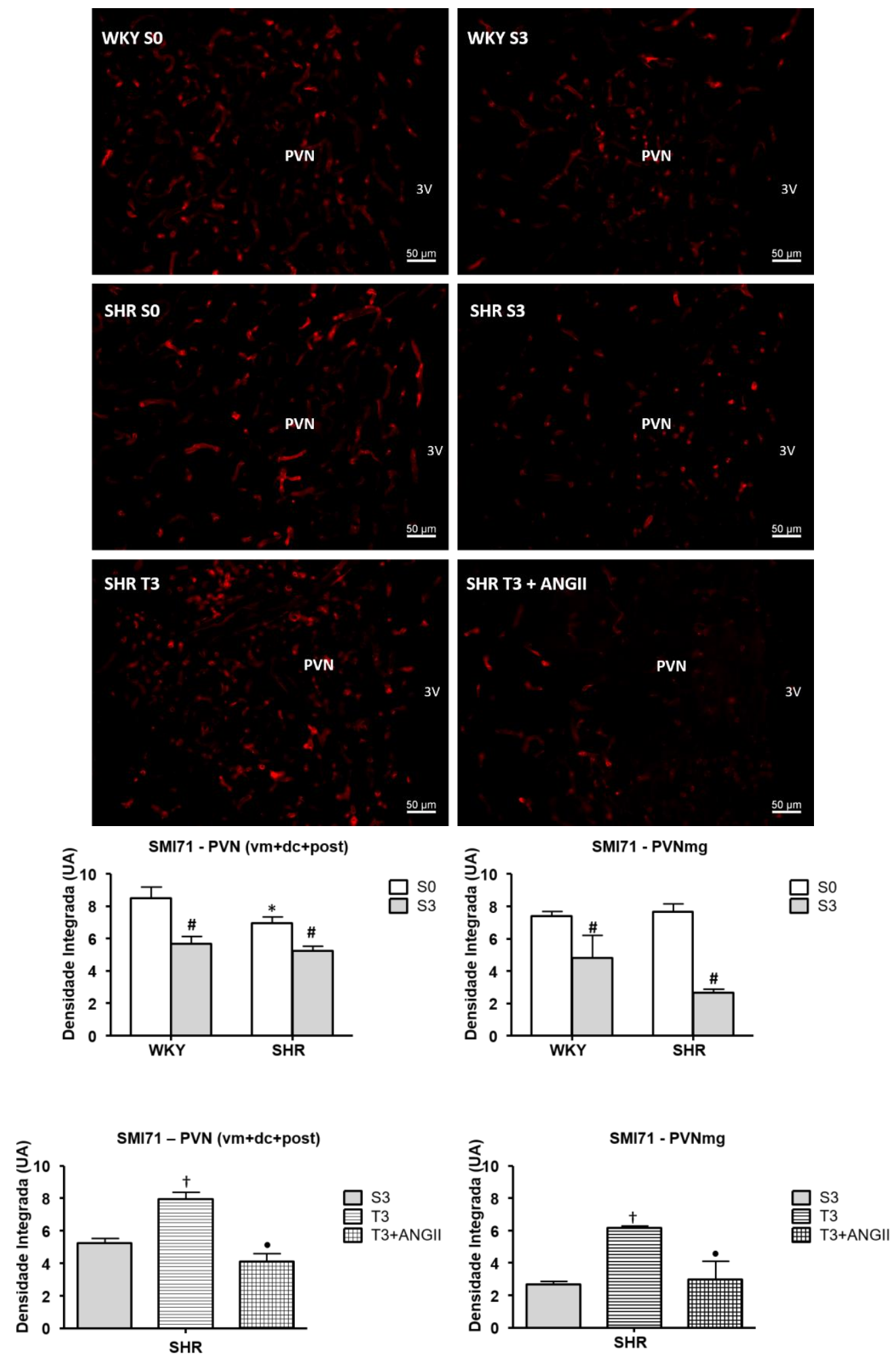

Figura 32 - Comparação da expressão do antígeno de barreira endotelial (EBA, anticorpo SMI-71, diluição 1:2000) no núcleo paraventricular do hipotálamo (PVN) de WKY e SHR sedentários nas semanas 0 (S0) e 3 (S3). Os SHR foram também treinados por 3 semanas na ausência (T3) e na presença de infusão i.c.v. concomitante de angiotensina II (T3+ANGII). Painéis superiores: Fotomicrografias ilustrativas da expressão de SMI 71 no PVN. 3V - terceiro ventrículo. Painéis inferiores: Quantificação da expressão de SMI 71 em diferentes subnúcleos do PVN. Significâncias $(\mathrm{P}<0,05):^{*} v s$. WKY † vs. sedentário \# vs. semana $0 \bullet v s$. T3. 
No NTS como um todo não observamos diferença significativa na expressão de SMI 71 entre SHR-S e WKY-S na semana 0. Há, no entanto, redução da expressão deste marcador nos SHR após 3 semanas de sedentarismo (Figura 33). Da mesma forma que o observado para o PVN, o treinamento dos SHR por 3 semanas foi acompanhado de aumento significativo na expressão do EBA, indicativo de melhora na integridade de BHE, o qual desaparecia em presença de infusão com ANGII (Figura 33).
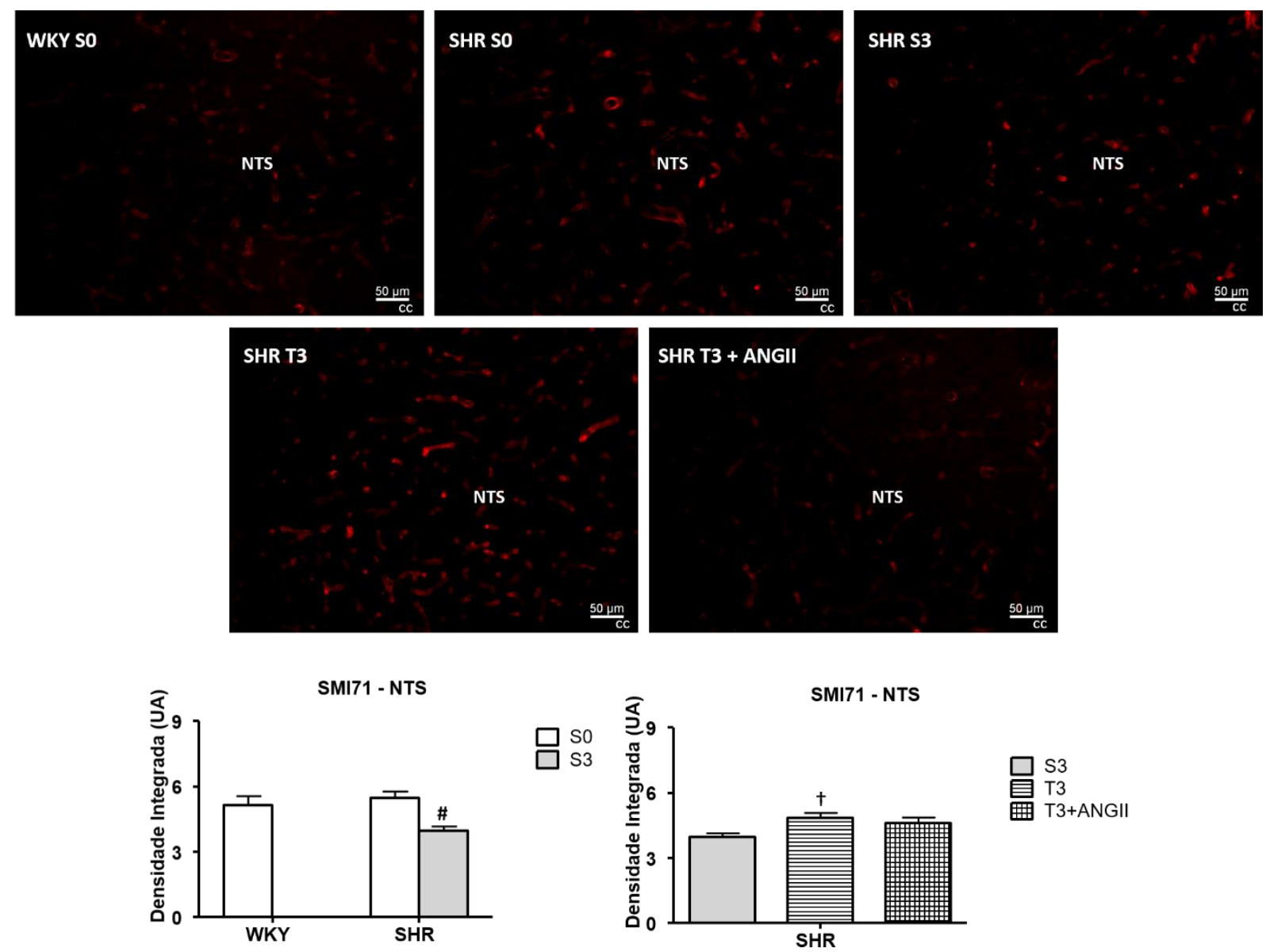

Figura 33 - Comparação da expressão do antígeno de barreira endotelial (EBA, anticorpo SMI-71, diluição 1:2000) no núcleo do trato solitário (NTS) de WKY e SHR sedentários nas semanas 0 (S0) e 3 (S3). Os SHR foram também treinados por 3 semanas na ausência (T3) e na presença de infusão i.c.v. concomitante de angiotensina II (T3+ANGII). Painéis superiores: Fotomicrografias ilustrativas da expressão de SMI 71 no NTS. cc, canal central Painéis inferiores: Quantificação da expressão de SMI 71 em toda a extensão do NTS. Significâncias $(\mathrm{P}<0,05)$ : † vs. sedentário \# vs. semana 0 .

Interessante foi a observação de que embora o treinamento tenha reduzido significativamente o extravasamento de FITC-Dextran no RVLM de SHR treinados (Figura 27), este efeito não foi acompanhado de alteração na expressão de EBA nesta 
área. Como observado na Figura 34, o transcorrer das 3 semanas de sedentarismo (tendência à redução) e o treinamento (tendência ao aumento) determinaram apenas pequenas alterações não significativas na expressão de SMI 71 nos SHR. Também o treinamento associado à infusão de ANGII mostrou tendência à redução quando comparado aos treinados por 3 semanas (Figura 34).
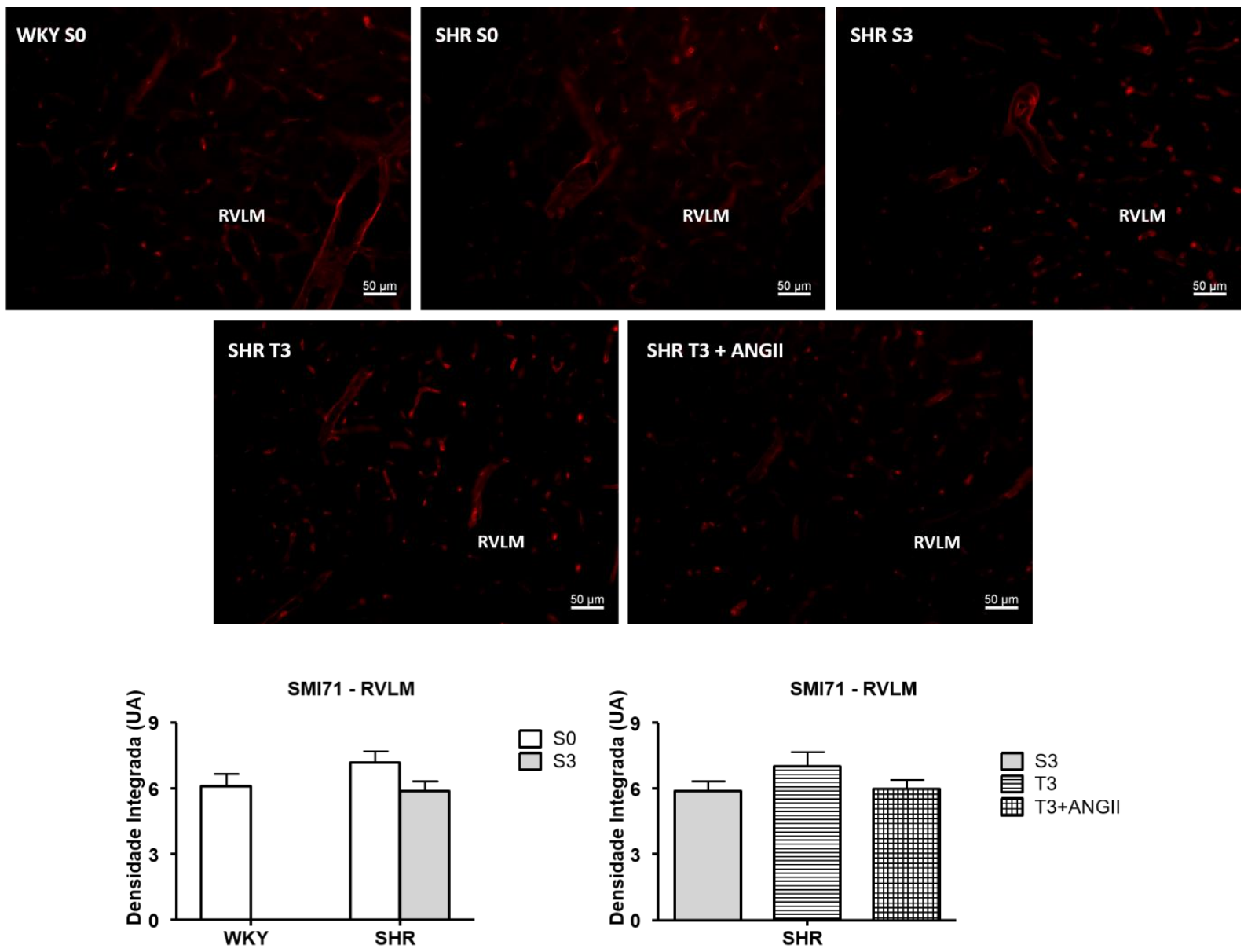

Figura 34 - Comparação da expressão do antígeno de barreira endotelial (EBA, anticorpo SMI-71, diluição 1:2000) na região rostro-ventrolateral do Bulbo (RVLM) de WKY e SHR sedentários nas semanas 0 (S0) e 3 (S3). Os SHR foram também treinados por 3 semanas na ausência (T3) e na presença de infusão i.c.v. concomitante de angiotensina II (T3+ANGII). Painéis superiores: Fotomicrografias ilustrativas da expressão de SMI 71 no RVLM. Painéis inferiores: Quantificação da expressão de SMI 71 no RVLM.

\subsubsection{Expressão de IBA-1 (Microglia)}

Para avaliarmos os efeitos da hipertensão e treinamento sobre a expressão da microglia, um importante modulador da funcionalidade da BHE, utilizamos 2 
marcadores: o CD11 e o IBA-1, com excelentes resultados para o IBA-1, escolhido para os testes a seguir.

No início dos protocolos não observamos grandes diferenças entre e densidade de expressão do IBA-1 nos WKY-S e SHR-S, mas após 3 semanas de sedentarismo houve redução da densidade da microglia nos WKY, mas aumento significativo nos SHR, de forma que em S3, os SHR mostravam valores significativamente mais elevados que os WKY pareados por idade $(81,48 \pm 1.89$ vs. $59,07 \pm 1,55$ UA, figura 35$)$. Três semanas de treinamento determinaram redução significativa da densidade de expressão da microglia nos SHR (de 81,48 $\pm 1,89$ para $72.02 \pm 2,03 \mathrm{UA}$ ), enquanto que a infusão de ANGII associada ao treinamento aumentou marcadamente sua expressão $(98,07 \pm 6.13$ UA, figura 38) em áreas autonômicas do PVN. O treinamento e a ANGII não alteraram a expressão de IBA 1 no PVN magnocelular dos SHR (figura 35).
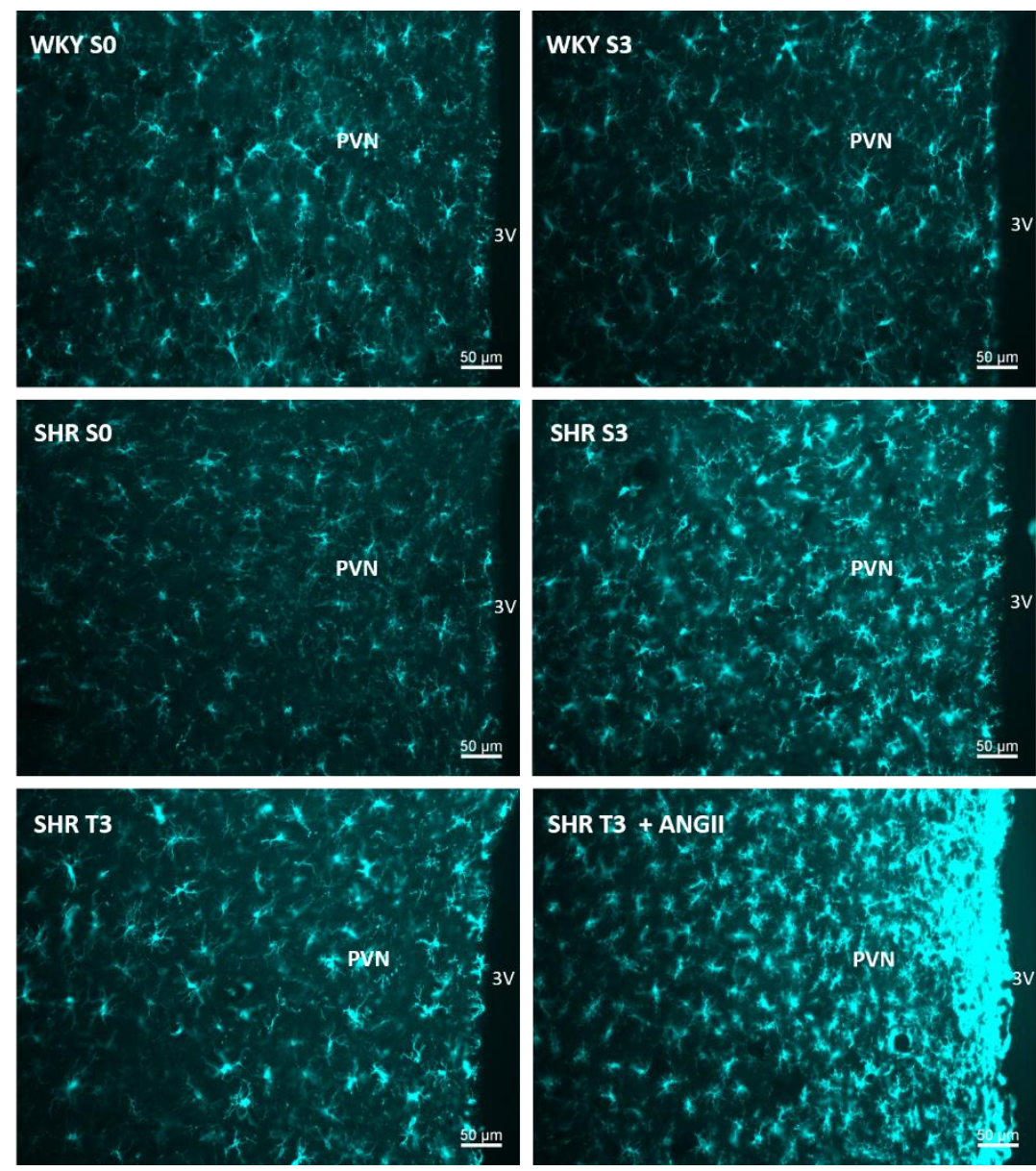

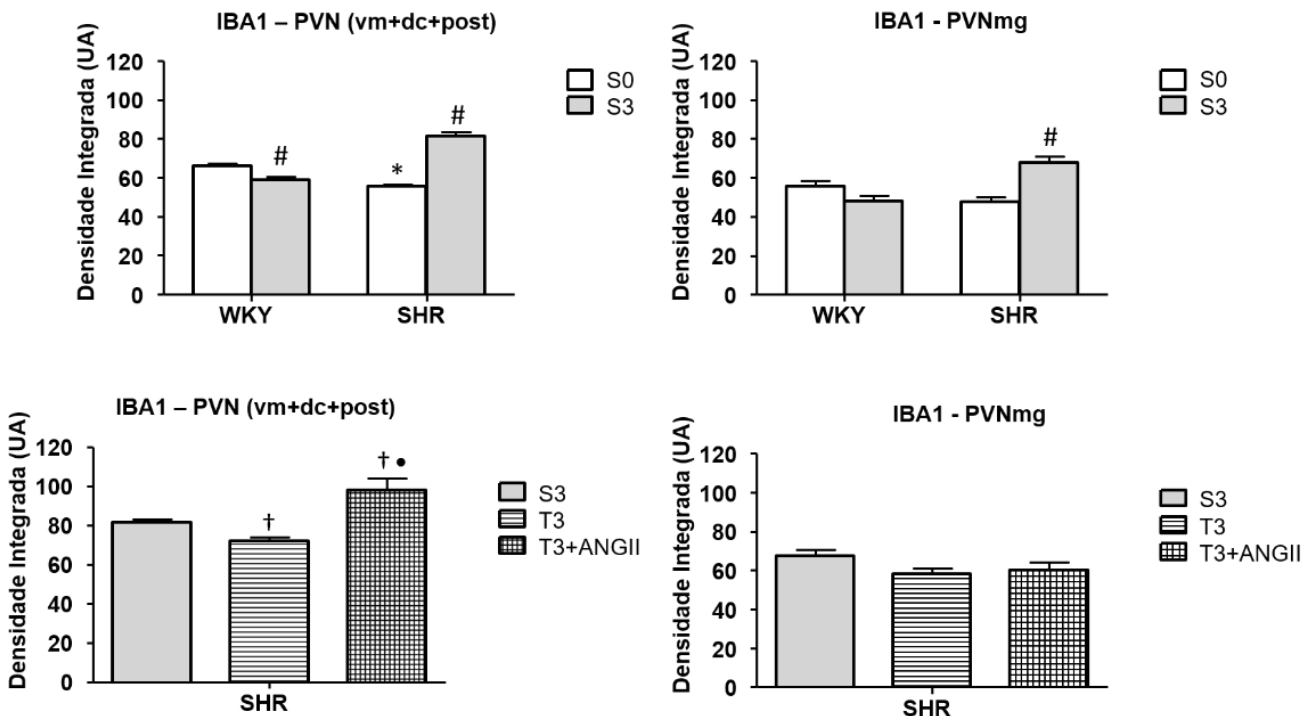

Figura 35 - Comparação da expressão do IBA-1 (marcador de microglia) no núcleo paraventricular do hipotálamo (PVN) de WKY e SHR sedentários nas semanas 0 (S0) e 3 (S3). Os SHR foram também treinados por 3 semanas na ausência (T3) e na presença de infusão i.c.v. concomitante de angiotensina II (T3+ANGII). Painéis superiores: Fotomicrografias ilustrativas da expressão de IBA-1 no PVN. 3V - terceiro ventrículo. Painéis inferiores: Quantificação da expressão de IBA-1 em diferentes subnúcleos do PVN. Significâncias $(\mathrm{P}<0,05):{ }^{*} v s$. WKY † vs. sedentário \# vs. semana $0^{\bullet} v s$. T3.

Também no NTS dos WKY-S e SHR-S a expressão da microglia foi aumentada durante as 3 semanas de sedentarismo (de 69,68 $\pm 1,15$ para $86,40 \pm 1,81$ UA e de $72,75 \pm 0.94$ para $108,94 \pm 2,07 \mathrm{UA}$, respectivamente, figura 36 ). Nos SHR o treinamento por 3 semanas também determinou redução significativa da expressão de IBA 1(T3 = 95,71 $\pm 1,66$ UA), mas a infusão de ANGII não alterou significativamente esse valor $(\mathrm{T} 3+\mathrm{ANGII}=99,86 \pm 4,32 \mathrm{UA})$. 

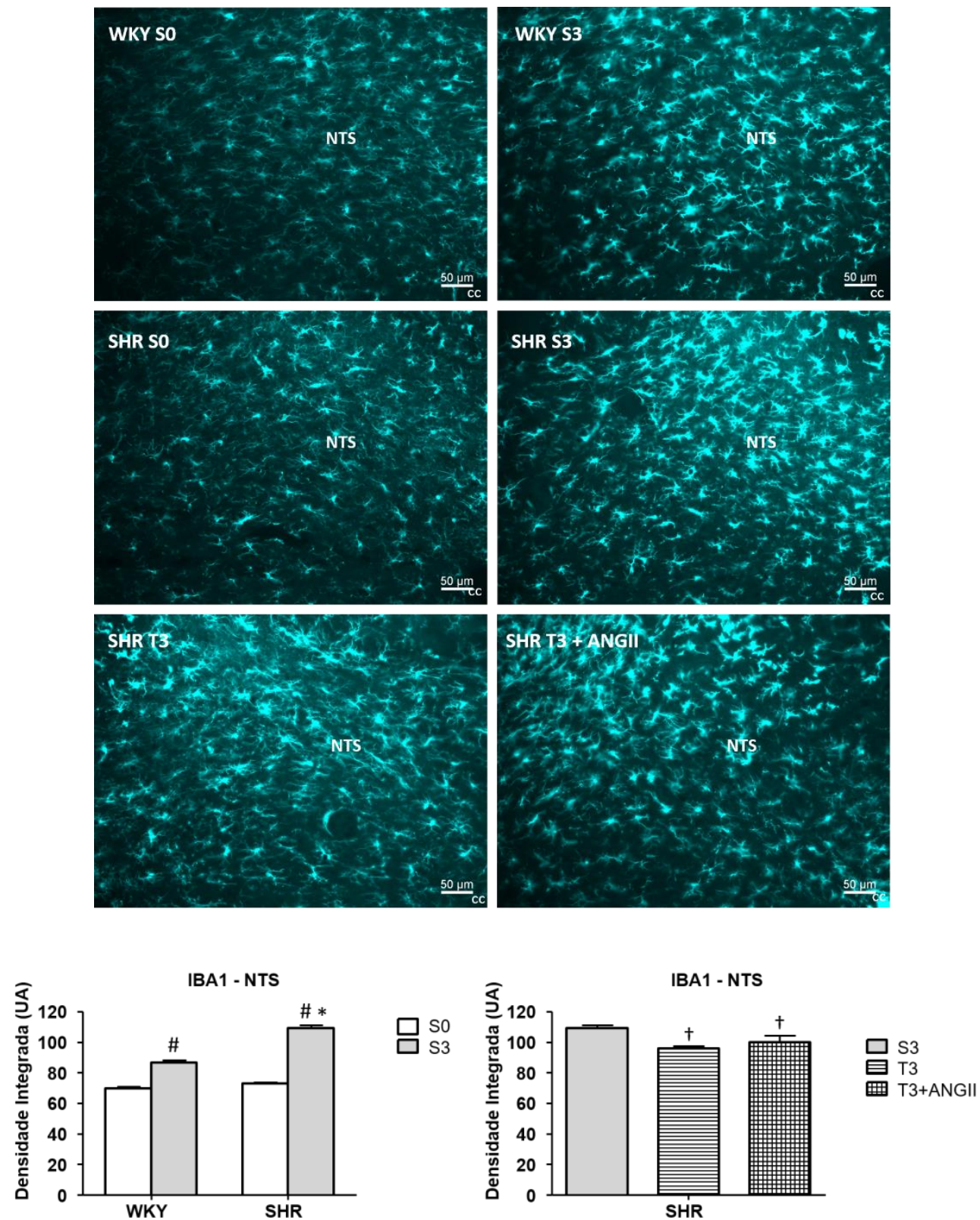

Figura 36 - Comparação da expressão do IBA-1 (marcador de microglia) no núcleo do trato solitário (NTS) de WKY e SHR sedentários nas semanas 0 (S0) e 3 (S3). Os SHR foram também treinados por 3 semanas na ausência (T3) e na presença de infusão i.c.v. concomitante de angiotensina II (T3+ANGII). Painéis superiores: Fotomicrografias ilustrativas da expressão de IBA1 no NTS, cc, canal central Painéis inferiores: Quantificação da expressão de IBA-1 em toda a extensão do NTS. Significâncias $(\mathrm{P}<0,05):{ }^{*} v s$. WKY † vs. sedentário \# vs. semana 0.

No RVLM, a única alteração observada na expressão de IBA 1 foi o aumento significativo no SHR após 3 semanas de sedentarismo, quando comparado ao valor exibido pelos SHR na semana inicial dos experimentos (compare SHR-S3 vs. SHR-S0 na figura 37). 

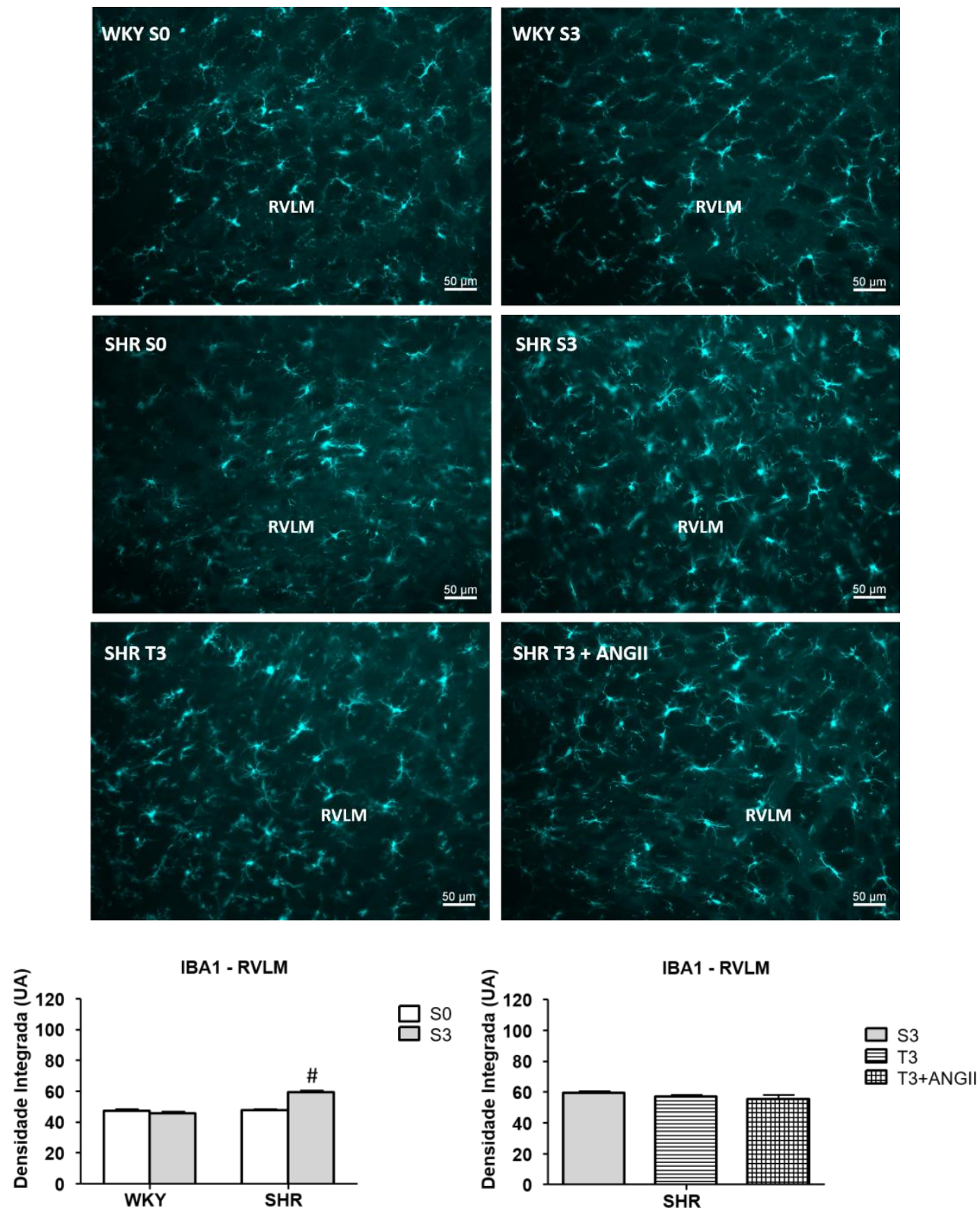

Figura 37 - Comparação da expressão do IBA-1 (marcador de microglia) no bulbo rostroventrolateral (RVLM) de WKY e SHR sedentários nas semanas 0 (S0) e 3 (S3). Os SHR foram também treinados por 3 semanas na ausência (T3) e na presença de infusão i.c.v. concomitante de angiotensina II (T3+ANGII). Painéis superiores: Fotomicrografias ilustrativas da expressão de IBA1 no RVLM. Painéis inferiores: Quantificação da expressão de IBA-1 no RVLM. Significância $(\mathrm{P}<0,05)$ : \# vs. semana 0.

Com relação a alterações na estrutura das células da microglia, constatamos principalmente no PVN que ela se mostrava menos ramificada nos SHR vs. WKY com ramificações menos evidentes em S3, quando comparadas a S0. Observamos também maior ramificação nos SHR treinados quando comparados a seus controles sedentários. 
Por outro lado, a infusão com ANGII modificou a estrutura do corpo celular da microglia, que se apresentavam mais romboides, com redução das ramificações (veja figura 38).
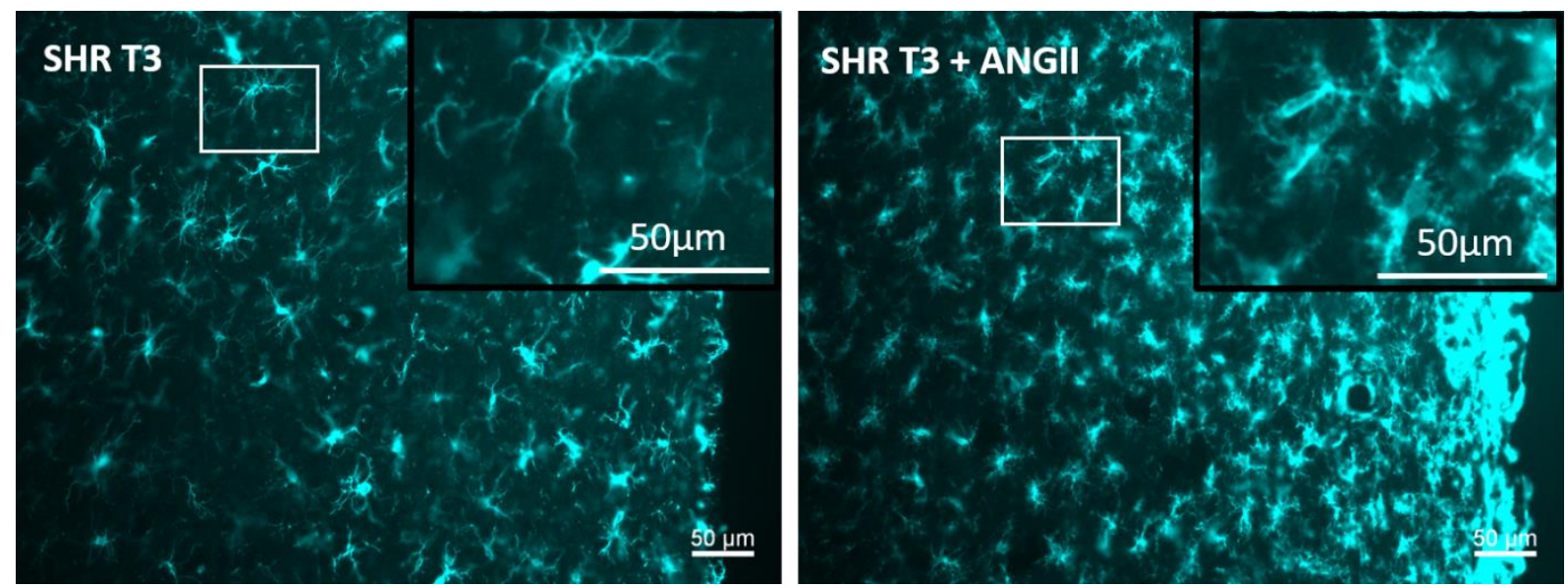

Figura 38 - Comparação da estrutura da microglia característica do PVN De um SHR treinado por 3 semanas (SHR-T3) e de outro treinado que recebeu simultaneamente a infusão de ANGII intracerebroventricular (T3+ANGII).

\subsubsection{Expressão de receptores AT1}

Para melhor avaliarmos os efeitos do treinamento sobre a funcionalidade da BHE em sedentários e treinados na presença ou ausência da infusão i.c.v. com ANGII, analisamos também a expressão de receptores AT1 nas áreas autonômicas estudadas. Interessante foi nossa observação de que durante a infusão de ANGII as alterações na expressão destes receptores se faziam preferencialmente com muita intensidade em células não neuronais (glia/ microglia), mascarando as alterações observadas em neurônios (figura 39). Aparentemente essa infusão de ANGII aumentou a expressão de AT1 possivelmente na microglia, pois quando comparamos a marcação para o IBA-1 na foto do PVN de um animal T3 + ANGII da figura 35 com a primeira imagem da figura 39, observamos uma semelhança na morfologia das marcações. Para contornar esta dificuldade, utilizamos dupla marcação de receptor AT1e NeuN e quantificamos as alterações na expressão de receptores observadas apenas nos neurônios préautonômicos do PVN, NTS e RVLM. 

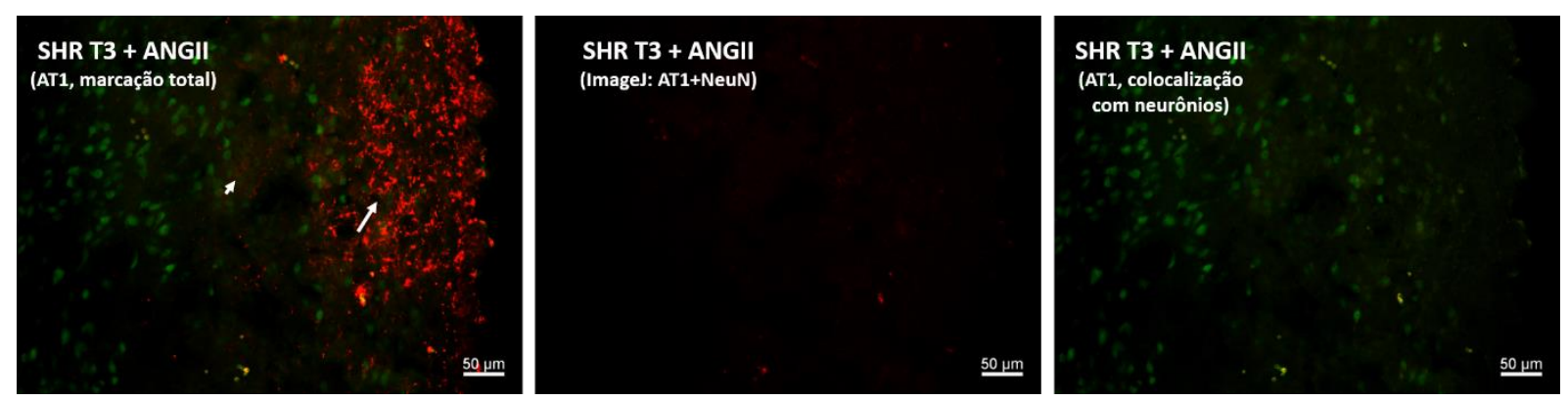

Figura 39 - Fotomicrografias de PVN obtidas por imunofluorescência para receptor AT1 (vermelho) e neurônios (verde). Na primeira imagem observa-se marcação vermelha de processos/ramificações que não condizem com a forma e estrutura de neurônios. Na segunda imagem observamos o resultado da soma das imagens de AT1 e neurônio. Na terceira imagem tem-se como resultado final apenas receptores AT1 presentes em neurônios.

Nos subnúcleos pré-autonômicos do PVN observamos tendência à maior expressão de AT1 nos SHR-S0 vs. WKY-S0 $(\mathrm{P}>0,05)$ e um nítido aumento de sua expressão nos SHR após 3 semanas de sedentarismo (SHR-S3 vs. SHR-S0, P<0,05, figura 40), sem alterações no PVN magnocelular. Interessante observar-se que o treinamento por 3 semanas foi acompanhado de intenso aumento na expressão de AT1R em

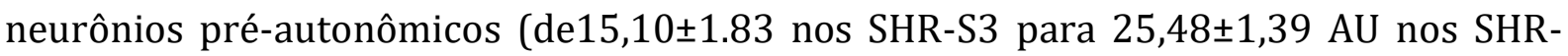
T3), a qual foi drasticamente reduzida pela infusão concomitante de ANGII $(4,61 \pm 0,39$ UA, figura 40). Os neurônios magnocelulares do PVN também mostraram redução da expressão de AT1R frente à infusão de ANGII, mas a elevação observada após 3 semanas de treinamento não atingiu níveis de significância (figura 40). 

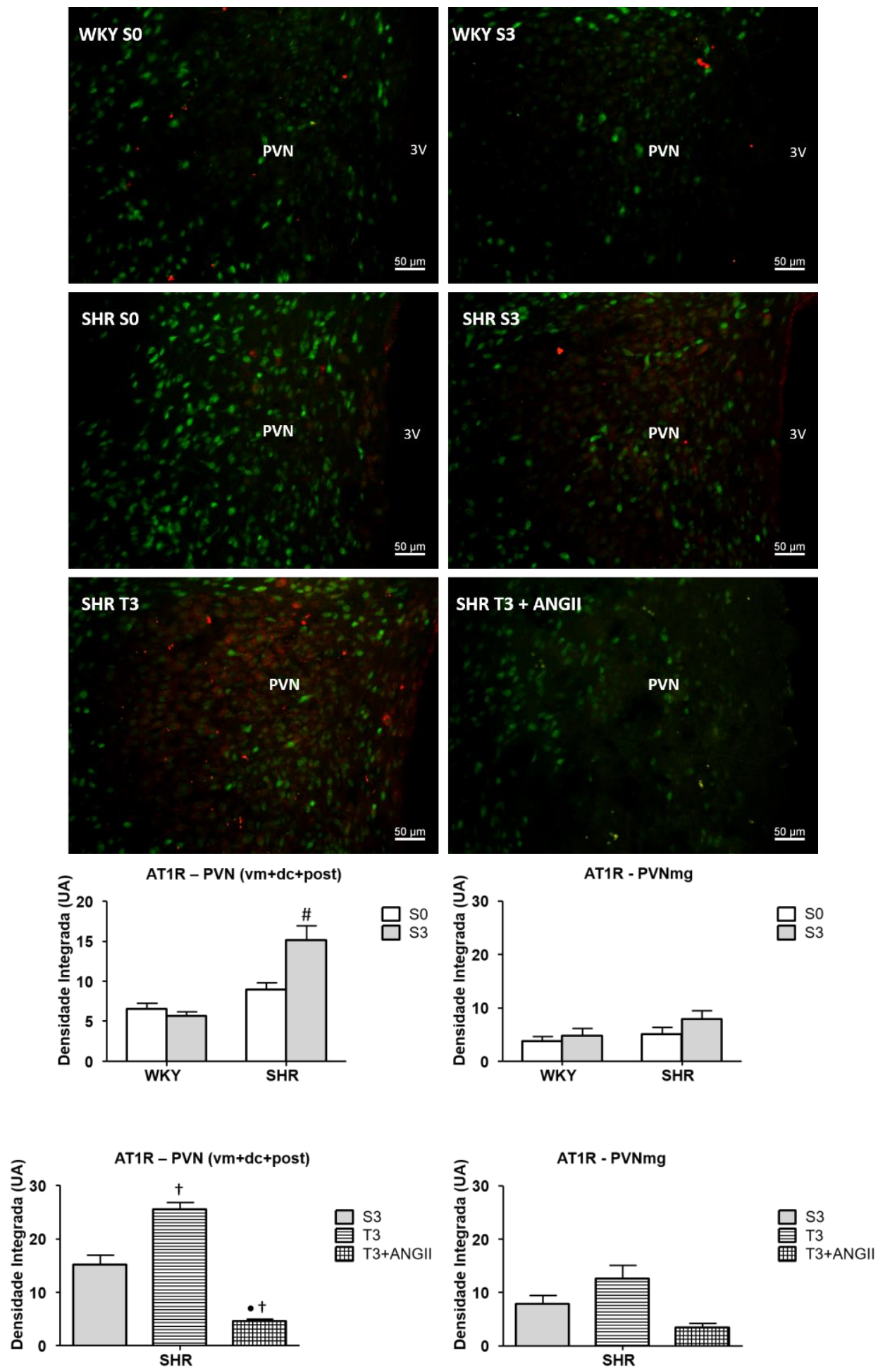

Figura 40 - Comparação da expressão de receptores AT1 no núcleo paraventricular do hipotálamo (PVN) de WKY e SHR sedentários nas semanas 0 (S0) e 3 (S3). Os SHR foram também treinados por 3 semanas na ausência (T3) e na presença de infusão i.c.v. concomitante de angiotensina II (T3+ANGII). Painéis superiores: Fotomicrografias ilustrativas da expressão de receptores AT1 no PVN. 3V - terceiro ventrículo. Painéis inferiores: Quantificação da expressão de receptores AT1 em diferentes subnúcleos do PVN. Significâncias $(\mathrm{P}<0,05)$ : † vs. Sedentário, \# vs. semana $0, \bullet v s$. T3. 
Os neurônios do NTS dos SHR já apresentavam maior densidade de receptores

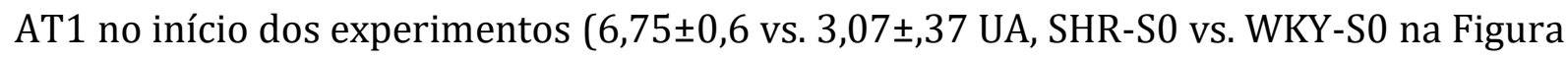
41) e sua expressão não foi alterada pelas 3 semanas de sedentarismo. Houve também grande aumente da densidade de receptores nos SHR após 3 semanas de treinamento (de 7,14 $\pm 0,40$ para $10,57 \pm 0,52 \mathrm{UA}$, figura 41), e este aumento foi completamente bloqueado pela infusão concomitante de doses subpressoras de ANGII $(6,90 \pm 0,45$ UA).
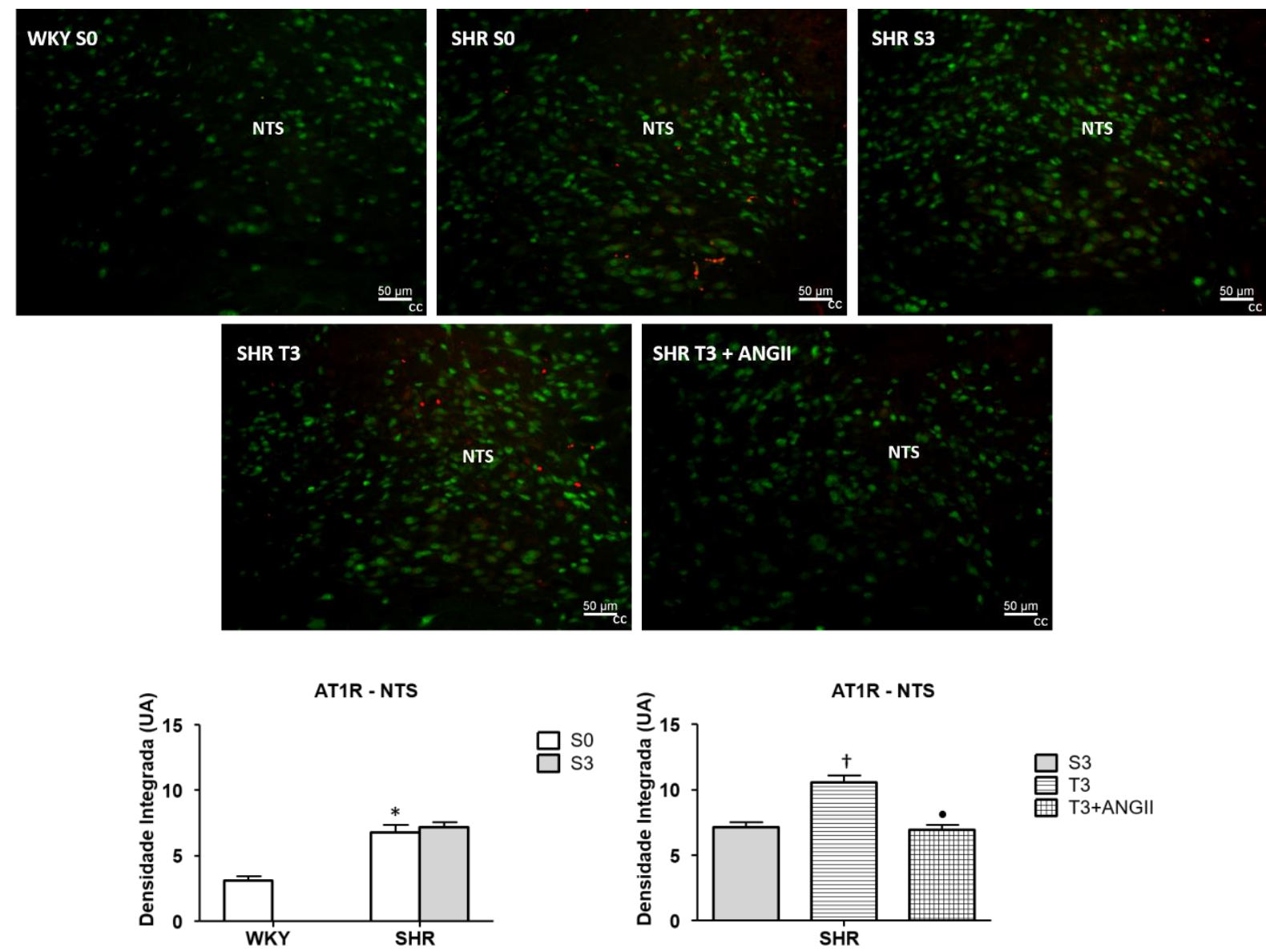

Figura 41 - Comparação da expressão de receptores AT1 no núcleo do trato solitário (NTS) de WKY e SHR sedentários nas semanas 0 (S0) e 3 (S3). Os SHR foram também treinados por 3 semanas na ausência (T3) e na presença de infusão i.c.v. concomitante de angiotensina II (T3+ANGII). Painéis superiores: Fotomicrografias ilustrativas da expressão de receptores AT1 em toda a extensão do NTS. cc, canal central. Painéis inferiores: Quantificação da expressão de receptores AT1 no NTS. Significâncias $(\mathrm{P}<0,05):{ }^{*} v s$. WKY, $\dagger v$ s. Sedentário, • vs. T3.

Por outro lado, nenhuma alteração significativa na expressão de receptores AT1 foi observada no RVLM de SHR mantidos sedentários, treinados ou treinados durante infusão concomitante de ANGII (figura 42). 

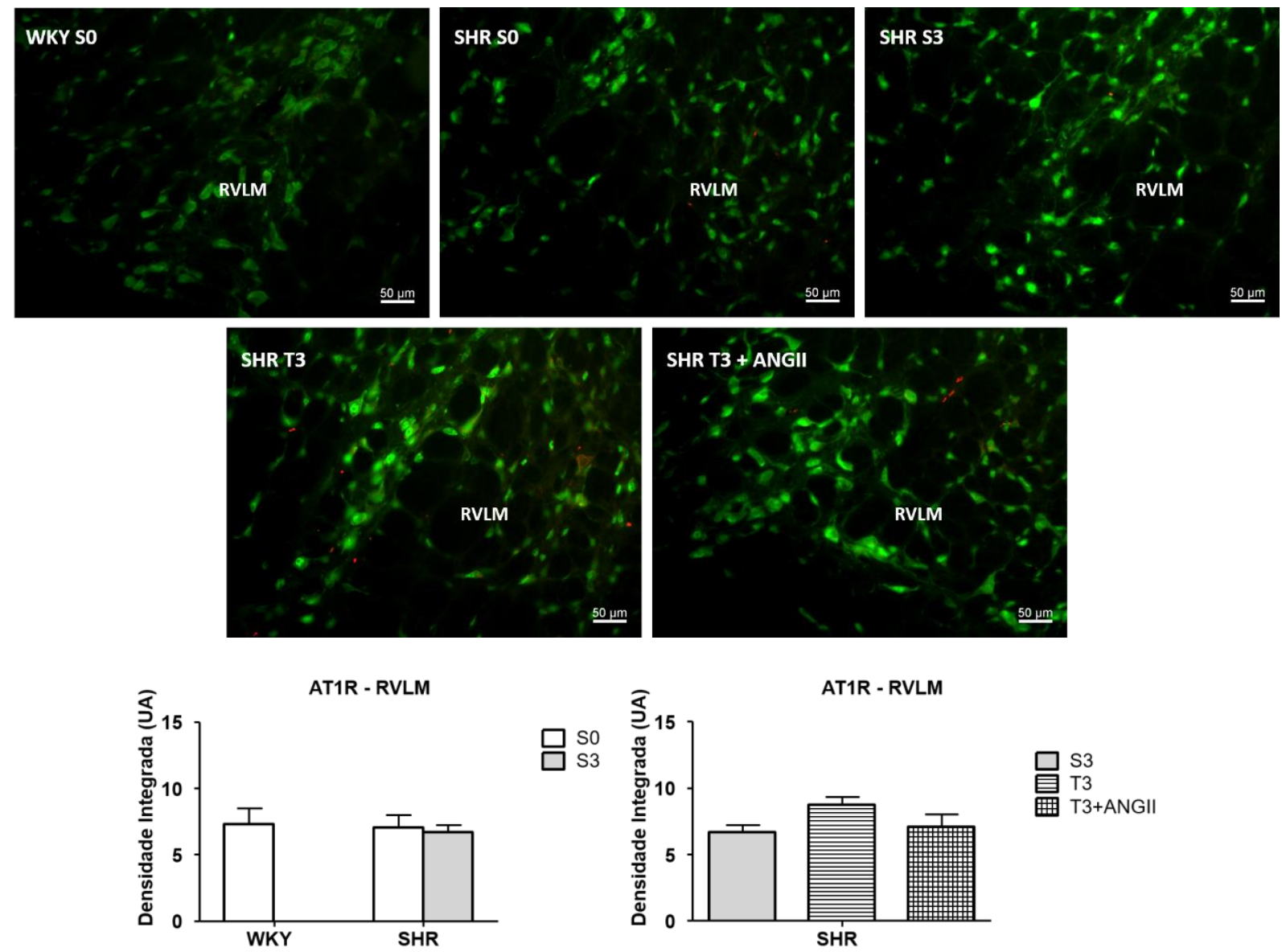

Figura 42 - Comparação da expressão de receptores AT1 no bulbo rostro-ventrolateral (RVLM) de WKY e SHR sedentários nas semanas 0 (S0) e 3 (S3). Os SHR foram também treinados por 3 semanas na ausência (T3) e na presença de infusão i.c.v. concomitante de angiotensina II (T3+ANGII). Painéis superiores: Fotomicrografias ilustrativas da expressão de receptores AT1 no RVLM. Painéis inferiores: Quantificação da expressão de receptores AT1 no RVLM.

\subsubsection{Proteína ácida fibrilar glial (GFAP)}

O GFAP, um antígeno específico a células gliais, os astrócitos, também foi utilizado para avaliar se a hipertensão e o treinamento aeróbio podiam modificar a permeabilidade da BHE por alterar a participação da glia na composição da BHE, dada a importância do contato íntimo de suas projeções ('end feet') com os vasos sanguíneos encefálicos.

As Figuras 43, 44 e 45 ilustram a imunorreatividade para o GFAP no PVN, NTS e RVLM, respectivamente de WKY-S e SHR-S e de SHR submetidos ao treinamento por 3 semanas na presença e na ausência de infusão concomitante de ANGII. Observamos intensa marcação de astrócitos e suas projeções vasculares que envolvem os vasos 
encefálicos e cuja proximidade/sobreposição prestam-se inclusive para delimitar capilares e mesmo vasos de maior calibre.

Observamos, tanto em núcleos pré-autonômicos quanto no magnocelular do PVN de WKY-S e SHR-S, que a expressão de GFAP aumentava após 3 semanas de sedentarismo (de $15,86 \pm 1,74$ para $25,55 \pm 2,64$ UA e de $12,86 \pm 1,42$ para $33,78 \pm 2,28 \mathrm{UA}$, respectivamente, figura 43). Um aumento proporcionalmente maior foi observado quando os SHR foram treinados por 3 semanas $(46,15 \pm 2,52$ UA). Não obstante o treinamento realizado simultaneamente à infusão de ANGII no $3^{\circ}$ ventrículo bloqueou completamente o aumento da expressão de GFAP no subnúcleos pré-autonômicos (ventromedial, dorsal cap e posterior) e no magnocelular, cujos valores foram similares aos observados na semana 0 dos SHR-S (figura 43).
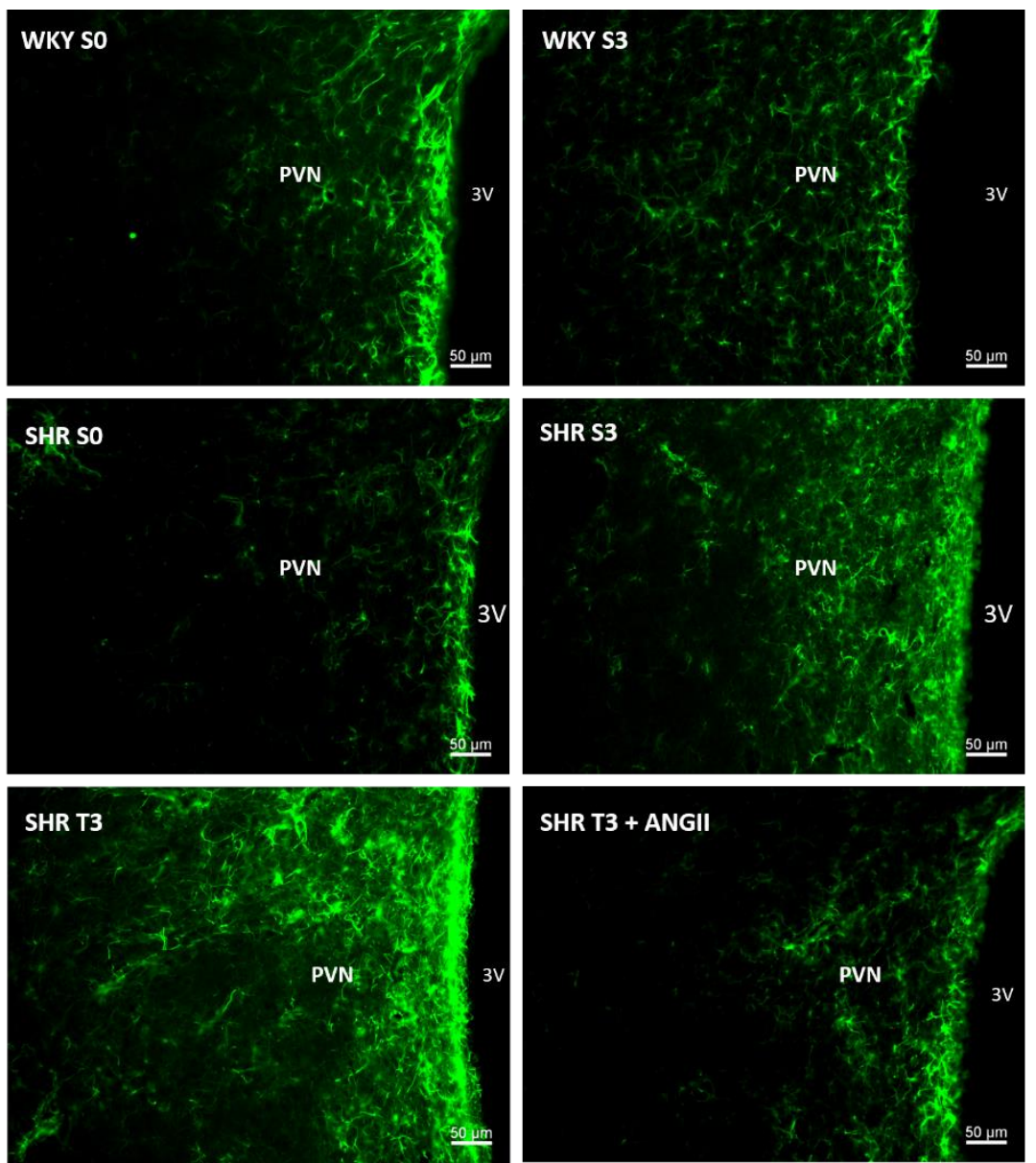

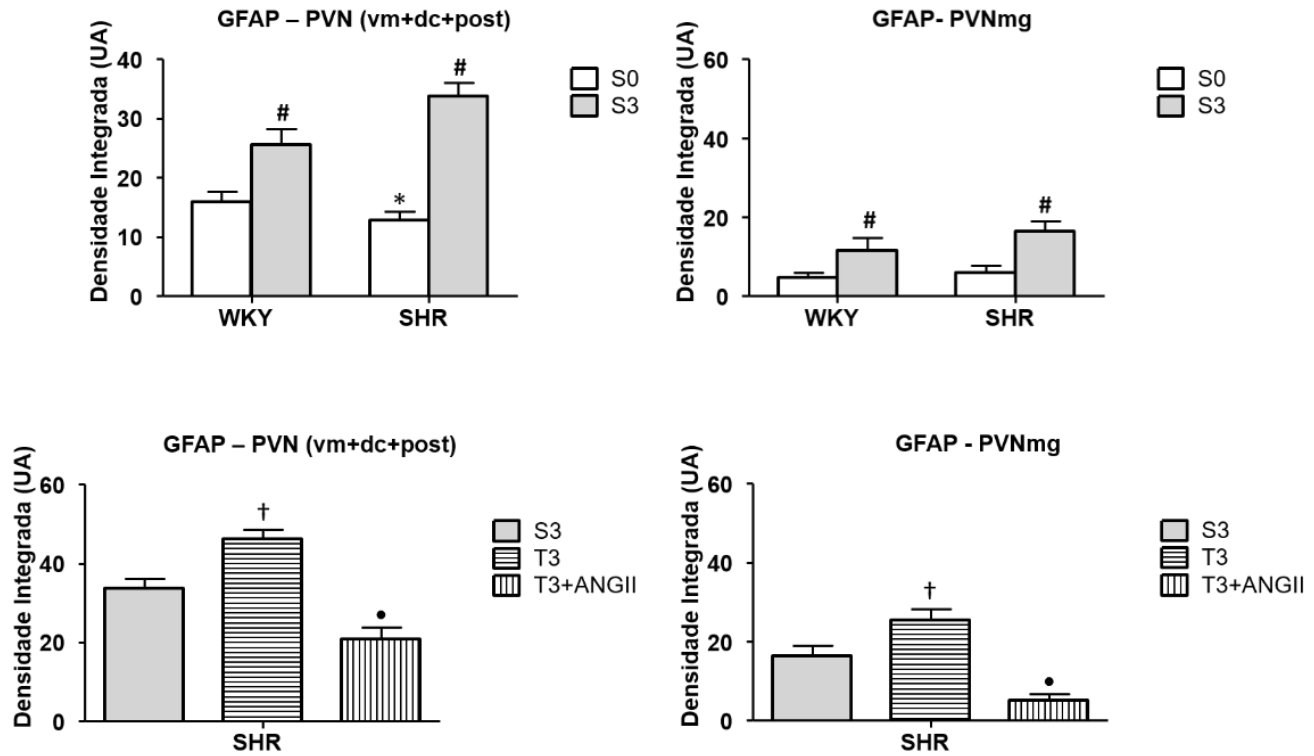

Figura 43 - Comparação da expressão do GFAP (glial fibrillary acidic protein) no núcleo paraventricular do hipotálamo (PVN) de WKY e SHR sedentários nas semanas 0 (S0) e 3 (S3). Os SHR foram também treinados por 3 semanas na ausência (T3) e na presença de infusão i.c.v. concomitante de angiotensina II (T3+ANGII). Painéis superiores: Fotomicrografias ilustrativas da expressão de GFAP no PVN. 3V - terceiro ventrículo. Painéis inferiores: Quantificação da expressão de GFAP em diferentes subnúcleos do PVN. Significâncias $(\mathrm{P}<0,05):{ }^{*} v s$. WKY † vs. sedentário \# vs. semana $0^{\bullet} v s$. T3.

O NTS de SHR-S exibia já na semana 0 maior expressão de GFAP que os respectivos controles WKY. Esta expressão foi ainda maior na 3ạ semana de sedentarismo (S3 vs. S0 na figura 44). Houve tendência a aumento adicional da expressão de GFAP nos SHR-T3 quando comparados aos SHR-S3 (de 55.96 \pm 3.14 para 63.37£3.77 UA. P>0,05). Por outro lado, sua expressão foi completamente bloqueada quando o treinamento foi realizado em presença de infusão continua de ANGII (T3+ANGII = 10,37 $\pm 1,31$ UA na Figura 44). 

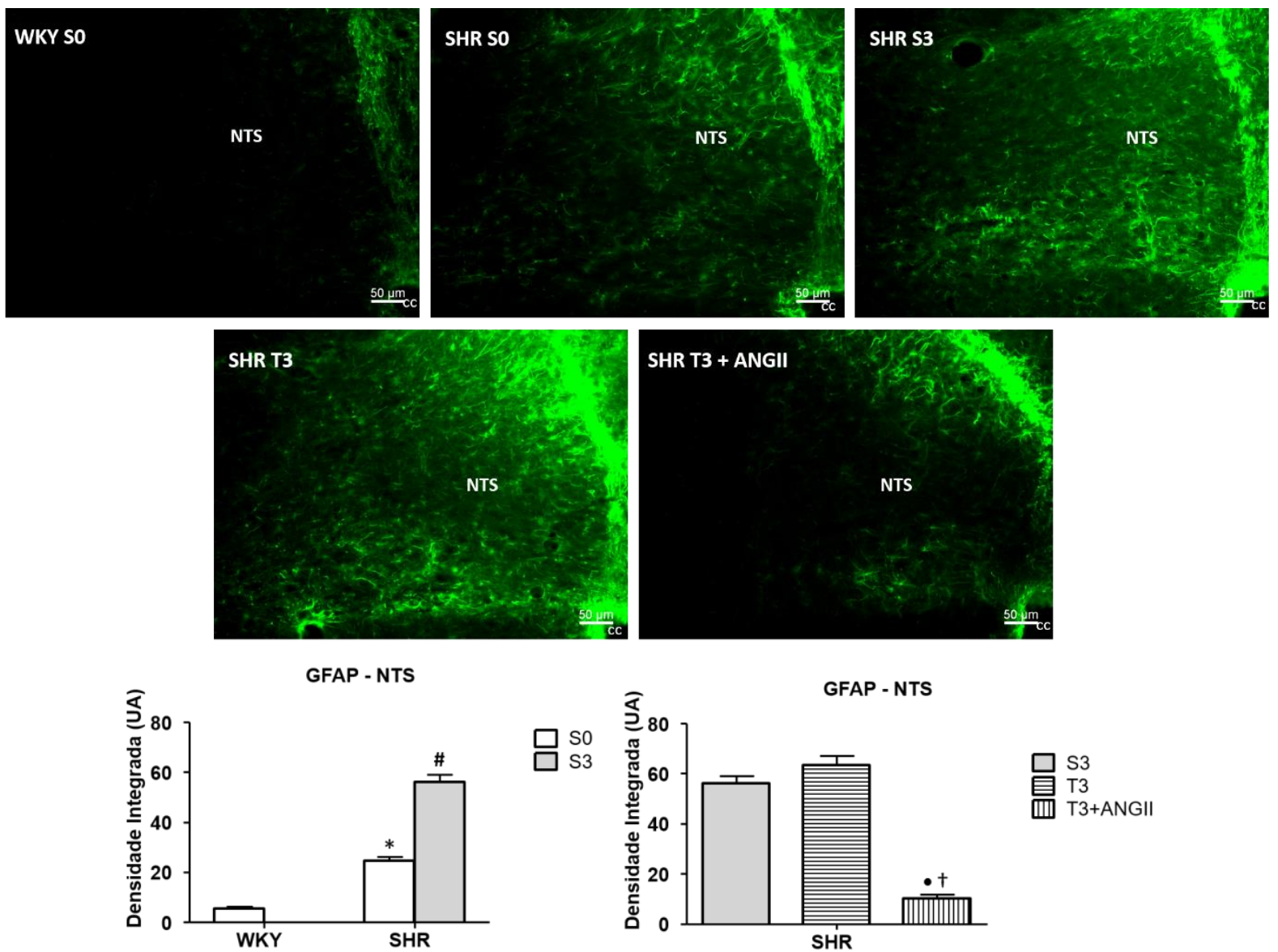

Figura 44 - Comparação da expressão do GFAP (glial fibrillary acidic protein) no núcleo do trato solitário (NTS) de WKY e SHR sedentários nas semanas 0 (S0) e 3 (S3). Os SHR foram também treinados por 3 semanas na ausência (T3) e na presença de infusão i.c.v. concomitante de angiotensina II (T3+ANGII). Painéis superiores: Fotomicrografias ilustrativas da expressão de GFAP no NTS. cc, canal central. Painéis inferiores: Quantificação da expressão de GFAP em diferentes subnúcleos do NTS. Significâncias $(\mathrm{P}<0,05):{ }^{*} v s$. WKY $\dagger v s$. sedentário \# vs. semana $0 \bullet$ vs. T3.

A expressão de GFAP no RVLM mostrou-se bastante reduzida quando comparada ao NTS e PVN. Os SHR-S0 quando comparados aos WKY-S0 apresentaram tendência à

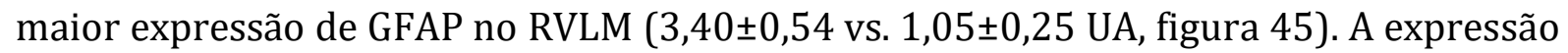
de GFAP nos SHR-S foi bastante aumentada após 3 semanas de sedentarismo (S3 vs. S0 na Figura 45). Houve também aumento adicional da expressão de GFAP nos SHR-T3

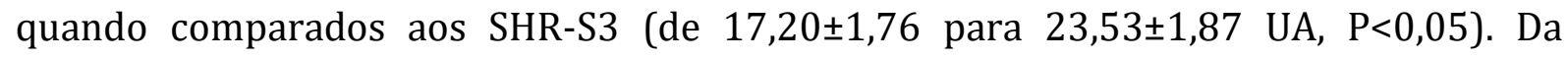
mesma forma que o observado para o NTS, a expressão de GFAP no RVLM foi completamente bloqueada quando o treinamento foi realizado em presença de infusão continua de ANGII (T3+ANGII = 1,08 $\pm 0,23$ UA na Figura 45). 

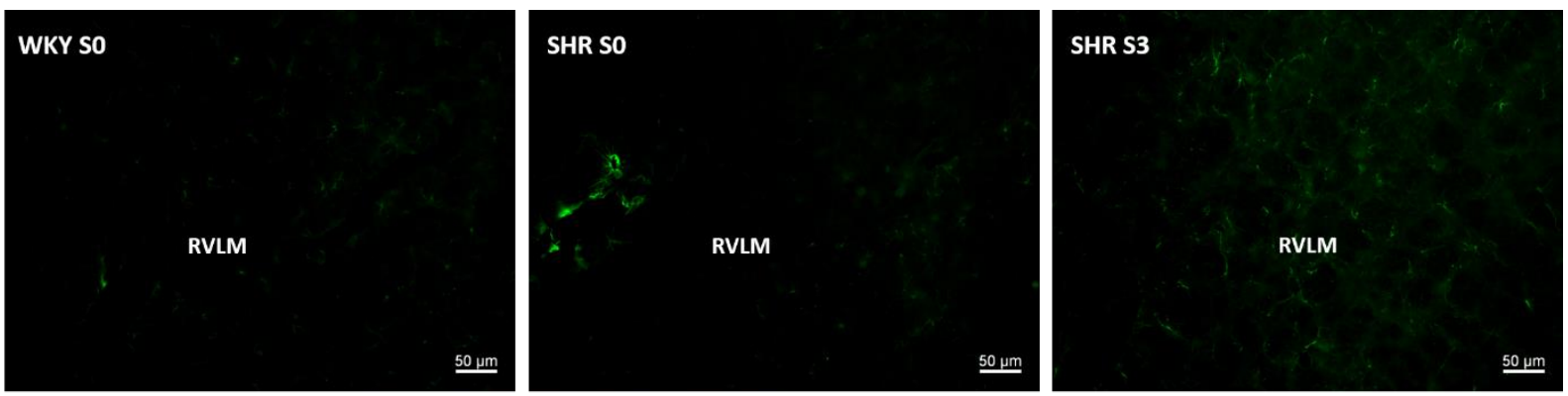

SHR T3
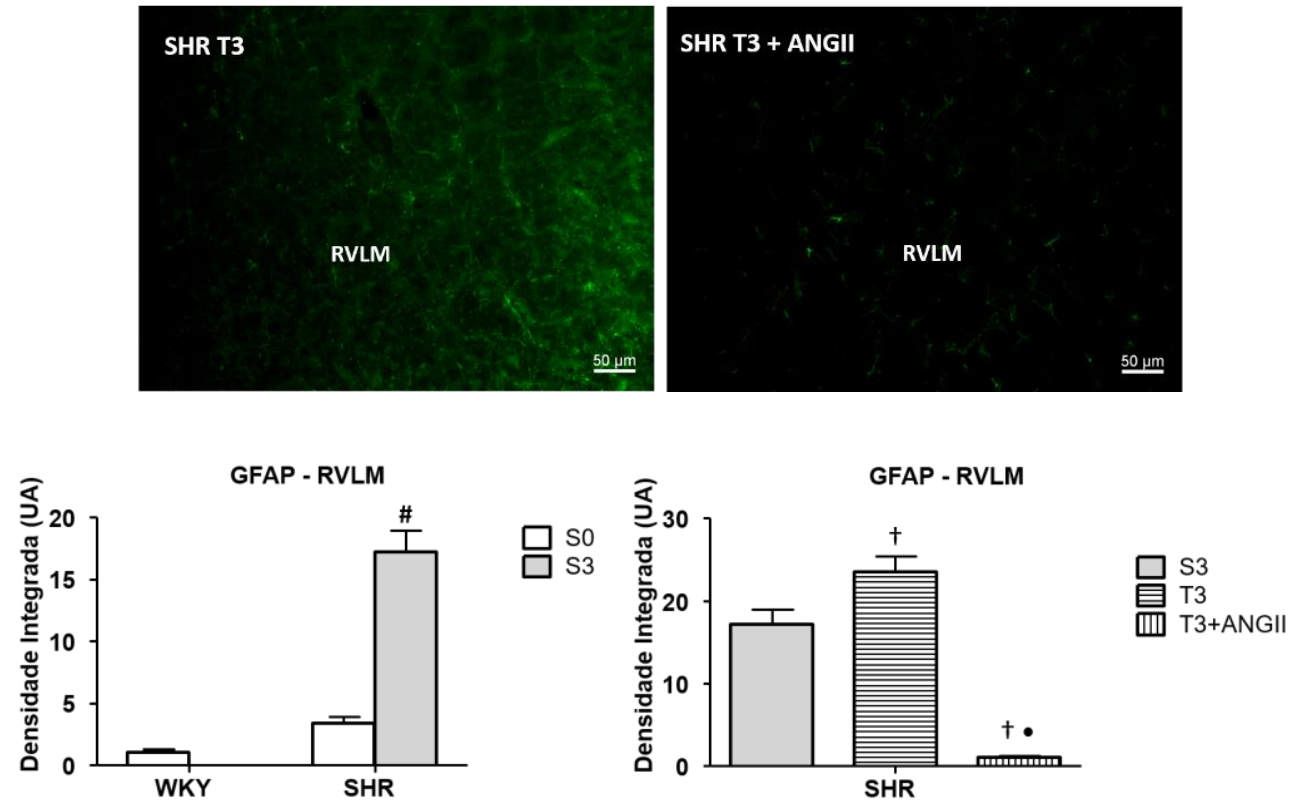

Figura 45 - Comparação da expressão do GFAP (glial fibrillary acidic protein) no bulbo rostroventrolateral (RVLM) de WKY e SHR sedentários nas semanas 0 (S0) e 3 (S3). Os SHR foram também treinados por 3 semanas na ausência (T3) e na presença de infusão i.c.v. concomitante de angiotensina II (T3+ANGII). Painéis superiores: Fotomicrografias ilustrativas da expressão de GFAP no RVLM. Painéis inferiores: Quantificação da expressão de GFAP no RVLM. Significâncias $(\mathrm{P}<0,05)$ : † vs. sedentário \# vs. semana $0 \bullet v s$. T3. 


\section{DISCUSSÃo}

Os resultados do presente estudo confirmaram dados da literatura de que a hipertensão arterial é acompanhada de perda da integridade da BHE no PVN, NTS e RVLM e de que a expressão aumentada de ANGII na hipertensão encontra-se envolvida com a lesão da BHE nesta área (BIANCARDI et al., 2014). Os dados do presente trabalho forneceram ainda várias outras observações originais:

- a BHE no PVN, NTS e RVLM dos SHR encontrava-se íntegra na fase préhipertensiva, mas lesada a partir dos 3 meses de idade, quando a hipertensão atingia a fase crônica, efeito este ausente nos WKY pareados por idade;

- além das áreas autonômicas o extravasamento do FITC-dextran, indicativo de lesão da BHE, ocorria também no PVN magnocelular, mas encontrava-se ausente no núcleo hipoglosso de SHR aos 3 meses de idade;

- a lesão da BHE dos SHR foi progressiva no PVN, aumentando significativamente entre o $3^{\circ}$. e o 5ํ. mês de idade, mas manteve-se estável no NTS e RVLM após a instalação da hipertensão;

- a perda da integridade da BHE após instalação da hipertensão foi acompanhada nas 3 áreas autonômicas de intensa ativação da microglia e de aumento da expressão de receptores AT1 em neurônios do PVN e NTS, mas não nos neurônios do RVLM;

- em todas as áreas autonômicas encefálicas a lesão da BHE foi pronta e completamente corrigida pelo treinamento aeróbio de baixa a moderada intensidade, um efeito até então desconhecido do exercício repetitivo, o qual se instalava após 2 semanas de treinamento, quando havia aumento significativo da expressão de antígeno da barreira endotelial e o extravasamento do FITC-dextran não mais diferia entre SHR e WKY pareados por idade;

- o treinamento aeróbio foi ainda efetivo em causar ligeira redução do extravasamento do FITC-dextran nos WKY treinados

- em ambos os grupos treinados a redução do extravasamento da BHE precedia e era acompanhada de redução da variabilidade da PAS e do simpático vasomotor e de aumento da variabilidade da frequência cardíaca, de seu componente de baixa frequência e da sensibilidade do barorreflexo espontâneo; 
- a elevada disponibilidade de ANGII local mostrou ser um fator condicionante da lesão da BHE no PVN, mas não no NTS e RVLM de SHR sedentários como comprovado pelo aumento do extravasamento do FITC-dextran e redução da expressão do antígeno de barreira endotelial apenas no PVN, quando SHR foram simultaneamente treinados e infundidos com ANGII intracerebroventricular;

- nos SHR a correção da integridade da BHE induzida pelo treinamento era também acompanhada de maior expressão de GFAP que marca as projeções gliais aos vasos encefálicos (PVN e RVLM) e menor expressão/atividade da microglia (PVN e NTS), mas aumento paradoxal da expressão de AT1 (PVN, NTS);

- as alterações na expressão de GFAP e microglia nos SHR treinados eram também dependentes da menor disponibilidade de ANGII, subsequente à redução do angiotensinogênio encefálico após treinamento (CHAAR et al., 2015), conforme evidenciado pela redução da expressão do GFAP e aumento da microglia quando ANGII era infundida durante o treinamento aeróbio;

- estas nossas observações originais sobre o extravasamento de corantes em áreas autonômicas de ratos hipertensos sedentários e treinados sugerem que a lesão da BHE condiciona a instalação da hipertensão arterial na linhagem SHR e que sua correção pelo treinamento aeróbio é de fundamental importância para a normalização da disfunção autonômica nos SHR, mesmo na persistência de níveis pressóricos elevados.

Os testes de esforço máximo, realizados ao longo dos protocolos experimentais, reproduziram dados prévios de nosso laboratório, confirmando a capacidade do treinamento aeróbio de baixa a moderada intensidade (50 a 60\% da capacidade máxima) em aumentar similarmente o desempenho físico dos SHR e WKY treinados, assim como o efeito do sedentarismo em diminuir parcialmente o desempenho em ambas as linhagens (CAVALLERI et al., 2011; CERONI et al., 2009; FELIX; MICHELINI, 2007; HIGA-TANAGUCHI et al., 2009; MELO et al., 2003). Observamos também que os animais de todos os grupos experimentais apresentaram ganho de peso, indicativo da higidez desses animais ao longo dos protocolos experimentais. 0 menor ganho de peso apresentado pelos SHR-T ao final dos protocolos, quando comparado aos SHR-S de mesma idade, pode ser explicado pela perda de massa gorda (mas preservação da massa magra), observação comum a animais submetidos ao treinamento aeróbio e que 
evidencia a eficácia do protocolo experimental nesta linhagem. Por outro lado, a ausência de diferença significativa de peso corporal nos WKY-T quando comparados aos WKY-S, pode estar relacionada com o menor desempenho físico em esteira destes animais, quando comparados aos SHR.

Além da capacidade física e peso corpóreo, avaliamos também os efeitos do treinamento aeróbio sobre os parâmetros hemodinâmicos basais (PAM e FC) e suas variabilidades. Diferentemente dos SHR-S e dos WKY-S e WKY-T que não apresentaram nenhuma alteração de pressão arterial ao longo dos protocolos de treinamento ou sedentarismo, os SHR-T exibiram redução significativa, mas parcial da PAM, a partir da 4⿳⺈. semana de treinamento. Esses dados também confirmam observações anteriores de nosso e outros laboratórios sobre a eficácia do treinamento aeróbio em reduzir sem, no entanto, normalizar a pressão arterial apenas nos grupos hipertensos (AMARAL et al., 2001; CAVALLERI et al., 2011; CERONI et al., 2009; FELIX; MICHELINI, 2007; HIGATANAGUCHI et al., 2009; MASSON et al., 2014; MELO et al., 2003; PAGANI et al., 1988).

A eficácia do treinamento aeróbio realizado pôde ser aferida por sua capacidade em induzir em ambos os grupos bradicardia de repouso, um importante marcador de treinabilidade (CLAUSEN, 1977). Importante observar que a redução da FC basal nos

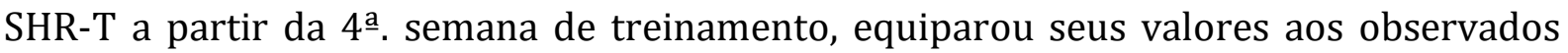
nos grupos normotensos, ou seja, o treinamento foi eficaz em corrigir o desequilíbrio entre os tônus simpático e vagal ao coração dos SHR, reduzindo o predomínio do simpático que caracteriza a taquicardia de repouso na hipertensão espontânea, a qual foi completamente revertida pelo treinamento aeróbio. Nos WKY-T também observamos bradicardia de repouso, cuja instalação foi ainda mais precoce que a observada nos SHRT. Dados da literatura tem indicado que a redução da FC induzida pelo treinamento pode ser devida à redução do simpático e/ou ao aumento do tônus vagal (BRAGA et al., 2000; CHAAR et al., 2015; DE ANGELIS, et al., 2004; MASSON et al., 2014; VÉRAS-SILVA et al., 1997). Realmente nossos dados mostraram que o aumento da variabilidade da FC (quantificada pelo intervalo de pulso) nos SHR-T entre a 4⿳亠丷a . e 8‥ semanas experimentais foi acompanhada de inalteração do LF, indicativo do atividade simpática, mas marcante aumento da atividade vagal, como indicado pelo componente HF. Por outro lado o aumento da variabilidade do IP induzido pelo treinamento nos WKY encontrava-se associado à redução de LF e inalteração do HF. Deve-se ter presente que tanto o 
aumento do HF quanto a redução do LF implicam em redução do balanço simpato-vagal ao coração, o que contribui sobremaneira para o aumento da variabilidade da FC e a instalação da bradicardia de repouso induzidas pelo treinamento e observadas em ambos os grupos experimentais.

A partir dos registros hemodinâmicos em repouso, realizamos também a análise espectral sobre séries temporais de PA pulsátil para verificar ao longo dos protocolos o papel do exercício físico sobre a variabilidade da PAS, sobre atividade simpática vasomotora (LF-PAS) e sobre a modulação hormonal (VLF-PAS). Observamos que os SHR sedentários quando comparados aos WKY de mesma idade apresentam elevada variabilidade da PAS, o que é um fator causal para o estabelecimento de lesões em órgãos-alvo e um importante fator de risco para a morbi-mortalidade (CHAAR et al., 2015; GOMÉZ-ANGELATS et al., 2004; HÖCHT, 2013; LEONCINI et al., 2013; MASSON et al., 2014; SU; MIAO, 2011; TATASCIORE et al., 2007). Importante foi nossa observação de que o treinamento aeróbio impediu um aumento ainda maior, idade-dependente, da variabilidade da PAS nos SHR, como observado no grupo mantido sedentário. Além disto, o treinamento determinou ligeira redução da variabilidade da PAS, mantendo-a inalterada ao longo das 8 semanas experimentais, o que determinou, ao final dos protocolos, redução significativa de seus valores quando comparada aos SHR-S. Houve apenas pequena redução, não significativa, da variabilidade da PAS nos WKY-T (vs. WKY-S) indicando a especificidade do treinamento aeróbio em corrigir preferencialmente a variabilidade da PA no hipertenso, contribuindo de forma importante para reduzir lesões de órgãos-alvo e a morbi-mortalidade. Importante ressaltar que esta melhora significativa ocorria mesmo na persistência de hipertensão, uma vez que o treinamento reduziu, mas não normalizou os níveis pressóricos.

Nossos dados também mostraram que a normalização da variabilidade da PA nos SHR induzida pelo treinamento era devida à redução do simpático vasomotor (queda significativa de LF já a partir da 1a. - 2ª . semanas experimentais). Observamos ainda redução significativa e normalização do componente HF na $2^{\mathrm{a}}$. semana de treinamento, indicando que fatores mecânicos associados à respiração e determinantes do retorno venoso também possam ter contribuído para a normalização da variabilidade da pressão, assim como para a redução parcial da PA nos SHR treinados. De fato, dados da literatura têm demonstrado a relação do componente LF da pressão com a modulação 
simpática do tônus vascular, do componente HF com a atividade vagal e respiratória, e, do VLF com mecanismos hormonais circulantes, como o sistema renina-angiotensina, as catecolaminas plasmáticas, o óxido nítrico derivado do endotélio, além da função miogênica vascular (JAPUNDZIC et al., 1990; PARATI et al., 1995; STAUSS, 2007). 0 componente VLF da PAS mostrou ligeira redução nos SHR-T vs. SHR-S indicativo de pequena redução na modulação hormonal sem, no entanto, atingir níveis de significância. Deve-se ressaltar que, devido ao curto intervalo de tempo em que a análise espectral foi realizada (séries de 5 minutos), não houve sensibilidade suficiente para detectar diferenças na modulação hormonal entre SHR e WKY, sedentários e treinados, a qual ocorre em intervalos de tempo mais prolongados.

Tem sido extensivamente demonstrado que o aumento da variabilidade da PA, e a redução da variabilidade da FC são importantes determinantes de risco cardiovascular, hipertensão e falência cardíaca (CHOBANIAN et al., 2003; STAUSS, 2007). Nossos resultados mostrando não só redução da variabilidade da PAS, mas simultâneo aumento da variabilidade do IP indicam a potencialidade do exercício aeróbio como medida terapêutica eficaz em reverter muitos dos danos cardiovasculares induzidos pela hipertensão, mesmo na presença de níveis pressóricos elevados.

A redução do componente simpático e o aumento da modulação parassimpática ao coração induzidos pelo treinamento aeróbio aumentaram também a sensibilidade do barorreflexo espontâneo de WKY e determinaram ligeira melhora nos SHR, com aumento significativo apenas para $\alpha \mathrm{HF}$ ao final dos protocolos. Deve-se, no entanto, ter presente que estes resultados não descartam a potencialidade do treinamento em melhorar significativamente a ativação do reflexo barorreceptor cardíaco de SHR, uma vez que o cálculo do barorreflexo espontâneo apresenta baixa sensibilidade e maior variabilidade quando comparado à ativação dos barorreceptores por alterações transitórias da pressão arterial (barorreflexo estimulado ou padrão ouro para a determinação da sensibilidade barorreflexa). Realmente dados de nosso laboratório comparando em SHR ambas as formas de ativação do barorreflexo indicaram que o treinamento aumenta a sensibilidade do barorreflexo estimulado com pequena ou nenhuma alteração do barorreflexo espontâneo (MASSON et al., 2014).

Importante ressaltar que todas as alterações benéficas induzidas pelo treinamento sobre o sistema cardiovascular de SHR, especialmente a melhora do 
controle autonômico da circulação, ocorreram apenas após a normalização da integridade da BHE em todos os núcleos autonômicos estudados. Não existem trabalhos na literatura que tenham avaliado os efeitos do treinamento aeróbio sobre a lesão já estabelecida da BHE. Nossos dados são, portanto, originais e mostraram não só o bloqueio da progressão da lesão da BHE na fase crônica da hipertensão, como normalização da função de barreira após 1-2 semanas de treinamento. Houve redução marcante do extravasamento do FITC-dextran pela BHE já a partir da $1^{\mathrm{a}} \stackrel{\text { - }}{ } 2^{\mathrm{a}} \stackrel{\mathrm{a}}{\text {. }}$ semana no NTS e da 2 a semana no PVN e no RVLM, quando os valores não mais diferiam daqueles apresentados pelos grupos normotensos. Tratam-se de observações de grande importância no entendimento dos mecanismos que condicionam a melhora induzida pelo treinamento no controle autonômico em indivíduos hipertensos. De fato, a manutenção da circulação cerebral em níveis adequados é fator crucial para o funcionamento normal das vias neuronais envolvidas na geração do tônus autonômico ao coração e vasos. Sabe-se que a BHE é formada por um sistema celular complexo, composto por células endoteliais, astrócitos, pericitos e lâmina basal, além da microglia. A comunicação cruzada entre esses tipos celulares modula a função da barreira e forma a chamada unidade neurovascular (ABBOTT et al., 2006; HAWKINS; DAVIS, 2005; JANZER, 1993; WOLBURG; LIPPOLDT, 2002; ZLOKOVIC, 2008). A BHE separa o encéfalo da circulação sanguínea sistêmica, formando uma interface fisiológica, regulatória e metabólica, cuja integridade é de fundamental importância para a homeostase do sistema nervoso central (ENGELHARDT; SOROKIN, 2009; JANZER, 1993; LAWTHER et al., 2011).

Nossos resultados, mostrando que a porcentagem de extravasamento da BHE em áreas autonômicas dos SHR-S era muito maior do que a observada nos WKY-S pareados por idade confirmam observações anteriores da literatura mostrando lesão da BHE em diferentes áreas encefálicas de hipertensos crônicos (AL-SARRAF et al., 2007; AMENTA et al., 2003; BIANCARDI et al., 2014; CAPONE et al., 2011; DAVIS; SMEDA, 2010; FARAC0; IADECOLA, 2013; FLEEGAL-DE-MOTTA et al., 2009; IADECOLA; DAVISSON, 2008; MUELLER; HEISTAD, 1980; TANG et al., 1993; UENO et al., 2004; YAO; MAY, 2013; ZHANG et al., 2010). Com exceção do trabalho recente de Biancardi et al., (2014) que analisou em SHR e hipertensos renais a lesão de BHE no PVN, NTS e RVLM (respectivamente, a área de integração vegetativa, neuroendócrina e comportamental, a 
1a. estação sináptica de todos os receptores periféricos no sistema nervoso central e a principal área em que se localizam os neurônios pré-motores simpáticos que inervam coração e vasos), os estudos anteriores não investigaram áreas autonômicas. A originalidade do presente trabalho encontra-se no fato de termos avaliado nestas áreas os efeitos sequenciais da instalação da hipertensão desde a fase pré-hipertensiva, os mecanismos que a condicionam e principalmente por termos avaliado a potencialidade de uma conduta não medicamentosa em reverter os efeitos deletérios da hipertensão sobre a integridade da BHE e sobre o controle autonômico da circulação. Nossas observações de que a BHE no PVN, NTS e RVLM de SHR com 1 mês de idade (e ainda normotensos) apresentava-se integra, ou seja, similar à dos normotensos de mesma idade, mas lesada a partir dos 3 meses de idade quando a hipertensão atinge sua fase crônica, indicam claramente a contribuição do aumento dos níveis pressóricos (e/ou de outros fatores associados à instalação da hipertensão) à lesão da BHE. Além disto, observamos que a lesão da BHE nos SHR-S não se fazia com a mesma intensidade e sequência temporal nas diferentes áreas analisadas. Quando comparado aos WKY pareados por idade, o extravasamento do FITC-dextran era cerca de 11 vezes maior no PVN, 16 vezes mais elevada no NTS e 13 vezes maior no RVLM de SHR quando comparados aos WKY pareados por idade. Além disto, atingia nos SHR-S níveis estáveis no NTS e RVLM a partir do $3^{\circ}$ mês de idade, sendo 2 a 2,5-vezes mais intensa no NTS, ao passo que no PVN apresentava uma elevação contínua até o 5ํ․ mês de idade, quando atingia níveis pouco mais elevados que os observados no NTS.

A lesão da BHE nos SHR-S aos 3 meses de idade foi comprovada pela redução significativa da expressão do antígeno de barreira endotelial no PVN e NTS e de redução de menor intensidade no RVLM, que não atingiu níveis de significância quando comparados aos WKY-S de mesma idade. Trabalhos da literatura tem demonstrado que a expressão do antígeno de barreira endotelial encontra-se relacionado à integridade da BHE (FINNIE et al., 2014; LIN et al., 2000; ROSENSTEIN et al., 1992; STERNBERGER; STERNBERGER, 1987; STERNBERGER et al., 1989). De fato, tem sido descrito redução e/ou ausência da expressão desse antígeno em alguns tipos de lesão da BHE como a observada na encefalomielite experimental (STERNBERGER et al., 1989), no dano microvascular induzido por toxinas (FINNIE et al., 2014) e na injúria encefálica induzida por radiação (JIN et al., 2014). De fato, comprovamos que o anticorpo SMI 71 (marcador 
específico do antígeno de barreira endotelial) marca intensamente os capilares do NTS, mas não o faz nos capilares da área postrema um órgão circumventricular bastante rico em capilares, mas desprovido de BHE (MILLER; LESLIE, 1994).

Interessante foi nossa observação de que a lesão da BHE nos SHR-S parece ser específica de áreas autonômicas uma vez que aos 3 meses de idade os SHR não apresentaram extravasamento de FITC-dextran no hipoglosso, uma contígua ao NTS. Em concordância a estas observações, Biancardi et al., (2014) já haviam demonstrado ausência de extravasamento na amígdala, caudato, globo pálido e córtex sensório-motor. Observamos também haver redução da expressão do antígeno de barreira endotelial no subnúcleo magnocelular do PVN, uma área que não se projeta para núcleos autonômicos, mas para a neuro-hipófise, liberando vasopressina e ocitocina para a circulação sanguínea quando estimulada. Embora o PVN magnocelular não seja considerado um núcleo autonômico propriamente dito, em trabalho recente Son et al., (2013) demonstraram que longas projeções dendríticas dos neurônios magnocelulares imunorreativos para a vasopressina projetam-se e estimulam neurônios pré-simpáticos do PVN que se projetam ao RVLM, o que foi caracterizado como um crosstalk entre populações neuronais. Esta observação indica que vasopressina, sintetizada por neurônios magnocelulares e liberada pelos dendritos em subnúcleos adjacentes, pode, via 'transmissão de volume' (FUXE et al., 2007), afetar neurônios localizados a relativa distância de sua origem, servindo como um sinal de integração entre os compartimentos neuroendócrino e pré-autonômico do PVN (SLADEK et al., 2015). Desta forma o PVN magnocelular, mesmo não sendo um núcleo autonômico clássico, poderia modular o controle autonômico da circulação em situações que integrem funções neuroendócrinas e vegetativas, como é o caso do exercício físico de alta intensidade. Portanto, a especificidade (ou não) de lesão da BHE apenas a áreas de controle autonômico de hipertensos é ainda um assunto em aberto que deverá ser melhor investigado em estudos futuros.

Observamos também que a perda da integridade da BHE após instalação da hipertensão foi acompanhada nas 3 áreas autonômicas de intensa ativação da microglia e de aumento da expressão de receptores AT1 em neurônios do PVN e NTS, mas não nos neurônios do RVLM. Com efeito, trabalhos recentes na literatura têm demonstrado importantes efeitos pró-inflamatórios da ANGII e ativação da microglia no PVN de SHR 
(BIANCARDI et al., 2015; MASSON et al., 2015). Aos 3 meses de idade não havia entre WKY-S e SHR-S grandes diferenças na densidade de expressão do receptor AT1 e do IBA-1 (marcador específico da microglia) no PVN, NTS e RVL. No entanto, a manutenção do sedentarismo cursou com aumento significativo da expressão do receptor AT1 apenas no PVN e intensa marcação pelo IBA-1 nas 3 áreas autonômicas. Biancardi et al. (2014) já haviam demonstrado em SHR e hipertensos renais que a hipertensão arterial era acompanhada de lesão da BHE em áreas autonômicas centrais e que tratamento com losartan, mas não com hidralazina reduzia significativamente a extravasamento de FITCdextran, sugerindo um papel preponderante para a ANGII na lesão da BHE. Ainda observando a co-localização de ANGII exógena marcada com neurônios, astrócitos e microglia, Biancardi et al., (2014) também descreveram que a ANGII se co-localizava em neurônios e microglia, mas não em astrócitos. Nossos dados mostrando intensa ativação da microglia no PVN, NTS e RVLM de SHR-S e o aumento significativo do receptor AT1 em neurônios do PVN e NTS confirmam a importância da ANGII na lesão da BHE, assim como o envolvimento da microglia em mediar os efeitos da ANGII. Sugerem adicionalmente que a elevação da PA, além da maior disponibilidade da ANGII, pode também contribuir direta e/ou indiretamente para a lesão da BHE uma vez que não há lesão em nenhuma das áreas autonômicas nos ratos com 1 mês de idade, quando ainda se encontravam na fase pré-hipertensiva.

Em conjunto nossas observações sobre a lesão da BHE nos SHR sedentários comprovaram que processos patológicos, como a hipertensão arterial crônica alteram as propriedades estruturais/funcionais dos capilares cerebrais em áreas de controle autonômico, tornando-os ineficientes como barreira paracelular, transcelular e/ou enzimática, com consequente abertura da BHE e aumento de sua permeabilidade (ALSARRAF et al., 2007; FARACO; IADECOLA, 2013; HOM et al., 2007;). A perda da seletividade da BHE é, muito provavelmente, um dos fatores condicionantes do desequilíbrio autonômico observado na hipertensão, cuja gravidade progride com o avanço da idade, como observado no PVN dos SHR sedentários.

Várias foram as observações originais do presente trabalho. Constatamos que o treinamento aeróbio de baixa a moderada intensidade foi efetivo em corrigir o extravasamento da BHE em todas as áreas autonômicas dos SHR. Observamos também que a restauração da integridade da BHE pelo exercício repetitivo era um processo 
rápido, observado no NTS já a partir da 1a․ semana, completando-se após 2 semanas de treinamento nas 3 áreas autonômicas analisadas, quando o extravasamento do FITCdextran era mínimo e não diferia daquele observado no ratos normotensos pareados por idade. A normalização da integridade da BHE pode ser comprovada pela alteração do padrão de imunorreatividade do antígeno de barreira endotelial, de aspecto descontínuo e pontuado nos SHR-S para um padrão contínuo ao longo dos capilares, assim como pelo aumento expressivo de sua imunorreatividade no PVN, NTS e RVLM de SHR submetidos a 14 sessões diárias consecutivas de treinamento aeróbio (equivalentes ao volume de treino atingido entre as semanas experimentais 2 e 3). Estas observações demonstram um importante efeito até então desconhecido do treinamento aeróbio na correção dos déficits estruturais/ funcionais da BHE de hipertensos, uma vez que não há na literatura nenhuma informação anterior sobre potenciais efeitos benéficos do exercício repetitivo sobre a função de barreira.

Importante ressaltar que a correção da integridade da BHE no SHR induzida pelo treinamento ocorria mesmo na persistência da hipertensão, era simultânea à redução do simpático vasomotor (observada entre a 1a. e 2ª semanas experimentais), precedia o aumento da variabilidade do IP e da atividade vagal ao coração, a instalação da bradicardia de repouso e a redução parcial da PA, adaptações benéficas do sistema cardiovascular observadas a partir da 4a․ semana experimental. Estas constatações temporais sugerem uma possível relação causa-efeito. Anteriormente já havíamos analisado os efeitos do treinamento sobre parâmetros autonômicos, expressão do sistema renina-angiotensina, alterações do estresse oxidativo e do perfil próinflamatório no PVN de SHR sedentários e treinados. Interessante foi a constatação de que a sequência temporal de alteração da expressão de angiotensinogênio (CHAAR et al., 2015), da redução de ativação da NADPH oxidase, da geração de espécies reativas de oxigênio e da normalização do perfil pró-inflamatório induzidos pelo treinamento aeróbio (MASSON et al., 2014), os quais se normalizavam após 2 semanas de treinamento, foi similar à sequência de alteração da permeabilidade da BHE nos SHR treinados. Além disto, foi observada uma correlação significativa entre a redução da expressão de angiotensinogênio no PVN induzida pelo treinamento (e a consequente diminuição das espécies reativas de oxigênio e a síntese de citocinas pró-inflamatórias) e a facilitação do controle autonômico da circulação nos SHR treinados (CHAAR et al., 
2015; MASSON et al., 2014;). Essas observações em conjunto com os dados do presente trabalho sugerem que o treinamento, ao reduzir a disponibilidade de ANGII, o estresse oxidativo e a inflamação local, corrige a lesão da BHE e melhora a perfusão tecidual, normalizando a atividade neuronal no PVN, NTS e RVLM e corrigindo o controle autonômico da circulação de hipertensos. Em trabalhos anteriores de nosso laboratório já havíamos demonstrado que o treinamento aeróbio de baixa a moderada intensidade melhorava o controle autonômico da circulação por induzir maior expressão e facilitar a atividade de neurônios ocitocinérgicos do PVN que se projetam ao complexo solitáriovagal, e cuja ativação potencializa o tônus vagal ao coração aumentando o ganho do reflexo barorreceptor cardíaco, reduzindo a FC basal e a taquicardia do exercício e facilitando a instalação da bradicardia de repouso, além de contribuir para a redução parcial da pressão arterial (BRAGA et al., 2000; CAVALLERI et. al., 2011; CERONI et al., 2009; HIGA et al., 2002; HIGA-TANIGUCHI et al., 2009; MARTINS et al., 2005;).

Sabe-se que a ativação de receptores AT1 pela ANGII em áreas autonômicas de controle cardiovascular de hipertensos encontra-se relacionada com a ativação da microglia (BIANCARDI et al., 2015; MASSON et al., 2015; WU et al., 2013). Nossas análises de imunofluorescência também mostraram, como descrito na literatura (VEERASINGHAM; RAIZADA, 2003), maior expressão de receptores AT1 no PVN e NTS de SHR sedentários quando comparados aos controles normotensos. Coerentemente, os SHR-S vs. WKY-S apresentavam elevada expressão do IBA-1 (um marcador específico da microglia), a qual foi significativamente reduzida no NTS e PVN dos SHR treinados por 3 semanas, com efeito de menor intensidade e não significativo no RVLM. Paradoxalmente, no entanto, o treinamento foi acompanhado de aumentos significativos da expressão de receptores AT1 em neurônios pré-autonômicos do PVN, NTS e, em menor proporção do RVLM. A explicação para esta discrepância reside no fato de que o treinamento aeróbio determina, no tecido cerebral assim como na periferia, rápida e intensa redução da expressão do angiotensinogênio, o precursor de todas as angiotensinas e, consequentemente, marcante redução da formação de ANGII (CHAAR et al., 2015; SILVA JR et al., 2015). Frente à reduzida disponibilidade de ANGII, ocorreria o upregulation dos receptores, um mecanismo de compensação bem descrito na literatura (NICKENIG; HARRISON, 2002), com aumentos significativos na densidade dos receptores AT1. Prova da ativação desse mecanismo compensatório foi nossa 
observação de que os SHR treinados por 3 semanas durante infusão simultânea de dose subpressora de ANGII no líquido cefalorraquidiano (grupo T3+ANGII), mostraram redução significativa na densidade desses receptores (downregulation) quando comparados aos animais treinados e infundidos com salina por 3 semanas.

Por outro lado, o treinamento aeróbio por 3 semanas determinou no PVN e NTS dos SHR (e em menor proporção no RVLM) redução significativa da ativação da microglia enquanto que a infusão concomitante de dose subpressora ANGII aumentou marcadamente a ativação da microglia apenas no PVN, sem a alterar no NTS e RVLM. Estas observações sugerem que a ANGII induz um perfil inflamatório e ativa preferencialmente o PVN, resultando em maior lesão da BHE nesta área pré-autonômica. Realmente, a comparação dos perfis temporais de extravasamento do FITC-dextran entre as diferentes áreas autonômicas indicou que enquanto a lesão da BHE no NTS e RVLM permanece estável após a instalação da hipertensão, no PVN ela é progressiva nos SHR-S com aumento significativo entre o $3^{\circ}$. e o $5^{\circ}$. mês de idade. De fato, a maior propensão à lesão da BHE no PVN foi comprovada nos grupos em que SHR treinados por 3 semanas foram simultaneamente infundidos com ANGII ou salina: a ANGII determinou aumento significativo do extravasamento do FITC-dextran apenas no PVN, com inalteração no NTS e RVLM, cujos valores foram similares aos observados nos SHR-T infundidos com salina. Além disso observamos alteração da morfologia da microglia no PVN dos SHR treinados e infundidos simultaneamente com ANGII (numerosas células com corpo celular romboide e poucas ramificações), quando comparados com animais treinados infundidos com salina (maioria das células com corpo celular mais fusiforme e múltiplas ramificações). 0 PVN tem sido apontado em vários trabalhos como uma área integrativa de grande importância na modulação autonômica da circulação (BIANCARDI et al., 2014; CHAAR et al., 2015; KHANG et al., 2011; MASSON et al., 2014, 2015a, 2015b; SHI et al., 2011, 2015, 2016; SLADEK et al., 2015), sendo bastante sensível à lesão da BHE (BIANCARDI et al., 2014; 2015). Também se encontra bem descrito na literatura que a morfologia mais romboide e com poucas ramificações da microglia está relacionada à sua ativação, a qual é acompanhada da liberação de diferentes citocinas pró-inflamatórias (KETTENMANN et al., 2010; MASSON et al., 2015b; OLAH et al., 2011; SHI et al., 2010). Sabe-se ainda que a elevada disponibilidade de ANGII é um importante fator determinante da ativação da microglia (BIANCARDI et al., 2016). Nossos dados, 
mostrando não só a redução da disponibilidade de ANGII como também menor ativação da microglia nos SHR treinados ressaltam o efeito benéfico do treinamento aeróbio em reduzir e/ou evitar o aumento da densidade bem como manutenção do fenótipo inativado da microglia, o que reflete uma drástica redução do processo neuroinflamatório desencadeado pela instalação da hipertensão. Correlacionando a expressão de IBA-1 no PVN com diferentes parâmetros autonômicos em SHR sedentários e treinados, Masson et al. (2015b) demonstraram que a inativação da microglia e a consequente redução da neuroinflamação subsequente ao treinamento contribuem sobremaneira para a sensível melhora da variabilidade do IP, instalação da bradicardia de repouso, aumento da sensibilidade do reflexo barorreceptor e diminuição da variabilidade da PAS, como demonstrado no presente trabalho. Embora não constituam estruturalmente a BHE, as células da microglia (macrófagos residentes do SNC) funcionam em estreita associação com a BHE, tendo importante papel na manutenção da função endotelial e da integridade BHE (KELLER, 2013; OBERMEIER et al., 2013). Propomos, portanto, a redução da disponibilidade local de ANGII e a manutenção da microglia em estado inativo contribuem sobremaneira para a correção da lesão da BHE induzida pelo treinamento aeróbio em hipertensos. Embora redução significativa da PA tenha ocorrido apenas a partir da $4 \stackrel{\text { a }}{ }$. semana de treinamento (ou seja, após correção do extravasamento do FITC-dextran), não podemos frente aos dados atuais descartar a contribuição ainda que parcial da redução dos níveis tensionais sobre a correção da lesão da BHE.

Além da participação da ANGII e da microglia na lesão (SHR-S) e correção (SHR-T) da BHE, analisamos também a expressão da proteína fibrilar acídica glial (GFAP), a qual marcas as projeções dos astrócitos que circundam os capilares sanguíneos, constituindo um outro componente da BHE (ABBOTT et al., 2006; LAWTHER et al., 2011). A expressão do GFAP nos SHR-S ao início dos protocolos de experimentais (3 meses de idade) encontrava-se aumentada no NTS e ligeiramente reduzida no PVN quando comparada aos WKY-S pareados por idade, havendo em todas as áreas um aumento idade-dependente. Observamos também que o treinamento dos SHR por 3 semanas determinou, nas 3 áreas analisadas, um aumento proporcionalmente maior da expressão do GFAP e que a infusão concomitante de ANGII reduziu marcadamente sua expressão no PVN (núcleos pré-autonômicos e magnocelular), NTS e RVLM. Esses 
resultados, em oposição ao descrito por Biancardi et al. (2014) que não observaram alteração na expressão de astrócitos e seus processos vasculares quando da infusão de intravascular de ANGII marcada, sugerem que o treinamento ao reduzir a disponibilidade de ANGII (e desativar a microglia), facilita a expressão e aumenta a densidade das projeções astrocíticas que envolvem os capilares em áreas autonômicas, contribuindo para a manutenção do fenótipo normal da BHE. A contribuição das projeções vasculares dos astrócitos na preservação da integridade da BHE em hipertensos treinados deverá ser melhor investigada em trabalhos futuros, uma vez que Krum et al., (1997) ao analisarem in vitro o papel de astrócitos e neurônios na integridade da BHE em células endoteliais, demonstraram que ambos, astrócitos e neurônios não eram essenciais à manutenção de sua integridade.

A melhora induzida pelo treinamento aeróbio nos diversos mediadores e componentes da BHE de SHR (redução da disponibilidade de ANGII, menor ativação da microglia, aumento da expressão do GFAP) devem ter contribuído significativamente para manter a integridade da BHE mesmo na presença de níveis pressóricos elevados, como confirmado nos SHR-T pela redução do extravasamento do FITC-dextran e pelo aumento do antígeno de barreira endotelial nas 3 áreas autonômicas analisadas. Deve-se ter presente que os animais normotensos, apesar de apresentarem valores absolutos de extravasamento do FITC-dextran bastante reduzidos, também mostraram melhora da função de barreira após o treinamento aeróbio, como demonstrado pela redução percentual do extravasamento no PVN, NTS e RVLM de WKY treinados quando comparados a seus controles sedentários. Importante ressaltar que esta melhora da função de barreira nos WKY-T foi acompanhada de redução da atividade simpática para o coração e aumento do barorreflexo espontâneo, indicando validade do treinamento aeróbio mesmo para indivíduos normotensos.

Em conjunto os dados do presente trabalho indicam que ao manter a integridade da BHE nos SHR e melhorar a perfusão de áreas autonômicas o treinamento aeróbio facilita o controle autonômico da circulação, contribuindo para a manifestação dos efeitos benéficos sobre o sistema cardiovascular de hipertensos. Nossas observações indicam ainda um novo efeito benéfico e até então desconhecido do treinamento aeróbio de baixa a moderada intensidade, qual seja a de normalizar a função da BHE em animais hipertensos, independente da manutenção de níveis pressóricos elevados. Estas 
observações são corroboradas por trabalhos em modelos de isquemia e reperfusão que mesmo não tendo investigado áreas autonômicas e nem utilizado o treinamento aeróbio, têm sugerido que o exercício físico possa atuar como agente preventivo da injúria encefálica e do acidente vascular cerebral em áreas corticais e no núcleo estriado (DING et al., 2004, 2006). 


\section{CONCLUSÕES}

Os dados do presente trabalho indicam que a BHE se encontra íntegra na fase pré-hipertensiva, mas lesada na fase crônica da hipertensão e que a lesão da BHE em ratos SHR é específica a áreas autonômicas encefálicas. Indicam ainda que a hiperatividade do sistema renina-angiotensina cerebral nos hipertensos, e em particular a maior disponibilidade de ANGII em áreas de controle autonômico é essencial para reduzir a expressão dos podócitos dos astrócitos que envolvem os capilares cerebrais e ativar a microglia, desencadeando o estresse oxidativo e a inflamação local que levam à lesão da BHE.

Por outro lado, o treinamento aeróbio de baixa a moderada intensidade iniciado na fase crônica da hipertensão reduz pronta e acentuadamente a lesão da BHE nos SHR, mantendo sua integridade no PVN, NTS e RVLM mesmo na persistência de níveis pressóricos elevados. Esta resposta adaptativa ao treinamento é condicionada pela redução da disponibilidade de ANGII nas áreas encefálicas, simultâneo aumento da expressão de podócitos dos astrócitos e desativação da microglia, os quais ocorrem simultaneamente à redução do simpático vasomotor (2ª semana de treinamento) e antes mesmo do aumento da variabilidade da frequência cardíaca, da atividade parassimpática ao coração, da instalação da bradicardia de repouso e queda parcial da pressão arterial, que se instalam a partir da $4^{\mathrm{a}}$. semana experimental.

Alterações na permeabilidade da BHE de hipertensos sedentários (lesão com prejuízo estrutural e funcional) e treinados (manutenção da integridade estrutural e funcional) são importantes fatores a condicionar respectivamente a disfunção autonômica que caracteriza a hipertensão arterial ou a sua correção pelo treinamento aeróbio de baixa a moderada intensidade. 


\section{RFERÊNCIAS*}

ABBOTT, N. J.; RÖNNBÄCK, L; HANSSON, E. Astrocyte-endothelial interactions at the blood-brain barrier. Nature Rev. - Neurosci., v. 7, p. 41-53, 2006.

AL-SARRAF, H.; GHAAEDI, F.; REDZIC, Z. Time course of hyperosmolar opening of the blood-brain and blood-CSF barriers in spontaneously hypertensive rats. J. Vasc. Res., v.44, p. 99-109, 2007.

AMARAL, S.L.; ZORN, T. M. T.; MICHELINI, L. C. Exercise training normalizes wall-tolumen ratio of the gracilis muscle arterioles and reduces pressure in spontaneously hypertensive rats. J. Hypertens., v. 18, p. 1563-1572, 2000.

AMARAL, S.L.; SILVEIRA, N. P.; ZORN, T. M. T.; MICHELINI, L. C. Exercise training causes skeletal muscle venular growth and alters hemodynamic responses in spontaneously hypertensive rats. J. Hypertens., v. 19, p.931-940, 2001.

AMENTA, F.; DI TULLIO, M. A.; TOMASSONI, D. Arterial hypertension and brain damage evidence from animal models (review). Clin. Exp. Hypert., v. 25, p. 359-380, 2003.

ANDERSON, E. A.; SINKEY, C. A.; LAWTON, W. J.; MARK, A. L. Elevated sympathetic nerve activity in borderline humans. Evidence from direct intraneural recordings. Hypertension, v. 14, p. 177-183, 1989.

ANTONIOS, T. F. T.; SINGER, D. R. J.; MARKANDU, N. D.; MORTIMER, P. S.; MACGREGOR, G. A. Structural skin capillary rarefaction in essential hypertension. Hypertension, v. 33, p. 998-1001, 1999.

ARMULIK, A.; GENOVÉ, G.; MÄE, M.; NISANCIOGLU, M. H.; WALLGARD, E.; NIAUDET, C.; HE, L.; NORLIN, J.; LINDBLOM, P., STRITTMATTER, K.; JOHANSSON, B. R.; BETSHOLTZ, C. Pericytes regulate the blood-brain barrier. Nature, v. 468, p. 557-562, 2010.

BAUMBACH, G. L.; SIGMUND, C. D.; FARACI, F. M. Cerebral arteriolar structure in mice overexpressing human rennin and angiotensinogen. Hypertension, v. 41:50-55, 2003.

BEZERRA, S. M. M. S.; SANTOS, C. M.; MOREIRA, E. D.; KRIEGER, E. M.; MICHELINI, L. C. Chronic $\mathrm{AT}_{1}$ receptor blockade alters autonomic balance and sympathetic responses in hypertension. Hypertension, v. 38, p. 569-575, 2001.

BIANCARDI, V. C.; SON, S. J.; AHMADI, S.; FILOSA, J. A.; STERN, J. E. Circulating angiotensin II gains access to the hypothalamus and brain stern during hypertension via breakdown of the blood-brain barrier. Hypertension, v. 63, p. 572-579, 2014.

${ }^{*}$ De acordo com:

ASSOCIAÇÃO BRASILEIRA DE NORMAS TÉCNICAS. NBR 6023: informação e documentação: referências: elaboração, Rio de Janeiro, 2002. 
BIANCARDI, V. C.; STRANAHAN, A. M.; KRAUSE, E. G.; STERN, J. E. Crosstalk between AT1 receptors and Toll like receptor 4 in microglia contributes to angiotensin II- derived ROS production in the paraventricular nucleus. Am. J. Physiol. Heart. Circ. Physiol., v. 310, p. H404-H415, 2015.

BIANCARDI, V. C.; STERN, J. E. Compromised blood-brain barrier permeability: novel mechanism by which circulating angiontensin II signals to sympathoexcitatory centers during hypertension. J. Phyisiol., v. 594, p. 1591-1600, 2016.

BRADBURY, M. W. B. The blood-brain barrier: transport across the cerebral endothelium. Circ. Res., v. 57, p. 213-222, 1985.

BRAGA, D. C.; MORI, E.; HIGA, K. T.; MORRIS, M.; MICHELINI, L. C. Central oxytocin modulates exercise-induced tachycardia. Am. J. Physiol. Regul. Integr. Comp. Physiol., v. 6, p. 1474-1482, 2000.

CAPONE, C.; FARACO, G.; PARK, L.; CAO, X.; DAVISSON, R. L., IADECOLA, C. The cerebrovascular dysfunction induced by slow pressor doses of angiotensin II precedes the development of hypertension. Am. J. Physiol. Heart. Circ. Physiol., v. 300, p. H397H207, 2011.

CAVALLERI, M. T.; BURGI, K, ; CRUZ, J.C.; JORDÃO, M.T.; CERONI, A.; MICHELINI, L. C. Afferent signaling drives oxytocinergic pre-autonomic neurons and mediates traininginduced plasticity. Am. J. Physiol. Reg. Int. Comp. Physiol., v. 301, p. R958-R966, 2011.

CERONI, A.; CHAAR, L. J.; BOMBEIN, R. L.; MICHELINI, L. C. Chronic absence of baroreceptor inputs prevents training-induced cardiovascular adjustments in normotensive and spontaneously hypertensive rats. Exp. Physiol., v. 94, p. 630 - 640, 2009.

CHAAR, L. J.; ALVES, T. P.; MICHELINI, L. C. Renin-angiotensin system in the paraventricular nucleus of the hypothalamus of hypertensive and normotensive rats: Training-induced time-course changes. In: VIII International Symposium on Vasoactive Peptides, 2011, Ouro Preto, MG Brasil. Abstracts - VIII International Symposium on Vasoactive Peptides, 2011. P-31, p. 50.

CHAAR, L. J.; ALVES, T. P.; BATISTA JR, A. M.; MICHELINI, L. C. Early Training-Induced Reduction of Angiotensinogen in Autonomic Areas-The Main Effect of Exercise on Brain Renin-Angiotensin System in Hypertensive Rats. Plos One, v. 10, p. e0137395, 2015.

CHOBANIAN, A. V.; BAKRIS, G. L.; BLACK, H. R.; CUSHMAN, W. C.; GREEN, L. A.; IZZO, J. L. JR; JONES, D. W.; MATERSON, B. J.; OPARIL, S.; WRIGHT, J. T. JR; ROCCELLA, E. J. Seventh report of the Join National Committee on prevention, detection, evaluation, and treatment of high blood pressure. Hypertension, v. 42, p. 1206-1252, 2003.

CLAUSEN, J. P. Effect of physical training on cardiovascular adjustment to exercise in man. Physiol. Rev., v. 57, p. 779-816, 1977. 
COHEN, J. J.; HARRINGTON, J. T.; KASSIRER, J. P.; MADIAS, N. E. The sympathetic nervous system in clinical and experimental hypertension. Kydney Inter., v. 30, p. 437-452, 1986.

DAMPNEY, R. A. L. Functional organization of central pathways regulating the cardiovascular system. Phys. Rev., v. 74, p. 323-363, 1994.

DAVIS, L. A.; SMEDA, J.S. Captopril treatment temporarily restores cerebral blood flow autoregulation in spontaneously hypertensive rats after hemorrhagic stroke. J. Cardiovasc. Pharmacol., v. 56, p.255-262, 2010.

DE ANGELIS, K.; WICHI, R. B.; JESUS, W. R. A.; MOREIRA, E. D.; MORRIS, M.; KRIEGER, E. M.; IRIGOYEN, M. C. Exercise training changes autonomic cardiovascular balance in mice. J. Appl. Physiol., v. 96, p. 2174-2178, 2004.

DE VRIES, H. E.; KUIPER, J.; DE BOER, A. G., VAN BERKEL, T. J. C.; BREIMER, D. D. The blood-brain barrier in neuroinflamatory diseases. Pharmacol. Rev., v. 49, p. 143-155, 1997.

DiBONA, G. F. The sympathetic nervous system and hypertension: recent developments. Hypertension, v. 43, p. 147-150, 2004.

DING, Y. H.; LUAN, X. D.; LI, J.; RAFOLS, J. A.; GUTHINKONDA, M.; DIAZ, F. G.; DING Y. Exercise-induced overexpression of angiogenic factors and reduction of ischemia/reperfusion injury in stroke. Curr. Neurovasc. Res., v. 1, 411-420, 2004.

DING, Y. H.; DING, Y.; LI, J.; BESSERT, D. A.; RAFOLS, J. A. Exercise pre-conditioning strengthens brain microvascular integrity in a rat stroke model. Neurol. Res., v. 28, p. 184-189, 2006.

ENGELHARDT, B.; SOROKIN, L. The blood-brain barrier and the blood-cerebrospinal fluid barriers: function and dysfunction. Semin. Immunopathol., v. 31, p. 497-511, 2009.

ESLER, M.; JENNINGS, G.; KORNER, P.; Willett, I.; DUDLEY, F.; HASKING, G.; ANDERSON, W.; LAMBERT, G. Assessment of human sympathetic nervous activity from measurements or norepinephrine turnover. Hypertension, v. 11, p. 3-20, 1988.

FARACO, G.; IADECOLA, C. Hypertension: a harbinger of stroke and dementia. Hypertension, v. 62, p. 810-817, 2013.

FELIX, J. V. C.; MICHELINI, L. C. Training-induced pressure fall in spontaneously hypertensive rats is associated with reduced angiotensinogen mRNA expression within the nucleus tractus solitarii. Hypertension, v. 50, p. 780-785, 2007.

FERGUSON, A. V.; LATCHFORD, K. J.; SAMSON, W. K. The paraventricular nucleus of hypothalamus a potential target for treatment of autonomic dysfunction. Expert. Opin. Ther. Targets., v. 12, p. 717-727, 2008. 
FLEEGAL-DE-MOTTA, M. A.; DOGHU, S.; BANKS, W. A. Angiotensin II modulates BBB permeability via activation of the AT1 receptors in brain endothelial cells. J. Cerebral Blood Flow Metabol., v. 29, p. 640-647, 2009.

FINNIE, J. W.; MANAVIS, J.; CHIDLOW, G. Loss of endothelial barrier antigen immunoreactivity as a marker of Clostridium perfringens type D epsilon toxin-induced microvascular damage in rat brain. J. Comp. Path., v. 151, p. 153-156, 2014.

FUXE K.; DAHLSTRÖM, A.; HÖISTAD, M.; MARCELLINO, D.; JANSSON, A.; RIVERA, A.; DIAZ-CABIALE, Z.; JACOBSEN, K.; TINNER-STAINES, B.; HAGMAN, B.; LEO, G.; STAINES, W.; GUIDOLIN, D.; KEHR, J.; GENEDANI, S.; BELLUARDO, N.; AGNATI, L. F. From the Golgi-Cajal mapping to the transmitter-based characterization of the neuronal networks leading to two modes of brain communication: wiring and volume transmission. Brain Res. Rev., v. 55, p. 17-54, 2007.

GHABRIEL, M. N.; LU, J. J.; HERMANIS, G.; ZHU, C.; SETCHELL, B. P. Expression of a bloodbrain barrier-specific antigen in the reproductive tract of the male rat. Reproduction, $\mathrm{v}$. 123, p. 389-397, 2002.

GANONG, W. F. The brain renin-angiotensin system. Ann. Rev. Physiol., v. 46, p. 17-31, 1984.

GARDEN, G. A.; MÖLLER, T. Microglia biology in health and disease. J. Neuroimmune Pharmacol., v. 1, p. 127-137, 2006.

GOMÉZ-ANGELATS, E.; DE LA SIERRA, A.; SIERRA, C.; PARATI, G.; MANCIA, G.; COCA, A. Blood pressure variability and silent cerebral damage in essential hypertension. Am. J. Hypert., v. 17, p. 696-700, 2004.

GRASSI, G.; CATTANEO, B. M.; SERAVALLE, G.; LANFRANCHI, A.; MANCIA, G. Baroreflex control of sympathetic nervous activity in essential and secondary hypertension. Hypertension, v. 31, p. 68-72, 1998.

HART, M. N.; HEISTAD, D. D.; BRODY, M. J. Effect of chronic hypertension and sympathetic denervation on wall/lumen ration of cerebral vessels. Hypertension, v.2:419-423, 1980.

HAWKINS, B. T.; DAVIS, T. P. The blood-brain barrier/neurovascular unit in health and disease. Pharmac. Rev., v. 57, p. 173-185, 2005.

HEAGERTY, A. M.; AALKJAER, C.; BUND, S. J.; KORSGAARD, N.; MULVANY, M. J. Small artery structure in hypertension: Dual processes of remodeling and growth. Hypertension, v. 21, p. 391-397, 1993.

HEISTAD, D. D.; BAUMBACH, G. L. Cerebral vascular changes during chronic hypertension: good guys and bad guys. J. Hypertension, v. 10, p. S71-S75, 1992.

HIGA, K. T.; MORI, E.; VIANA, F. F.; MORRIS, M. MICHELINI, L. C. Baroreflex control of heart rate oxytocin in the solitary-vagal complex. Am. J. Physiol. Regul Integr. Comp. 
Physiol, v. 282, p. 537-545, 2002.

HIGA-TANIGUCHI, K. T.; FÉLIX, J. V. C.; MICHELINI, L. C. Brainstem oxytocinergic modulation of heart rate control in rats: effects of hypertension and exercise training. Exp. Physiol., v. 94, p. 1103- 1113, 2009.

HÖCHT, C. Blood pressure variability: prognostic value and therapeutic implications. ISRN Hypertension, v. 2013, p.1-16, 2013.

HOFFMAN, W. E.; SCHELling, P.; PHILlIPS, M. I.; GANTEN, D. Evidence for local angiotensin formation in brain of nephrectomized rats. Neurosci. Lett., v. 3, p. 299-303, 1976.

HOM, S.; FLEEGAL, M. A.; EGLETON, R. D.; CAMPOS, C. R.; HAWKINS, B. T.; DAVIS, T. P. Comparative changes in the blood-brain barrier and cerebral infarction of SHR and WKY rats. Am. J. Phisiol. Regul. Integr. Comp. Physiol., v. 292, p. R1881-R1892, 2007.

IADECOLA, C.; DAVISSON, R. L. Hypertension and cerebrovascular dysfunction. Cell Metab., v. 7, p.476-484, 2008

ITO, H.; TAKEMORI, K.; KAWAI, J.; SUZUKI, T. AT1 receptor antagonist prevents brain edema without lowering brain blood pressure. Acta Neurochir. Suppl., v. 76, p. 141$145,2000$.

JAPUNDZIC, N.; GRICHOIS, M. L.; ZITOUN, P.; LAUDE, D.; ELGHOZI, J. L. Spectral analysis of blood pressure and heart rate in conscious rats: effects of autonomic blockers. $\mathbf{J}$. Auton. Nerv. Sys., v. 30, p. 91-100, 1990.

JANZER, R. C. The blood brain barrier: cellular basis. J. Inher. Metab. Dis., v. 16, p. 639647, 1993.

JIN, X.; CHEN, Z.; LIU, X.; LIANG, B.; ZHANG, H.; ZHANG, Z. The expression of endothelial barrier antigen (EBA) and S100B in the rat parietal cortex following brain irradiation.

Brain Res., v. 558, p. 84-89, 2014.

JUHLER, M.; BlASBERG, R. G.; FENSTERMACHER, J. D.; PATLAK, C. S.; PAULSON, O. B. A spatial analysis of the blood-brain barrier damage in experimental allergic encephalomyelitis. J. Cereb. Blood Flow Metab., v. 5, p. 545-553, 1985.

KANG, Y. M.; GAO, F.; LI, H. H. CARDINALE, J. P.; ELKS, C.; ZANG, W. J.; YU, X. J.; XU, Y. Y.; QI, J.; YANG, Q.; FRANCIS, J. NF-KB in the paraventricular nucleus modulates neurotransmitters and contributes to sympathoexcitation in heart failure. Basic. Res. Cardiol., v. 106, p. 1087-1097, 2011.

KANNEL, W. B. Left ventricular hypertrophy as a risk factor in arterial hypertension. Eur. Heart J., v. 13, p. 82-88, 1992.

KELLER, A. Breaking and building the wall: the biology of the blood-brain barrier in health and disease. Swiss. Med. Weekly, v. 143, p. 1-9, 2013. 
KETTENMANN, H.; HANISCH, U. K.; NODA, M.; VERKHRATSKY. Physiology of microglia. Physiol. Rev., v. 91, p. 461-553, 2011.

KREUTZBERG, G. W. Microglia: a sensor for pathological events in the CNS. TINS, v. 19, p. 312-318, 1996.

KRUEGER, M.; HÄRTIG, W.; REICHENBACH, A.; BECHMANN, I.; MICHALSKI, D. Bloodbrain barrier breakdown after embolic stroke in rats occurs without ultrastructural evidence for disrupting tight junctions. Plos ONE, v. 8, p. e56419, 2013.

KRUM, J. M.; KENYON, K. L.; ROSENSTEIN, J. M. Expression of blood-brain barrier characteristics following neuronal loss and astroglial damage after administration of anti-thy-1 immunotoxin. Exp. Neurol., v. 146, p. 33-45, 1997.

KUCUK, M.; KAYA, M.; KALAYCI, R.; CIMEN, V.; KUDAT, H.; ARICAN, N.; ELMAS, I.; KORKUT, F. Effects of losartan on blood-brain barrier permeability in long-term nitric oxide blockade-induced hypertensive rats. Life Sci., v. 71, p. 937-946, 2002.

LAWTHER, B. K.; KUMAR, S.; KROVVIDI, H. Blood-brain barrier. Cont. Edu. Anaest., Critical Care Pain, v. 11, p. 128-132, 2011.

LEONCINI, G.; VIAZZI, F.; STORACE, G.; DEFERRARI, G.; PONTREMOLI, R. Blood pressure variability and multiple organ damage in primary hypertension. J. Human. Hypert., v. 27, p. 663-670, 2013.

LIN, B.; GINSBERG, M. D. Quantitative assessment of the normal cerebral microvasculature by endothelial barrier antigen (EBA) immunohistochemistry: application to focal cerebral ischemia. Brain Res., v. 865, p. 237-244, 2000.

MACKINLEY, M. J.; ALBISTON, A. L.; ALLEN, A. M.; MATHAI, M. L.; MAY, C. N.; MCALLEN, R. M.; OLDFIELD, B. J.; MENDELSOHN, F. A. O.; CHAI, S. Y. The brain renin-angiotensin system: location and physiological roles. Int. J. Bioch. Cell Biol., v. 35, p. 901-918, 2003.

MARC, Y.; LLORENS-CORTES, C. The role of the brain renin-angiotensin system in hypertension: implications for new treatment. Prog. Neurobiol., in press, 2011.

MARTINS, A. S.; CRESCENZI, A.; STERN, J.E.; BORDIN, S.; MICHELINI, L.C. Hypertension and exercise training differentially affect oxytocin and oxytocin receptor expression in the brain. Hypertension, v. 46, p. 1-6, 2005.

MASSON, G. S.; COSTA, T. S. R.; YSHII, L.; FERNANDES, D. C.; SOARES, P. P. S.; LAURINDO, F. R.; SCAVONE, C.; MICHELINI, L. C. Time-dependent effects of training on cardiovascular control in spontaneously hypertensive rats: role for brain oxidative stress and inflammation and baroreflex sensitivity. Plos One, v. 9, p. e94927, 2014.

MASSON, G. S.; NAIR, A. R.; DANGE, R. B.; SILVA-SOARES, P. P.; MICHELINI, L. C.; FRANCIS, J. Toll-Like Receptor 4 Promotes Autonomic Dysfunction, Inflammation and Microglia Activation in the Hypothalamic Paraventricular Nucleus: Role of Endoplasmic Reticulum Stress. Plos One, v. 10, p. e0122850, 2015a. 
MASSON, G. S.; NAIR, A. R.; SILVA SOARES P. P.; MICHELINI, L. C.; FRANCIS, J. Aerobic training normalizes autonomic dysfunction, HMGB1 content, microglia activation and inflammation in hypothalamic paraventricular nucleus of SHR. Am. J. Physiol. Heart Circ. Physiol., v. 309, p. H1115-1122, 2015b.

MATSUKAWA, T.; MANO, T.; GOTOH, E.; ISHII, M. Elevated sympathetic nerve activity in patients with accelerated essential hypertension. J. Clin. Invest., v. 92, p. 25-28, 1993.

MELO, R. M.; MARTINHO JR, E.; MICHELINI, L. C. Training-induced, pressure-lowering effect in SHR: Wide effects on circulatory profile of exercised and non-exercised muscles. Hypertension, v. 42, p. 851-857, 2003.

MILLER, A. D.; LESLIE, R. A. The area postrema and vomiting. Front. Neuroendocrinol., v. 15, p. 301-320, 1994.

MUELLER, S. M.; HEISTAD, D. D. Effect of chronic hypertension on the blood-brain barrier. Hypertension, v. 2, p. 809-812, 1980.

NIMMERJAHN, A.; KIRCHHOFF, F.; HELMCHEN, F. Resting microglial cells are highly dynamic surveillants of brain parenchyma in vivo. Science, v. 308, p. 1314-1318, 2005.

NICKENIG, G.; HARRISON, D. G. The AT1-type angiotensin receptor in oxidative stress and atherogenesis. Part II: AT1 receptors regulation. Circulation, v. 105, p. 530-536, 2002.

OBERMEIER, B.; DANEMAN, R.; RANSOHOFF, R. M. Development, maintenance and disruption of the blood-brain barrier. Nature Med, v. 19, p. 1584-1596, 2013.

OLAH, M.; BIBER, K.; VINET, J.; BODDEKE, H. W. G.M. Microglia phenotype diversity. CNS Nerol. Dis. - Drug Targ., v.10, p. 1-11, 2011.

PAGANI, M.; SOMERS, V.; FURLAN, R.; DELL'ORTO, S.; CONWAY, J.; BASELLI, G.; CERUTTI, S.; SLEIGHT, P.; MALLIANI, A. Changes in autonomic regulation induced by physical training in mild hypertension. Hypertension, v. 12, p. 600-610, 1988.

PAN, Y.X.; GAO, L.; WANG, W.Z.; ZHENG, H.; LIU, D.; PATEL, K. P.; ZUCKER, I. H.; WANG, W. Exercise training prevents arterial baroreflex dysfunction in rats treated with central angiotensin II. Hypertension, v. 49, p. 519-527, 2007.

PARATI, G.; SAUL, J. P.; DI RIENZO, M.; MANCIA, G. Spectral analysis of blood pressure and heart rate variability in evaluating cardiovascular regulation - a critical appraisal. Hypertension, v. 25, p. 1276-1286, 1995.

PATON, J. F. R.; RAIZADA, M. K. Neurogenic hypertension. Exp. Physiol., v. 95, p. 569$571,2010$.

PAXINOS, G.; WATSON, C. The rat brain in stereotaxic coordinates. $2^{\text {nd }}$ ed. New York: Academic Press, 1986. 264p. 
PHILLIPS, M. I.; WEYHENMEYER, J.; FELIX, D; GANTEN, D.; HOFFMAN, W. E. Evidence for an endogenous brain renin-angiotensin system. Fed. Proc., v. 38, p. 2260-2266, 1979.

PHILLIPS, M. I.; DE OLIVEIRA, E. M. Brain renin angiotensin in disease. J. Mol. Med., v. 86, p. 715-722, 2008.

ROSENSTEIN, J.M.; KRUM, J. M.; STERNBERGER, L. A.; PULLEY, M. T.; SETERNBERGER, N. H. Immunocytochemical expression of endothelial barrier antigen (EBA) during brain angiogenesis. Develop. Brain Res., v. 66, p. 47-54, 1992.

SANGALETI, C. T.; CRESCENZI, A.; MICHELINI, L. C. Endogenous angiotensin and pressure modulate brain angiotensinogen and $\mathrm{AT}_{1 \mathrm{~A}}$ mRNA expression. Hypertension, $\mathrm{v}$. 43, p. 317-323, 2004.

SANTOS, C. M.; PONTIERI, V.; NETO, L. M.; MICHELINI, L. C. Losartan improves baroreflex control of heart rate of coarcted hypertensive rats. Am. J. Physiol., v. 269, p. H812-H818, 1995.

SANTOS, C. M.; MOREIRA, E. D.; KRIEGER, E. M.; MICHELINI, L. C. Chronic AT 1 receptor blockade alters aortic nerve activity in hypertension. Hypertension, v. 31, p. 973-977, 1998.

SAWCHENKO, P. E.; SWANSON, L. W. The organization of noradrenergic pathways from the brainstem to the paraventricular and supraoptic nuclei in the rat. Brain Res., v. 257, p. 275-325, 1982.

SIHM, I.; SCHROEDER, A. P.; AALKJ, C.; HOLM, M.; MORN, B.; MULVANY, M.; THYGENSEN, K.; LEDERBALLE, O. The relation between peripheral vascular structure, left ventricular hypertrophy, and ambulatory blood pressure in essential hypertension. Am. J. Hypert., v. 8, p. 987-996, 1995.

SHI, P.; DIEZ-FREIRE, C.; JUN, J. Y.; QI, Y.; KATOVICH, M. J.; LI, Q.; SRIRAMULA, S.; FRANCIS, J.; SUMMERS, C; RAIZADA, M. K. Brain microglial cytokines in neurogenic hypertension. Hypertension, v. 56, p. 297-303, 2010.

SHI, Z.; GAN, X. B.; FAN, Z. D.; ZHANG, F.; ZHOU, Y. B.; GAO, Z. Y.; DE, W.; ZHU, C. Q. Inflammatory cytokines in paraventricular nucleus modulate sympathetic activity and cardiac sympathetic afferent reflex in rats. Acta Physiol., v. 203, p. 289-297, 2011.

SILVA JR, S. D.; ZAMPIERI, T. T.; RUGGERI, A.; CERONI, A.; CASARINI, D. E.; MICHELINI, L. C. Sequential effects of aerobic training on the renin-angiotensin system in the renal artery. In: VIII International Symposium on Vasoactive Peptides, 2011, Ouro Preto, MG Brasil. Abstracts - VIII International Symposium on Vasoactive Peptides, 2011. P-35, p. 51.

SILVA JR, S. D.; ZAMPIERI, T. T.; RUGGERI, A.; CERONI, A.; ARAGÃO, D. S.; FERNANDER, F. B.; CASARINI, E. E.; MICHELINI, L. C. Downregulation of vascular renin-angiotensin 
system by aerobic training - Focus on the balance between vasoconstrictor and vasodilator axes. Circ. J., v. 79, p. 1372-1380, 2015.

SLADEK, C. D.; STEVENS, W.; SONG, Z.; JOHNSON, G. C. MACLEAN, P. S. The 'metabolic sensor' function of rat supraoptic oxytocin and vasopressin neurons is attenuated during lactation but not in diet induced obesity. Am. J. Physiol. Reg. Integ. Comp. Physiol., v. 310, p. R337-345, 2015.

SOARES, P.P.; DA NOBREGA, A.C.; USHIZIMA, M.R.; IRIGOYEN M.C. Cholinergic stimulation with pyridostigmine increases heart rate variability and baroreflex sensitivity in rats. Auton. Neurosci., v. 113, p. 24-31, 2004.

SON, S. J.; FILOSA, J. A.; POTAPENKO, E. S.; BIANCARDI, V. C.; ZHENG, H.; PATEL, K. P.; TOBIN, V. A.; LUDWIG, M.; STERN, J. E. Dendritic peptide release mediates interpopulation crosstalk between neurosecretrory and preautonomic networks. Neuron, v. 78, p. 1036-1049, 2013.

SPYER, K. M. In: LOWEY, A. D.; SPYER, K. M. (eds.) The central nervous organization of reflex circulatory control. New York: Oxford University Press, 1990. p. 362-368.

STAUSS, H. M. Identification of blood pressure control mechanisms by power spectral analysis. Clin. Exp. Pharmac. Physiol., v. 34, p.362-368, 2007.

STERNBERGER, N. H.; STERNBERGER, L. A. Blood-brain barrier protein recognized by monoclonal antibody. Proc. Natl. Acad. Sci. USA, v. 84, p. 8169-8173, 1987.

STERNBERGER, N. H.; STERNBERGER, L. A.; KIES, M. W.; SHEAR, C. R. Cell surface endothelial proteins altered in experimental allergic encephalomyelitis. J. Neuroimmunol., v. 21, p. 241-248, 1989.

SU, D.F; MIAO, C.Y. Blood pressure variability and organ damage. Clin. Exp. Pharmacol. Physiol., v. 28, p. 709-715, 2011.

TAKESHITA, A.; TANAKA, S.; KUROIWA, A.; NAKAMURA, M. Reduced baroreceptor sensibility in borderline hypertension. Circulation, v. 51, p. 738-742, 1975.

TANG, J.; XU, Z. Q.; DOUGLAS, F. L., RAKHIT, A.; MELETHIL, S. Increased blood-brain barrier permeability of amino acids in chronic hypertension. Life Sciences, v. 53, p. 417420, 1993.

TATASCIORE, A.; RENDA, G.; ZIMARINO, M.; SOCCIO, M.; BILO, G.; GIAFRANCO, P.; SCHILLACI, G.; DE CATERINA, R. Awake systolic blood pressure variability correlates with target organ damage in hypertensive subjects. Hypertension, v.50, p. 325-332, 2007.

TOYUS, R. M.; SCHIFFRIN, E. L. Reactive oxygen species and hypertension: a complex association. Antiox. Redox. Signal., v. 10, p. 1041-1044, 2008. 
TRASHER, T. N. Unloading arterial baroreceptors causes neurogenic hypertension. Am. J. Physiol. Regulatory. Integrative Comp. Physiol., v. 282, p. R1044-R1053, 2002.

UENO, M.; SAKAMOTO, H.; TOMIMOTO, H; AKIGUCHI, I., ONODERA, M. HUANG, C. L.; KANENISHI, S. Blood-brain barrier is impaired in the hippocampus of young adult spontaneously hypertensive rats. Acta Neuropathol., v. 107, p. 532-538, 2004.

VEERASINGHAM, S. J.; RAIZADA, M. K. Brain renin-angiotensin system dysfunction in hypertension: recent advances and perspectives. Br. J. Pharmacol., v. 139, p. 191-202, 2003.

VÉRAS-SILVA, A.; MATTOS, K. C.; GAVA, N. S.; BRUM, P. C.; NEGRÃO, C. E.; KRIEGER, E. M. Low-intensity exercise training decreases cardiac output and hypertension in spontaneously hypertensive rats. Am. J. Physiol., v. 273, p. H2627-H2631, 1997.

YAO, S. T.; MAY, C. N. Intra-carotid angiotensin II activates tyrosine hydroxylaseexpressing rostral ventrolateral medulla neurons following blood brain barrier disruption in rats. Neurosc., v. 245, p. 148-156, 2013.

WILHELM, I.; FAZAKAS, C.; KRIZBAI, I. A. In vitro models of the blood-brain barrier. Acta Neurobiol. Exp., v. 71, p. 113-128, 2011.

WOLBURG, H.; LIPPOLDT, A. Tight junctions of the blood-brain barrier: development, composition and regulation. Vasc. Pharmacol., v. 38, p. 323-337, 2002.

WU, C.Y.; ZHA, H.; XIA, Q. Q.; YUAN, Y.; LIANG, X. Y.; LI, J. H.; GUO, Z. Y.;LI, J. J. Expression of angiotensin II and its receptors in activated microglia in experimentally induced cerebral ischemia in the adult rats. Mol. Cell Biochem., v. 382, p.47-58, 2013.

ZHANG, M.; MAO, Y.; RAMIREZ, S. H.; TUMA, R. F.; CHABRASHVILI, T. Angiotensin II induced cerebral microvascular inflammation and increased blood-brain barrier permeability via oxidative stress. Neurosci., v. 171, p. 852-858, 2010.

ZLOKOVIC, B. V. The blood-brain barrier in health and chronic neurodegenerative disorders. Neuron, v. 57, p. 178-201, 2008.

ZUBCEVIC, J.; WAKI, H.; RAIZADA, M. K.; PATON, J. F. R. Autonomic-immune-vascular interaction: an emerging concept for neurogenic hypertension. Hypertension, v. 57, p. 1026-1033, 2011. 